\title{
Transportation Policy Strategies for Iowa to Advance the Quality of Life
}





\section{Transportation Policy Strategies for Iowa to Advance the Quality of Life}

David J. Forkenbrock

Director, Public Policy Center

Public Policy Center

The University of Iowa 2004 
This study was funded by the Iowa Department of Transportation. The conclusions are the independent products of university research and do not necessarily reflect the views of the funding agency.

Copyright (C) 2004 by the

Public Policy Center

The University of Iowa

Iowa City, IA 52242

All rights reserved 


\section{PREFACE}

In March 2002, the Iowa Transportation Commission requested that the Public Policy Center develop a strategic plan to help guide it in making major road investments. We took the approach that any potential transportation improvement should be evaluated on the basis of its capability to aid the state in pursuing particular policy goals. The three major policy goals we explored were:

- promoting economic development,

- encouraging sensible urban development patterns, and

- contributing to an improved quality of life.

Following publication of Policy Strategies for Iowa in Making Major Road Investments, the Commission asked us to do two things. First, we were asked to continue our research and consider transportation modes other than roads; second, the Commission asked us to take our ideas to representative groups across Iowa. The second element was included to see how Iowans would respond to the general policy directions advanced in the Policy Strategies monograph and to search for further ways to make transportation a positive feature of the state.

Working with the Commission, we identified nine communities in which to conduct focus group meetings. They included five metropolitan areas-Cedar Rapids, Council Bluffs, Davenport, Des Moines, and Sioux City—and four smaller communities-Charles City, Creston, Mount Pleasant, and Spencer. Each focus group meeting lasted three hours and explored the three general policy areas listed above. Several commissioners and Iowa Department of Transportation staff observed each meeting.

Participants in the focus group meetings included people with expertise in different aspects of the economy from both the public and private sectors, people interested in the role of transportation in bringing about sensible urban land use patterns, and people with varied perspectives on how transportation investments can best contribute to an enhanced quality of life for different groups of Iowans. The discussions brought to light a series of issues and options that are examined in this monograph.

The monograph is structured around overarching policy issues in the following manner. First, building on the Policy Strategies monograph, we define each policy issue and discuss how transportation can play a role in addressing it. Perspectives of focus group participants are discussed, in light of the circumstances facing the state. We also examine available data pertaining to the issue. Finally, we tie together all of this information and make several specific recommendations regarding each policy 
issue. The recommendations combine the analysis of available data with insights derived from the focus group meetings.

In summary, our main objective was to provide the Iowa Transportation Commission with the best possible insights to help guide it when making investment decisions that will be important factors in Iowa's quality of life in future years. 


\section{ACKNOWLEDGMENTS}

In the preface, we mentioned that this research was funded by the Iowa Transportation Commission. We thank the Commission for this opportunity, and we especially appreciate the strong interest in this study on the part of the seven Commissioners, all of whom participated in the sessions as hosts and as observers. Barbara MacGregor, Chair of the Commission, took a particularly active and supportive role in the meetings. She attended nearly all of the sessions and exhibited a contagious enthusiasm for the entire effort.

Completion of this study would have been much more difficult without the assistance of Swati Aggarwal, Miguel Gaddi, Alexis Kuklenski, Saweda LenisLiverpool, and Jason White, graduate students in urban and regional planning who had research assistantships at the Public Policy Center. They were extremely effective in helping us identify people to invite to the focus group sessions, in summarizing the discussions that took place there, and in assembling data on the current circumstances facing transportation in Iowa.

Paul Hanley, a professor of urban and regional planning, was a great help in conducting the analysis of commuting patterns. Teresa Lopes, editor at the Public Policy Center, ensured that the text is accessible to a wide audience, while maintaining the monograph's technical accuracy. Kathy Holeton, administrative assistant at the Center, helped develop the graphics and assisted us in too many other ways to mention. Forrest Holley was kind enough to provide air transportation to four of the more distant sessions; he also was a helpful observer at the meetings.

Finally, we thank the 174 participants of the nine focus group sessions; their names and affiliations are listed in Chapter 2. One has to be impressed by the enthusiasm, knowledge, and commitment exhibited in every case. These individuals showed patience, flexibility, a willingness to place the best interests of the state first, and plenty of good humor, while sharing ideas that have the potential to make transportation in Iowa more effective.

With real appreciation, we acknowledge the many and diverse contributions of these good people. 



\section{TABLE OF CONTENTS}

PREFACE




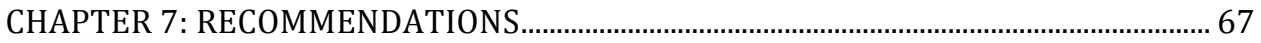

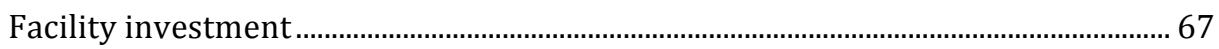

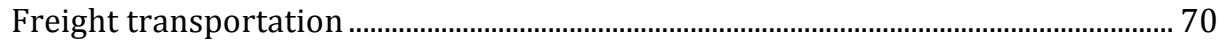

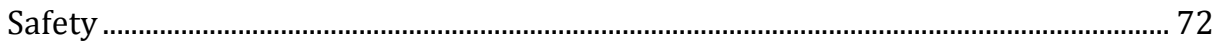

Expanding alternative modes ....................................................................................... 74

Financing needed transportation improvements and services ................................ 75

Conclusion: multimodal transportation is the future ……………………………...... 77

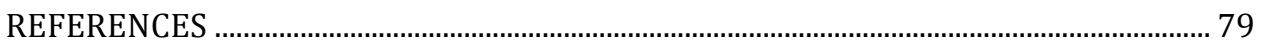

APPENDIX A: SUMMARIES OF FOCUS GROUP MEETINGS.................................................. 83 


\section{FIGURES}

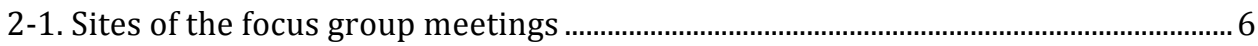

3-1. Iowa's 99 counties and nine metropolitan areas ..................................................... 16

3-2. Percent of Iowa workers employed outside the county of residence, $2000 \ldots \ldots . .17$

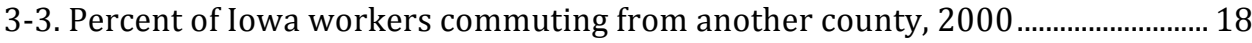

3-4. Number of workers by census tract and mean travel time to work

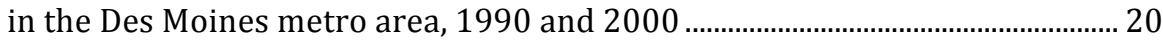

3-5. Average vehicle miles traveled per county resident, 2000 ...................................... 21

3-6. Daily operations and runway lengths of Iowa airports........................................... 30

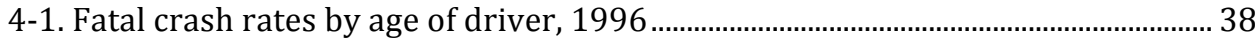

$5-1$. Use of carpools and public transit in Iowa metropolitan areas, 2000 .................. 49

5-2. Relative need for public transit service among rural Iowa counties...................... 53

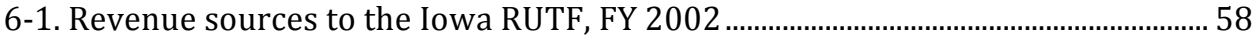

6-2. Comparison of annual registration fees for a $\$ 26,000,3,400$ pound auto versus a pickup truck of equal price and weight ............................................ 61 



\section{TABLES}

3-1. Amount and value of freight shipped to, from, and within Iowa by various modes ..................................................................................................................... 23

3-2. Iowa airport characteristics and operations, 2003 ….................................................. 29

4-1. Time of day and road type for fatal crashes involving large trucks

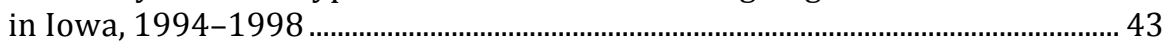

4-2. Type of crash and type of roadway for fatal crashes involving large trucks in Iowa, 1994-1998 .......................................................................................... 44

5-1. Variables in the rural transit need index .................................................................... 52

6-1. Iowa VMT and RUTF Receipts, FY 1985-2002 ….................................................... 58

6-2. Local financing of transportation in nine Iowa communities, FY 2003 ................ 60 


\section{CHAPTER 1 INTRODUCTION}

Collectively, transportation facilities constitute the largest single capital investment in virtually all states, including Iowa. Most of these investments were made at various times during the 20th century to meet real or perceived needs. Over the past half-century or so, the nature of Iowa's economic activity has changed substantially, as have its settlement patterns and the ways in which its people move about and ship goods. Cumulatively, these changes have produced a very different Iowa than existed at the time much of the state's transportation infrastructure was put in place.

The changes Iowa has been experiencing will, of course, continue to occur. Transportation investments that were appropriate for yesterday's social and economic circumstances may not work well today and may be badly out of step with tomorrow's needs. Stated differently, how the state invested its transportation resources in the past may not be the best guide as to how it should do so in the coming years. How can decision makers determine which types of transportation investments will be most beneficial, given the dynamic nature of transportation demand?

Our answer to this critical question is that Iowa's leaders must follow a three-step logical process:

- identify the high-priority policy goals to be pursued,

- consider the most efficient types of investments to pursue these goals, and

- allocate available resources to appropriate investments.

The first step necessitates establishing a clear picture of what the state hopes to accomplish through investments in transportation facilities. One of the primary objectives of our research has been to help identify goals that, if pursued, can advance the quality of life in Iowa in a meaningful way.

\section{A CONSULTATION PROCESS}

This monograph builds on an earlier effort, Policy Strategies for Iowa in Making Major Road Investments, which examined road investment issues. Following its publication, the Iowa Transportation Commission asked us to expand the analysis to include other transportation modes and to explain the policy strategies to representative groups of stakeholders across the state. The Commission was interested to see how people in various Iowa communities might react to these strategies and whether they could offer suggestions for implementing them. 
In response to this request, we first identified locales for the meetings, and then selected the participants who could best provide a balanced perspective and firsthand knowledge of how transportation can advance three major policy issues:

- economic development,

- sensible urban development patterns, and

- quality of life in general.

Nine focus group meetings were eventually organized, and each person invited to participate received a copy of Policy Strategies. The nine focus group meeting sites and the participants who took part in each in each are shown in Chapter 2. In that chapter, we also summarize the process followed in these meetings and how we applied the insights gleaned from the participants.

\section{EVALUATING THE ROLE OF TRANSPORTATION}

Ultimately, the most important role of transportation is to advance the quality of life. It makes choice possible in terms of where we live, work, shop, recreate, and socialize; it also enables us to consume goods from far away places and to enjoy visits by those who live in other locations. But to maximize the ability of transportation to advance quality of life, several important issues must be addressed:

- safety concerns for motorized or non-motorized travel;

- a growing concentration of combination trucks on major highways through Iowa, especially Interstate 80;

- urban congestion that increases travel times and effectively reduces the accessibility of many destinations;

- the need for more choices in transportation modes so that diverse types of materials, commodities, and products can be shipped efficiently;

- land-use patterns that include low-density residential subdivisions well beyond the developed urban area and a lack of jobs-housing balance in most parts of the state's larger metropolitan areas;

- the need for increased economic opportunities including new businesses, expansion of existing businesses, and retention of those that might be considering relocating elsewhere;

- changing transportation needs and mobility issues of the state's growing older population; and

- lifestyle changes, such as the trend in which residents of smaller communities and rural areas increasingly must seek employment and services in larger communities that often are a considerable distance away.

In this monograph, we develop transportation investment strategies that grow out of the analyses in the earlier monograph, further analysis of circumstances in Iowa 
related to the above eight issues, and the input of participants in the nine focus group meetings.

\section{OVERVIEW OF THE MONOGRAPH}

As the title of this monograph implies, our central objective is to explore transportation investment strategies that have the potential to enhance the quality of life for Iowa's residents and visitors. We conducted an extensive public outreach effort to ensure that a diverse array of stakeholders had the opportunity to participate in the process of devising these strategies. In Chapter 2, we document this outreach process and acknowledge the participants who contributed to each of the meetings.

Chapter 3 examines strategies for fostering economic development within the state. It probably is fair to say that the most common reason for investing in highways, rail improvements, and airport facilities is to strengthen prospects for economic development. It is therefore important to have a good sense of when such investments are actually likely to foster economic growth by helping to attract mobile resources-like capital and skilled labor - that can locate wherever the opportunity is most promising. In Chapter 3 , we examine several practical ways in which transportation investments can actually enhance Iowa's economic prospects, including facilitating long-distance commuting, managing growth to avert worsening congestion, improving freight-moving capacity, and upgrading strategically located airports.

Chapter 4 studies the safety of Iowa's road system. We examine three main safety issues: conversion of two-lane highways to four lanes or to substantially upgraded two-lane facilities, needs of older drivers, and concerns about large trucks mixing with autos on major highways, and. Of course, safety is a fundamental element of quality of life, and we assess the magnitude of safety problems in these three critical dimensions. We then explore practical ways to improve road safety.

Chapter 5 focuses on the changing roles of several transportation modes and how they may affect Iowa's future. Certain of these modes require unconventional transportation investments. While economic development, safe travel, and livable, sustainable land use patterns are fundamental to long-term quality of life, there are other transportation strategies that can improve the quality of life for different groups of people even more directly. Among these are providing facilities to support non-motorized transportation; better modal choices in cities, smaller communities, and rural areas; and more cost-effective access to distant locations.

Chapter 6 explores better ways to finance transportation in Iowa. We show the extent to which roads and highways in the state increasingly are financed by means that have no direct relationship to the amount of actual road use. To address this inequitable circumstance, we propose a mileage-based approach to assessing road user charges. 
Chapter 7 brings together the main conclusions and recommendations from the preceding chapters and suggests an integrated, balanced investment strategy geared toward strengthening the quality of life in Iowa.

Brief summaries of the nine focus group meetings are presented in Appendix A. 


\section{CHAPTER 2 FOCUS GROUP MEETINGS}

In Chapter 1 we highlighted three major policy areas where transportation can and must make a contribution to the future quality of life in Iowa. These policy areaseconomic development, sensible urban development patterns, and quality of life in general-are critical for Iowa as it competes for skilled (and thus mobile) workers, as well as for investment capital. Our earlier monograph, Policy Strategies for Iowa in Making Major Road Investments, explored general considerations in using road investments to help pursue these three objectives. Because the policy directions recommended in that monograph represent a significant change from some current policies and conventions, the Iowa Transportation Commission and our research team felt that it would be advisable to present them to a wide array of stakeholders across the state of Iowa.

Two important purposes could be pursued with this consultation process. First, our ideas could be debated by well-informed people with diverse perspectives, and second, we could gain a sense of the general acceptability of our ideas. Our consultation process consisted of six key elements:

- identifying sites across the state, including metropolitan areas and small-tomedium-sized communities;

- for each selected site, determining the transportation stakeholder groups that should be represented and inviting them to the appropriate meeting;

- providing those who agreed to participate with the earlier monograph and the specific issues to be discussed;

- informing the local news media so that interested persons could observe the focus group meetings and offer their comments during a public discussion period;

- conducting the meetings; and

- preparing a detailed transcript of the meetings.

\section{FOCUS GROUP MEETING SITES AND FORMAT}

In May 2003, the Iowa Transportation Commission and the research team met to identify the locales for the focus group meetings. We felt that the meetings should be held in both rural and metropolitan areas across the state. The meetings were conducted at the following places and times:

1) Sioux City, June 24

2) Creston, July 9 
3) Council Bluffs, July 23

4) Spencer, July 30

5) Davenport, September 9

6) Charles City, September 23

7) Mount Pleasant, September 30

8) Cedar Rapids, October 7

9) Des Moines, October 21

Figure 2-1 depicts the nine meeting sites. The map shows that these sites were quite uniformly distributed across the state.

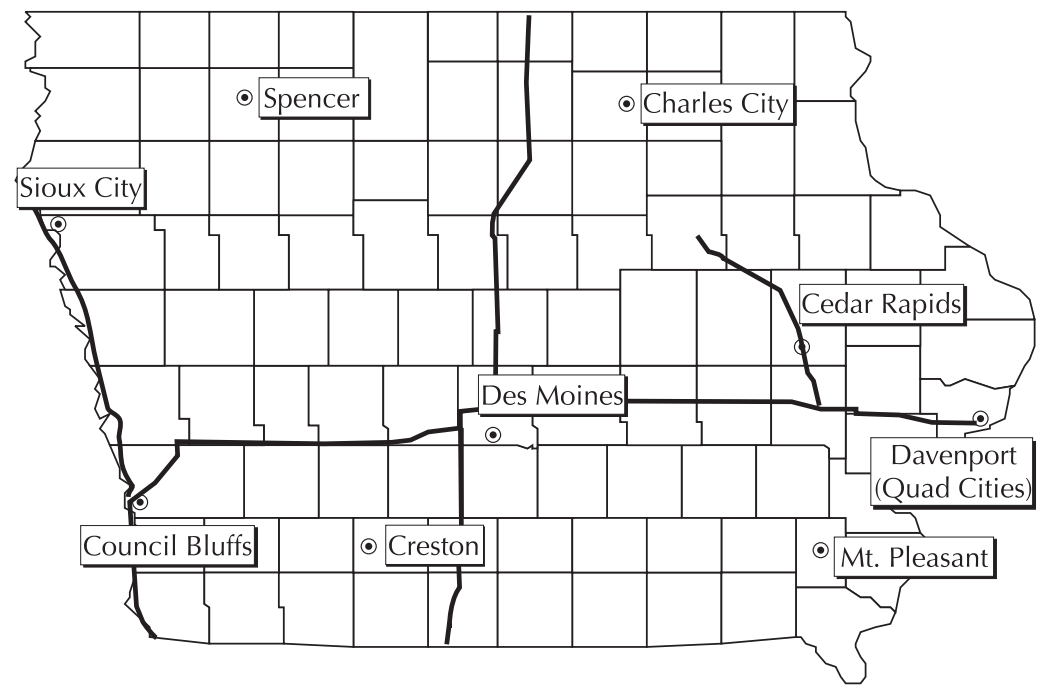

Figure 2-1. Sites of the focus group meetings

All meetings had the same general format:

- welcoming remarks by the hosting commissioner (each meeting was hosted by one of the seven Iowa Transportation Commissioners, and generally two other commissioners were in attendance),

- an overview of the major issues related to transportation investments in Iowa by Professor Forkenbrock (this overview reviewed materials sent to participants earlier),

- a two-hour focus group discussion,

- a summary of the conclusions and perspectives emerging from the focus group, and

- a one-hour open discussion including members of the audience. 


\section{FOCUS GROUP PARTICIPANTS}

For all meetings, we identified and invited people who were representatives of the following general stakeholder groups:

- road users, including local AAA executives, intercity bus operators, motor carriers, and freight logistics firms;

- users of other modes, including the Iowa Rail Passengers Association and leaders of local bicycle and aviation clubs;

- transportation service providers, including railroad executives, urban and rural public transit providers, and airport managers;

- local officials, including mayors, county supervisors, city managers, public works directors, city and county engineers, metropolitan planning organization (MPO) directors, and regional planning affiliation (RPA) directors;

- business promoters, including leaders of local chambers of commerce, senior staff of the Iowa Department of Economic Development, and executives of businesses that rely heavily on transportation;

- environmental and sustainable growth interests, including the Sierra Club, 1000 Friends of Iowa, the Iowa Environmental Council, and other state and local environmental groups;

- agricultural interests, including the local leaders of the Iowa Farm Bureau, elevator operators and farm cooperatives, and local leaders of the Iowa Corn Growers Association, the Iowa Soybean Association, Iowa Pork Producers Association, and the Iowa Cattlemans Association;

- interests of older persons, including members of the Iowa Chapter of the AARP; and

- $\quad$ kindergarten- $12^{\text {th }}$ grade school transportation leaders, including area education agency leaders.

As this list shows, we made an effort to be as inclusive as possible. Generally, about 32 persons were invited to each meeting through a letter from Barbara MacGregor, Chair of the Iowa Transportation Commission. A few days after the letters were received, we called the invitees to confirm their participation and answer questions about the event. Those agreeing to participate were sent packets that contained a summary of topics to be discussed and a list of other confirmed participants.

We were impressed by the willingness of invitees to participate. Generally only those with severe scheduling problems declined our invitation. The following persons participated in the nine focus group meetings: 


\section{Sioux City}

- Lynn Anderson, Vice President of Marketing, Iowa Chicago \& Eastern Railroad and the Dakota Minnesota \& Eastern Railroad, Sioux Falls, South Dakota

- Mike Fox, Director of Distribution, Terra Industries, Inc., Sioux City

- Dan Jensen, Director, Sioux City Transit, Sioux City

- Skip Meisener, Transportation Planning/Traffic Engineering, Siouxland Interstate Metropolitan Planning Council, Sioux City

- Tom Miller, Grain Marketing Manager, Farmers Cooperative Elevator, Farnhamville

- Brent Nelson, Senior Planner, City of Sioux City

- Dave Ott, Director of Transportation, Wells Dairy, Le Mars

- Lane Palmer, Development Resources Coordinator, Iowa Department of Economic Development, Des Moines

- Jim Redmond, Northwest Iowa Sierra Club, Sioux City

- Robert Rice, Director, District 6, AEA 12, Iowa Department of Education, Sioux City

- Mary Ann Sargent, Manager, AAA Minnesota/Iowa, Sioux City

- Paul Sitzmann, Chair, Plymouth County Board of Supervisors, Hinton

- Rick Sneider, Executive Director, Woodbury County Conservation Board, Sioux City

- Barbara Sloniker, Vice President, Government Relations and Transportation, Siouxland Chamber of Commerce, Sioux City

- Richard Storm, Woodbury County Engineer, Sioux City

- Ken Todd, President, Siouxland Cyclists, Sioux City

- Debi Weaver, President, Midwest Continental, Inc., Sioux City

- Dwight Wikstrom, President, Woodbury County Farm Bureau, Hornick

\section{Creston}

- Dwight Conover, President, First National Bank, Creston

- Shonda Deranleau, Transit Director, Southern Iowa Trolley, Creston

- Lyn Hartley, Director, Public Projects, Burlington Northern Santa Fe Railroad, Kansas City, Kansas

- Doug Holiday, Region 7 Director, Iowa Corn Growers Association, Greenfield

- Jay Howe, 1000 Friends of Iowa, Greenfield

- Don Irelan, Chair, Union County Board of Supervisors, Creston 
- Kevin Kruse, Building Official, City of Creston

- Scott Nixon, Union County Engineer, Creston

- Timothy Ostroski, Executive Director, ATURA Transportation Planning Affiliation, Creston

- Lane Palmer, Development Resources Coordinator, Iowa Department of Economic Development, Des Moines

- Joseph Parker, City Administrator, Creston

- Brian Rohrig, Regional Director, Iowa Soybean Association, Orient

- Merlea Schultz, Manager, AAA, West Des Moines

- Manuel Silva, Jr., Executive Director, Union County Development Association, Creston

- John Tapken, Director, Union County Conservation Board, Creston

- Julie Weisshaar, Public Relations Contact, AEA 14, Iowa Department of Education, Creston

\section{Council Bluffs}

- Clyde Anderson, Sierra Club-Missouri Valley Group, Omaha, Nebraska

- Doug Beckman, District 9 Director, Iowa Farm Bureau, Glenwood

- M.J. Broomfield, Executive Director, Southwest Iowa Planning Commission, Atlantic

- Keith Forman, 1000 Friends of Iowa, Glenwood

- Thomas Hanafan, Mayor, Council Bluffs

- Jerry Hare, Pottawattamie County Engineer, Council Bluffs

- Delbert King, Pottawattamie County Board of Supervisors, Council Bluffs

- Roger Koppen, CEO, Farmers Cooperative Elevator, Farhamville

- Roland Lynch, Director, Iowa Association of Railroad Passengers, Council Bluffs

- Bill McGinn, Vice Chair, Council Bluffs Airport Authority, Council Bluffs

- Paul Mullen, Executive Director of Transportation Planning, Metropolitan Area Planning Agency, Omaha, Nebraska

- Bob Mundt, President, Council Bluffs Chamber of Commerce, Council Bluffs

- Lane Palmer, Development Resources Coordinator, Iowa Department of Economic Development, Des Moines

- Michael Payette, Assistant Vice President, Union Pacific Railroad Company, Chicago, Illinois

- Greg Reeder, City Engineer, Council Bluffs 


\section{Spencer}

- Gary Bechler, Manager, American Bottling Company, Spencer

- Gayle Brandt, Director of Airport Services, Leading Edge Aviation, Inc., Spencer

- Blake Fonnesbeck, Public Works Director, Spencer

- Keith Forman, 1000 Friends of Iowa, Glenwood

- William Garner, Administrator of Prairie Lakes AEA 8, Iowa Department of Education, Fort Dodge

- Terry Gray, Partner, Spencer Truck Line, Inc., Spencer

- Reverend Paul Hansen, AARP, Spencer

- Richard Harves, District 1 Director, Clay County Corn Growers Association, Dickens

- David Horan, Executive Director, Northwest Iowa Planning \& Development Commission, Spencer

- Rick Hunsaker, Executive Director, Region XII Council of Governments, Carroll

- Tom Kuhlman, Executive Vice President, Iowa Great Lakes Chamber of Commerce, Arnolds Park

- Rose Lee, Executive Director, Regional Transit Authority/RIDES, Spencer

- Cleber Meyer, Mayor, Spencer

- Lane Palmer, Development Resources Coordinator, Iowa Department of Economic Development, Des Moines

- Scott Rinehart, Clay County Engineer, Spencer

- Thomas Rohe, Plymouth County Engineer, Le Mars

- Bob Rose, Executive Director, Spencer Chamber of Commerce, Spencer

- Kirby Schmidt, Planning Director, City of Spencer

- Jim Stillman, Chair, Iowa Soybean Promotion Board, Emmetsburg

\section{Davenport}

- Sheila Bosworth, Sierra Club of Iowa, Princeton

- Bob Bowman, East Central District Director, Iowa Corn Growers Association, DeWitt

- Dee Bruemmer, Director, Davenport Public Works, Davenport

- Jon Burgstrum, Assistant Scott County Engineer, Davenport

- John Coseart, Vice President and Chief Financial Officer, Heartland Express, Coralville 
- Tom Determann, President, Determann Industries, Inc., Camanche

- Dave Farrell, Transportation Manager, ALCOA, Bettendorf

- Jeffrey Fick, Vice President, Hon Industries, Inc., Muscatine

- Dan Havens, General Supervisor for Customer Service, Heinz USA, Muscatine

- Tim Huey, Director, Scott County Planning and Development, Davenport

- Mike Jurzyk, Senior Vice President, Wenger Truck Line, Davenport

- Robert Lamb, Vice President, Quad Cities Development Group, Rock Island, Illinois

- Gina McCullough, Planning Director, Bi-State Regional Commission, Rock Island, Illinois

- Rex McCreight, Midwest Regional Manager, North Star Steel, Wilton

- Dennis Miller, Executive Vice President, Iowa Interstate Railroad, Iowa City

- John Riches, Manager of Community Relations, ALCOA, Bettendorf

- Bill Tobin, Planning and Transportation Director, East Central Intergovernmental Association, Dubuque

- Scott Tunnicliff, Executive Director, Bettendorf Chamber of Commerce, Bettendorf

- Mike Van Milligan, City Manager, Dubuque

- Jim White, Senior Vice President, Deere \& Company, Moline, Illinois

- Randy Zobrist, Executive Director, Great River Bend Services, Davenport

\section{Charles City}

- Joni Dunn, Chair, Mason City Airport Commission, Mason City

- Jim Erb, Mayor, Charles City

- Timothy Fox, Executive Director, Charles City Area Development Corporation, Charles City

- Byron Held, Secretary, Senior Citizens of Charles City, Charles City

- Jim Hughes, Chairperson, National Resource Conservation Service, Charles City

- Sharon Juon, Executive Director, Iowa Northland Regional Council of Governments, Waterloo

- Bill Kyle, President, Charles City Aeronautics, Charles City

- Tom Masey, Executive Director, Upper Explorerland Regional Planning Commission, Postville

- Larry Murphy, Mayor, Oelwein 
- Joe Myhre, Executive Director, North Iowa Area Council of Governments, Mason City

- Steve Pondell, Vice President of Operations, Cambrex Charles City, Inc., Charles City

- Jeff Rhoda, Executive Director, Mason City Area Chamber of Commerce, Mason City

- Fran Schmitt, President, Floyd County Cattlewoman's Association, Rockford

- Leo Staudt, Chair, Floyd County Board of Supervisors, Charles City

- Walt Stephenson, General Manager, Waterloo Metropolitan Transit Authority, Waterloo

\section{Mount Pleasant}

- Chuck Albright, Henry County High Wheelers, Mount Pleasant

- Jim Armstrong, Appanoose County Engineer, Centerville

- Mary Buczek, Treasurer, Iowa Association of Rail Passengers, Davenport

- Rachel Engwall, 1000 Friends of Iowa, Fairfield

- Chuck Finley, Operations Manager, Celestica, Mount Pleasant

- Bob Hoxie, Director of Safety, Training, and Public Funding, Burlington Trailways, West Burlington

- Mike Hurley, Southeast Iowa Transit Authority, Burlington

- Daniel Johnson, District 7 Director, Iowa Farm Bureau Federation, Ottumwa

- Sharon Leeper, Manager, Burlington Regional Airport, Burlington

- Mike McKim, Customer Logistics Manager, Hearth and Home Technologies, Mount Pleasant

- David McLaughlin, Manager, Stockport Elevator, Stockport

- Paul Nowicki, Assistant Vice President, Burlington Northern Santa Fe Railroad, Chicago, Illinois

- Lane Palmer, Development Resources Coordinator, Iowa Department of Economic Development, Des Moines

- Brent Schleisman, City Administrator, Mount Pleasant

- Jim Senior, Manager, Appanoose County Community Railroad, Centerville

- Bruce Slagle, City Manager, Burlington

- Brian Tapp, Executive Director, Southeast Iowa Regional Planning Commission, Burlington

- Carr Tyndall, Director, Fort Madison Area Chamber of Commerce, Fort Madison 


\section{Cedar Rapids}

- Bob Ballou, District Director, Iowa Soybean Association, Monticello

- Lu Barron, Chair, Linn County Board of Supervisors, Cedar Rapids

- Wes Brackey, Vice President and Chief Financial Officer, CRST International, Inc., Cedar Rapids

- Kevin Burke, Chief Operating Officer, CRANDIC Railway Co., Cedar Rapids

- Tim Busch, Engineering Manager, Navigation Systems, Rockwell Collins, Marion

- Pat Cancilla, Board of Directors, 1000 Friends of Iowa, Solon

- Eve Casserly, Program Manager, AARP, Coralville

- Suki Cell, Vice President for Public Affairs, Cedar Rapids Area Chamber of Commerce, Cedar Rapids

- Dan Curren, Facilities Manager, Worley Warehousing, West Branch

- Jeff Davidson, Executive Director, Johnson County Council of Governments, Iowa City

- Sean Dolan, Vice President, Iowa Pork Producers Association, Coggon

- Dave Elgin, City Engineer, Cedar Rapids

- Doug Elliott, Executive Director, East Central Iowa Council of Governments, Cedar Rapids

- John Ely, Jr., Director, Iowa Association of Railroad Passengers, Cedar Rapids

- Steve Gannon, Linn County Engineer, Marion

- William Hoekstra, Director, Five Seasons Transportation, Cedar Rapids

- Bob Kazimour, Chairman and CEO, RFK Transportation, Inc., Cedar Rapids

- David Machacek, District Director, Iowa Farm Bureau, Alburnett

- Pam Mackey-Taylor, Secretary, Sierra Club of Iowa, Marion

- Larry Mullendore, Director of Aviation, Eastern Iowa Airport, Cedar Rapids

- Lane Palmer, Development Resources Coordinator, Iowa Department of Economic Development, Des Moines

- Dan Sabin, President, Iowa Northern Railway, Coralville

- Jeff Schott, City Manager, Marion

- Bernie Smith, Member, Hawkeye Bicycle Association, Cedar Rapids

- Jane Tompkins, Director of Development, City of Cedar Rapids

- Phil Wedgewood, Public Affairs Director, AAA, West Des Moines 
- Marty Wymore, Executive Director, Region Six Planning Commission, Marshalltown

\section{Des Moines}

- Mark Ackelson, President, Iowa Natural Heritage Foundation, Des Moines

- Eric Anderson, City Manager, Des Moines

- Kurt Bailey, Polk County Engineer, Des Moines

- Angela Connolly, Chairperson, Polk County Board of Supervisors, Des Moines

- Bob Dickson, Standing Member, Central Iowa Business Aviation Association, Des Moines

- Sandy Evett, Logistics Manager, Barilla America, Inc., Lincolnshire, Illinois

- Ed Fallon, President, 1000 Friends of Iowa, Des Moines

- Bill Flannery, Aviation Director, Des Moines International Airport, Des Moines

- Gary Fox, Traffic Engineer, Des Moines

- Jim George, Dallas County Engineer, Adel

- Mike Gleason, Distribution Manager, Lennox Industries, Inc., Urbandale

- Becky Groff, Associate State Director for Community Services, AARP Iowa, Des Moines

- Pat Hendricks, President, Iowa Association of Railroad Passengers, Clive

- Tom Kane, Executive Director, Des Moines Area Metropolitan Planning Organization, Des Moines

- Bob Kindred, Assistant City Manager, Ames Area Metropolitan Planning Organization, Ames

- Lindsay Larson, District 5 Department Director, Iowa Farm Bureau Federation, West Des Moines

- Rich Leopold, Executive Director, Iowa Environmental Council, Des Moines

- Lori Leporte, President, Des Moines Cycle Club, Des Moines

- Tom Mathews, Member, Executive Committee, Sierra Club of Iowa, Des Moines

- Marty McVey, Chief Economist, Agri Industries, Des Moines

- Peter Rickershauser, Vice President, Network Development, Burlington Northern Santa Fe, Fort Worth, Texas

- Jeanette Scoles, Executive Director, Heart of Iowa Regional Transit Agency, Des Moines 
- Kent Sovern, Senior Vice President, Greater Des Moines Partnership, Des Moines

- Steve Spade, Director, Des Moines Metropolitan Transit Authority, Des Moines

- Robert Sturgeon, President, Barr-Nunn Transportation, Inc., Granger

- Cherie Tiffany, Sales Agent, AAA, West Des Moines

- William Van Orsdel, President, Wavo Properties, L.P., Des Moines

- Dick Vegors, Marketing Manager, Department of Economic Development, Des Moines

- Kevin Wiskus, Plant Manager, Rubbermaid Homade Products, Centerville

The foregoing list of participants brought with them considerable knowledge of transportation issues and problems, as well as potential solutions. Their ideas substantially influenced the discussions, conclusions, and recommendations in the chapters that follow. As noted earlier, brief summaries of the nine focus group meetings are presented in Appendix A.

In the chapters to follow, we frequently relate the topics discussed to points made by focus group participants. We blend their insights with the results of our analysis to formulate policy recommendations as to how transportation change can best contribute to an enhanced quality of life in Iowa. 


\section{CHAPTER 3 ECONOMIC DEVELOPMENT}

Perhaps the most discussed topic at the nine focus group sessions was economic development. During the past two decades, economic development has been the motivation for a large share of highway upgrades in Iowa, as well as for investments in facilities serving other transportation modes (1). Economic development occurs when the income and product generated within an area increases. Increased production requires that either more resources (land, labor, materials, and capital) be employed or that existing resources be employed more productively.

State and local governments are limited in their ability to increase income and employment. National and international market forces and policies largely determine the economic environment in which businesses operate. Our goal is to identify instances in which improvements in public facilities can alter the way individuals and businesses deploy their resources, directing more toward the state or community of concern.

How can transportation investment influence business decisions? Transportation is best thought of as a necessary "tool" for transporting goods and people from one place to another. Investments in highways and other facilities generate benefits only to the extent that they lower transportation costs. In the final analysis, all the benefits of a transportation facility, and therefore the justification for building it, flow from its ability to expedite transportation. There really is no separate economic development justification for transportation investments; they have to lower transportation costs.

By lowering transportation costs, an investment in a highway or other facility promotes productivity growth because it enables more to be produced per dollar spent on input. But the investment also consumes resources. These resources come from user fees or general taxes, both of which operate to discourage productivity. Depending on which of the two effects is greater, the investment may or may not contribute to better productivity. When a project produces transportation cost savings that exceed the project's total costs, we say that the investment is economically efficient. Efficient projects make us more productive, more competitive.

In this chapter, we explore possible strategies for using transportation investments to stimulate economic development by lowering the costs of doing business in Iowa. Based on the analysis in our earlier monograph (2) and input from the focus groups, we address several specific issues related to the role of transportation in bolstering Iowa's economic development prospects. Specifically, we explore reducing the costs of: 
- commuting from rural areas and smaller outlying communities by upgrading and prioritizing maintenance on important routes;

- commuting within metropolitan areas by reducing congestion on freeways, expressways, and arterials;

- shipping commodities, intermediate goods, and manufactured products to destinations outside the state; and

- traveling by air to numerous destinations outside the state quickly and economically.

As a reference for subsequent maps provided in this and following chapters, Figure 3-1 shows the boundaries of Iowa's 99 counties. Metropolitan counties, of which there are 12 designated by the U.S. Census Bureau, are shaded and have darker borders. Names of the state's nine cities with populations over 50,000 also are shown in Figure 3-1. For ease of reference, we include the borders of metropolitan counties and portions of the interstate highway system in subsequent maps.

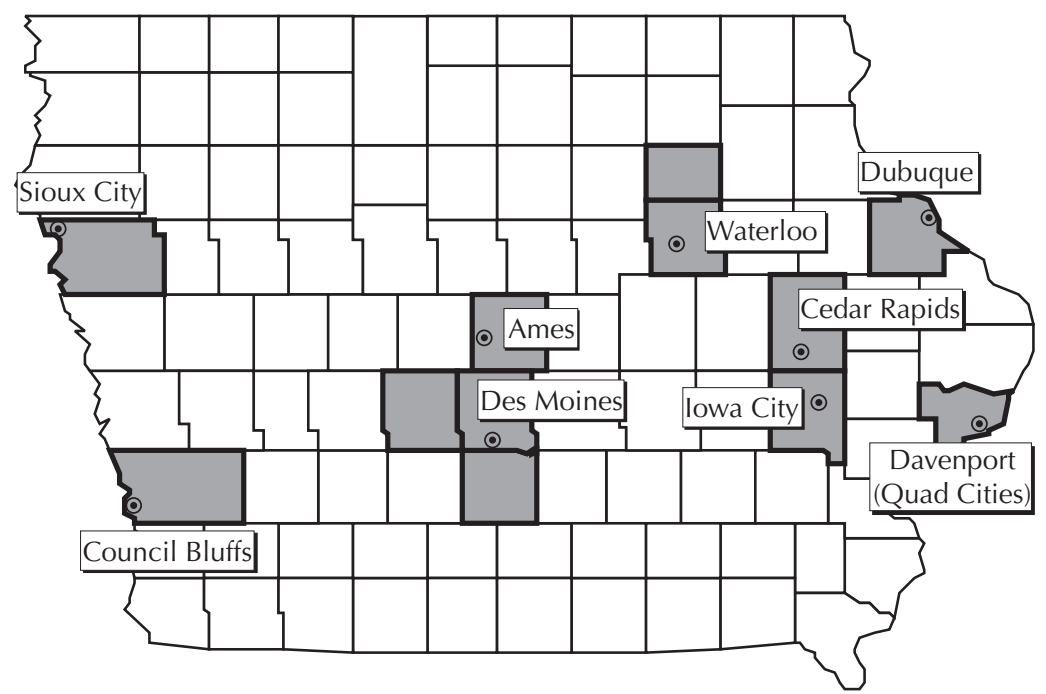

Figure 3-1. Iowa's 99 counties and nine metropolitan areas

\section{COMMUTING FROM RURAL AREAS}

During the past 50 years, the populations of most rural counties in Iowa have steadily declined, while metropolitan counties generally have grown. There are two interrelated reasons for population decline in rural areas. First, impressive gains in productivity in the agricultural sector have led to larger farms with fewer workers per acre. Second, with fewer workers in these counties, economic sectors that serve these workers have shrunk. Given these sustained and sizable changes, many residents of rural counties have chosen either to relocate to a metropolitan area or to commute to the better-paying jobs such areas offer (see 3). Many commutes from 
rural to metro areas involve traveling to another county (including counties in contiguous states). Figure 3-2 shows how the percentage of residents with jobs outside their county varied across Iowa in 2000. It is noteworthy that residents in the northwestern quadrant of the state tend to work in their county of residence. There are comparatively few urban areas within a reasonable commuting distance for many of these counties.

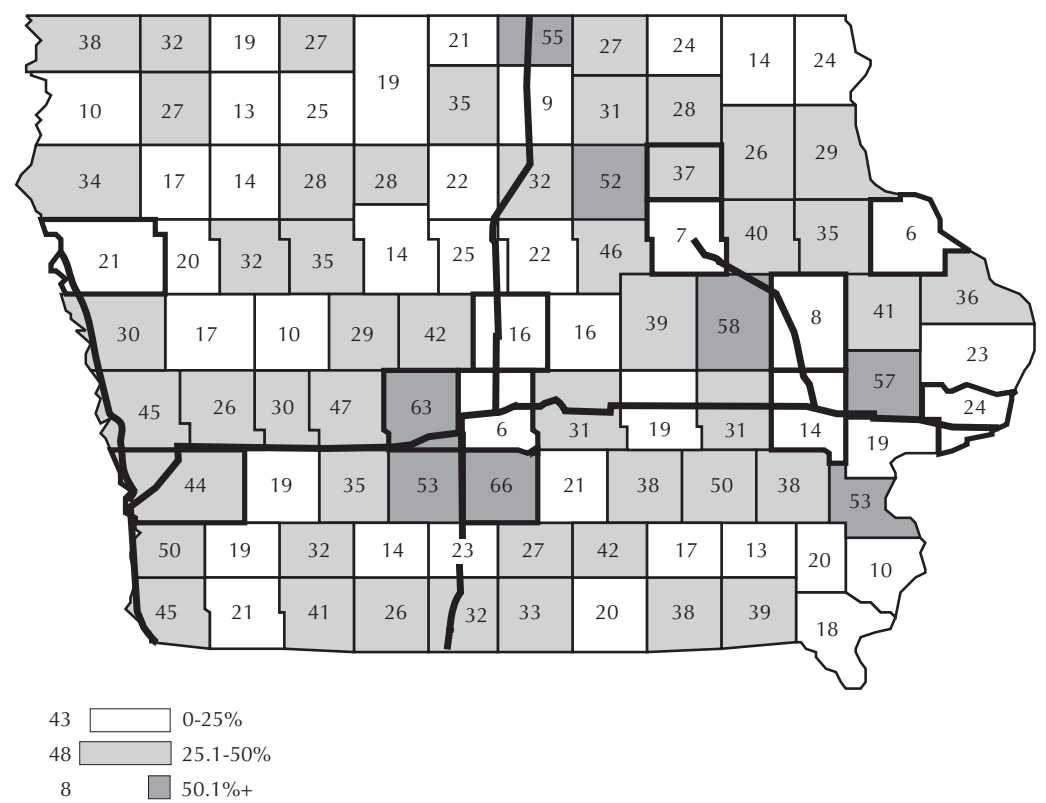

Figure 3-2. Percent of Iowa workers employed outside the county of residence, 2000

SOURCE: (4)

Figure 3-2 shows a discernable pattern of commutation. One would expect the percentages of workers employed outside the county to be comparatively small in metro counties because the preponderance of workers are probably employed within the metro area itself. Perceptible rings appear around metropolitan counties, representing counties from which over one-quarter of the workers travel to jobs outside their counties of residence. The figure indicates that fairly long-distance commuting is quite common in parts of Iowa. In some counties, substantial fractions of the working population (up to two-thirds) commute to jobs outside the county in which they live. It follows that good commutation routes into metropolitan areas are of growing importance.

Another way of looking at long-distance commuting in Iowa is to consider how important workers coming from other counties are to a given county. Figure 3-3 depicts the percentage of all workers in each county who commute from other counties. The figure shows that about one-fifth of the workers in the 12 metro counties commute from other counties. This suggests that inter-county commuters 
are important to the economies of Iowa's metro areas. Further, the figure shows that nearly 40 percent of the workers in various counties along interstate highways come from other counties.

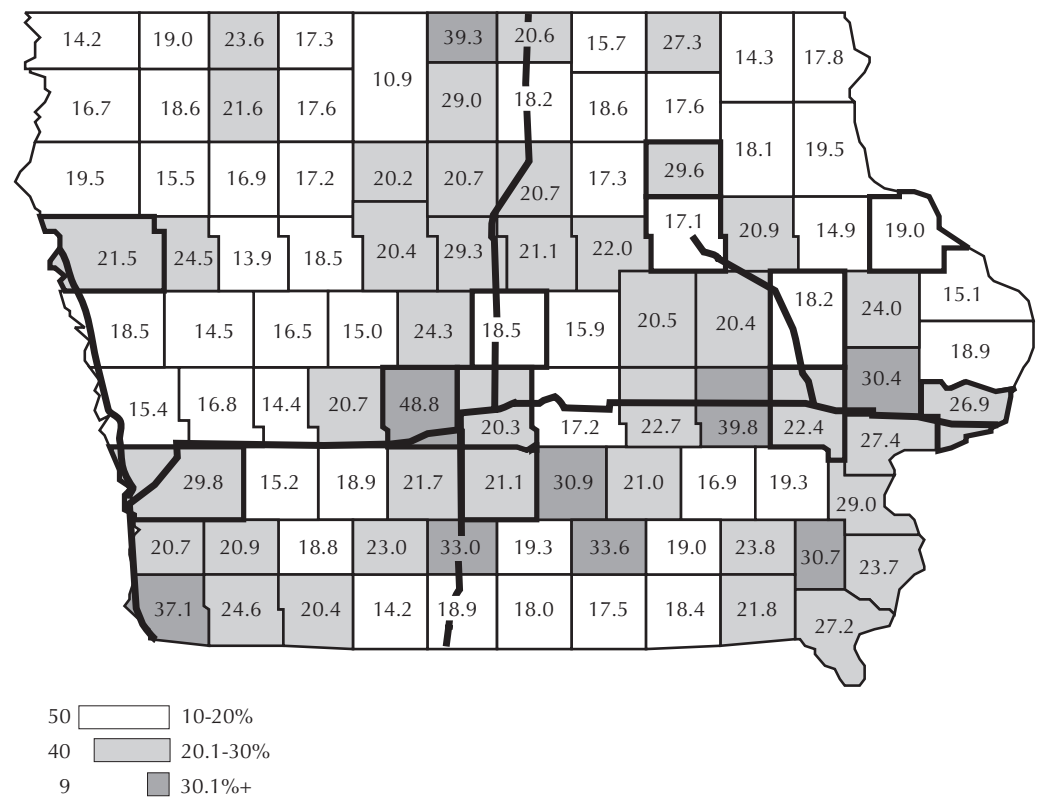

Figure 3-3. Percent of Iowa workers commuting from another county, 2000

SOURCE: (5)

The main point of the preceding two figures is that longer-distance, inter-county commuting is a major phenomenon in Iowa. In several of the focus group meetings, representatives of large employers mentioned that their facilities draw workers from numerous counties and that some of these workers journey considerable distances.

The implication is that long-distance commuting is important to Iowa from at least two standpoints. First, it enables smaller, non-metropolitan communities to remain at least moderately viable because residents are able to earn substantially better salaries and benefits than would be possible near home. Second, employers in metro areas are able to draw from a larger labor pool; this is important because many of the long-distance commuters make valuable contributions to their employing organizations.

Given the importance of long-distance commuting in Iowa, it is vital that commuting routes be well maintained. Of course, the Iowa DOT's maintenance priorities are based, at least in part, on the traffic volumes of different primary roads. It is possible, however, that even more emphasis should be placed on facilities that are particularly important to long-distance and inter-county commutation. Targeted 
surveys could be carried out to help identify routes that are most often traveled by commuters. Snow-removal and surface maintenance on these facilities could then be elevated beyond other roads of the same functional classification and similar average daily traffic (ADT).

\section{COMMUTING WITHIN METROPOLITAN AREAS}

A somewhat different commuting issue is found within Iowa's metropolitan areas: ensuring that workers can journey to their jobs in a smooth, orderly manner. Traffic congestion, of course, is a common byproduct of growth, and many U.S. cities currently experience it to a far greater extent than any of Iowa's metro areas. Still, as several of the state's metro areas continue to grow, the threat of significant traffic congestion will increase. One of the most important transportation policies related to economic development is long-term management of traffic in Iowa's metro areas to reduce the specter of more severe congestion.

To gain a perspective of commuting patterns within a growing Iowa metropolitan area, we have examined the region surrounding the Des Moines area. Figure 3-4 depicts the number of workers residing in selected outlying census tracts and their mean travel time to work for 1990 and 2000. Other data not displayed here indicate that upwards of 40 percent of these workers commute to locations in Des Moines and its inner suburbs (principally West Des Moines and Urbandale). The figure shows that in the south and southwest sectors, the number of workers grew substantially during the 1990s (the weighted average growth rate in workers in the tracts included in this analysis was 88 percent). This suggests that low-density exurban development is occurring around Des Moines, and the eventual result is likely to be heavier inward and cross-suburban commutation. With the rapid growth in Dallas County in the western portion of the metro area (37 percent during the 1990s and 13 percent from 2000 to 2003), commuting traffic generated there almost certainly is increasing proportionally.

Figure 3-4 also shows that the average commuting time increased during the 1990s. The weighted average increase for the area analyzed was 1.1 minutes, a 4.1 percent increase. Figure 3-5 provides further insight into the effects of outer suburban growth on trip distances within the Des Moines metropolitan area. Dallas County has the greatest number of average vehicle miles traveled among the Iowa counties included in the analysis. Warren County, in the southern portion of the Des Moines metro area, has comparatively high average VMT as well. Both counties are well above the average for counties in the state.

As suburban commutation increases, the normal process is for radial and circumferential expressways and freeways to be added to increase both flow speeds and capacity. These facilities usually serve their purposes quite well for a time, but eventually growing demand leads to diminished flow speeds due to congestion, and air quality problems arise. The lower the residential densities in outer suburban areas, the longer the commuting trips will be, and the foregoing problems will become worse as time passes. 

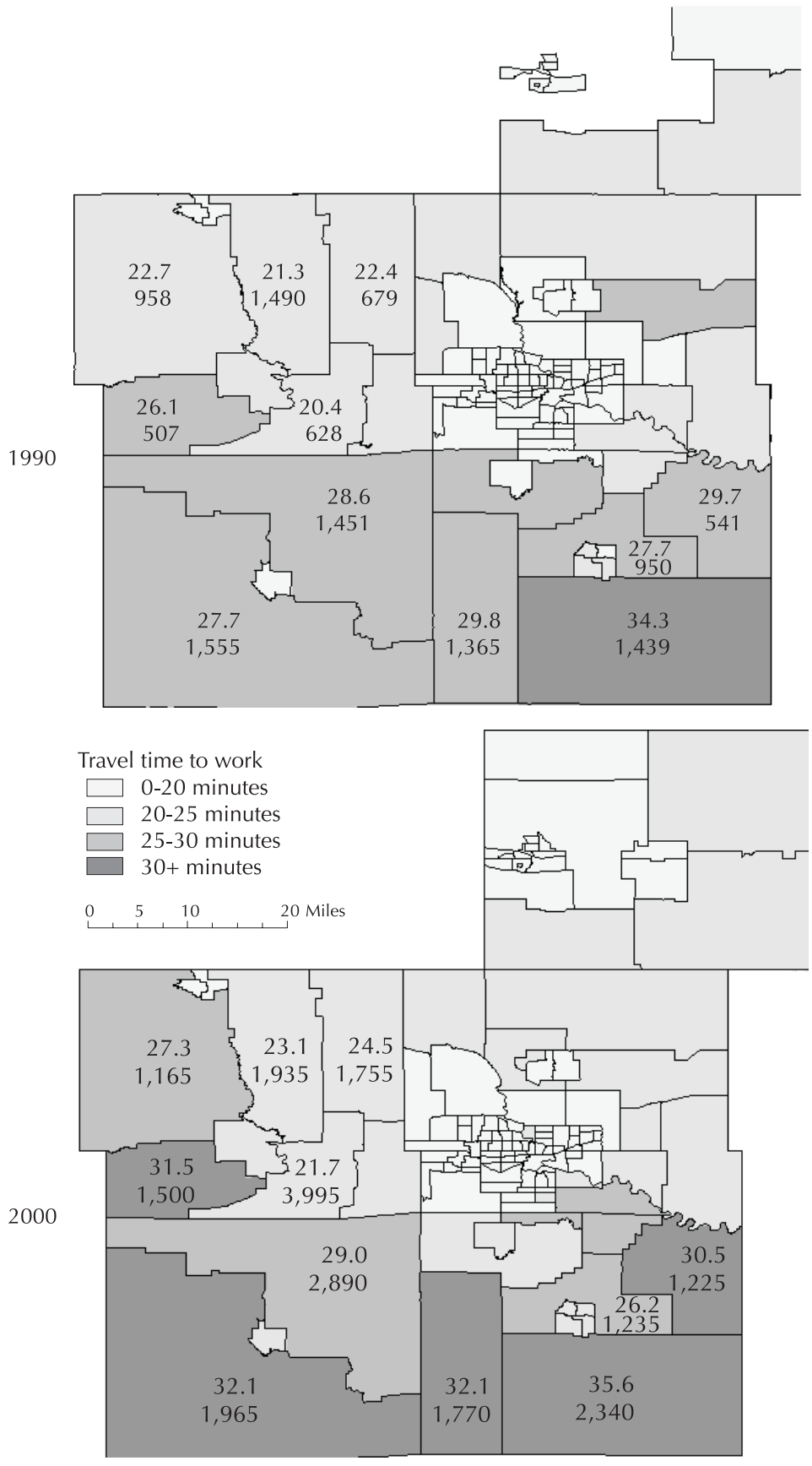

Figure 3-4. Number of workers by census tract and mean travel time to work in the Des Moines metro area, 1990 and 2000*

* The top number equals the average minutes for the journey to work, and the bottom number indicates the number of workers residing in the tract.

SOURCE: $(6,7)$ 


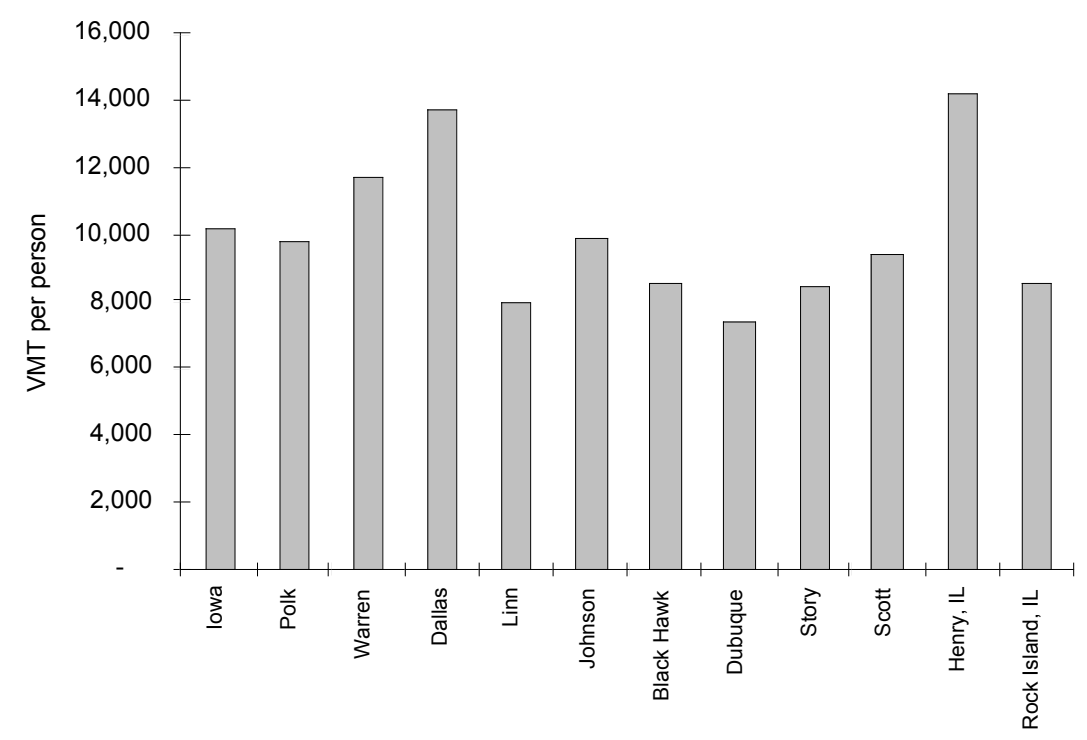

Figure 3-5 Average vehicle miles traveled per county resident, 2000 SOURCES: $(8,9)$

It has become well established in the transportation planning field that within metro areas, it is not possible to invest your way out of traffic congestion in the long run. Rather, to keep a metro area competitive for economic growth by maintaining an acceptable level of accessibility to locations throughout the area, an integrated set of regional policies is needed. As Downs (10) stresses, regional policies are needed to combat congestion. He characterizes these policies as supply-side (e.g., investing in road or transit systems and managing incidents effectively) or demand-side (pricing road use, land use policies, and encouraging carpooling). As applied to metropolitan areas in Iowa, specific policies might include:

- Encouraging metropolitan-area-wide growth management encompassing transportation investment strategies and land use planning. Most metro areas have multiple governments, and quite often they plan and invest in infrastructure, including road systems, independently of one another. A given jurisdiction is unlikely to forego a development opportunity simply because it is not in the best interests of the overall metro area or of a neighboring jurisdiction. It is significant that a low-density development pattern in an outer suburb will have consequences for other jurisdictions, especially those into which its residents travel. Thus, it is imperative that municipal jurisdictions work together on a regional basis.

- Working with regional governments to relate facility investment to sensible growth patterns across the metro area. Accommodating low-density development in outer suburbs by constructing upgraded arterial highways will only precipitate further development in locations farther outside the currently developed area. 
- Encouraging a balance of jobs and housing in emerging suburbs by considering this balance when making facility investment decisions within a metro area. Such a balance can materially reduce trip lengths for commuters, thereby slowing the growth in traffic volumes on radial and circumferential arterials and expressways.

- Building on the previous point, a polycentric urban form is a logical way to minimize vehicle miles traveled (VMT) within a growing metropolitan area. As the area grows, transportation facilities and land use controls can encourage the clustering of economic activities in a series of centers. These activity centers can be connected by high-capacity transportation facilities, and more localized traffic can flow into the nearest center. Such a growth management approach, however, requires foresight and commitment.

- Continually exploring the potential for transportation modes other than the auto. More and more, large metro areas are seeking ways to retrofit passenger rail and express bus services on congested routes. It certainly is preferable to plan ahead and make provisions for these services as a metro area grows. Iowa cities generally are in good positions to carry out this sort of advance planning. We discuss potential roles for alternative modes in Chapter 5.

The central point of this discussion is that congestion and the resulting inaccessibility of locations tend to make a metro area much less attractive to economic development. Congestion operates counter to economic development in two interrelated ways. First, travel times within the area are increased, thereby increasing the cost of moving people and goods. Second, congested roadways precipitate incidents (e.g., crashes, mechanical break-downs, weather-related problems), and the potential for these incidents makes arrival times much less certain. Unreliable arrival times are a major problem for just-in-time (JIT) industries, both manufacturing and retail. JIT is, of course, becoming a major feature of the economy, and thus the competitiveness of congested cities will be affected.

In summary, a regional approach to progressive land use planning, coupled with careful investments in urban transportation facilities, can help make commuting within metro areas more efficient over the long run. This suggests that a reactive policy of building or upgrading facilities when travel demand calls for them is too shortsighted to ensure that commuting will not become a drag on economic development in future years. The Iowa DOT thus has a special role to play in averting congestion in growing metropolitan areas. It has jurisdiction over the major highways serving the entire area and so can help foster a regional approach in planning, financing, constructing, and operating transportation improvements. The Iowa DOT can help boost the influence of the metropolitan planning organization (MPO), thereby encouraging regional approaches to avoiding long-term congestion.

\section{SHIPPING GOODS}

Currently, Iowa relies very heavily on trucks to move its commodities, products, and goods. As Table 3-1 shows, the latest Federal Highway Administration (FHWA) 
freight analysis for Iowa indicates that in terms of weight, 76.4 percent of the goods shipped to, from, and within Iowa went by truck (11). In terms of dollar value, the 1998 percentage was 86.8 . FHWA estimates that approximately the same percentage will carry through to 2020 . It is thus clear that Iowa's economy relies very heavily on truck transportation.

Table 3-1. Amount and value of freight shipped to, from, and within Iowa by various modes

(Values in parentheses are column percentages)

\begin{tabular}{lcccccc}
\hline \multirow{2}{*}{ Mode } & \multicolumn{3}{c}{ Tons (millions) } & \multicolumn{3}{c}{ Value (billions of dollars) } \\
\cline { 2 - 6 } & $\mathbf{1 9 9 8}$ & $\mathbf{2 0 1 0}$ & $\mathbf{2 0 2 0}$ & $\mathbf{1 9 9 8}$ & $\mathbf{2 0 1 0}$ & $\mathbf{2 0 2 0}$ \\
\hline \multirow{2}{*}{ Highway } & 318 & 435 & 518 & 177 & 322 & 500 \\
& $(76.2)$ & $(76.4)$ & $(76.2)$ & $(86.3)$ & $(85.9)$ & $(85.1)$ \\
Rail & 80 & 105 & 124 & 17 & 28 & 45 \\
& $(19.2)$ & $(18.5)$ & $(18.2)$ & $(8.3)$ & $(7.5)$ & $(7.7)$ \\
Air & $<1$ & $<1$ & $<1$ & 8 & 20 & 34 \\
& $(0.0)$ & $(0.0)$ & $(0.0)$ & $(3.9)$ & $(5.3)$ & $(5.8)$ \\
Water & 19 & 29 & 38 & 3 & 5 & 8 \\
& $(4.6)$ & $(5.1)$ & $(5.6)$ & $(1.5)$ & $(1.3)$ & $(1.4)$ \\
Other & $<1$ & $<1$ & $<1$ & $<1$ & $<1$ & $<1$ \\
& $(0.0)$ & $(0.0)$ & $(0.0)$ & $(0.0)$ & $(0.0)$ & $(0.0)$ \\
State total & 416 & 570 & 680 & 205 & 375 & 587 \\
& $(100.0)$ & $(100.0)$ & $(100.0)$ & $(100.0)$ & $(100.0)$ & $(100.0)$ \\
\hline
\end{tabular}

SOURCE: (11)

Participants in the nine focus group meetings expressed mixed feelings about this dependence on trucks. On the one hand, they said, the trucking industry is highly competitive, so trucking companies strive to offer high-quality service at competitive prices. Representatives of manufacturing and retail companies who participated in the meetings felt that, in general, the service they receive from trucking companies is reliable and cost-effective. On the other hand, focus group meeting participants often expressed concern about the safety of occupants of passenger vehicles that share the road with large freight trucks. We discuss safety issues related to these trucks in Chapter 4.

\section{Major issues in modal competition}

To be sure, it would benefit Iowa's economic development prospects to have a greater degree of modal competition. Currently, there are relatively few markets in which two or more transportation modes compete to any significant extent. Traditionally, trucking has been the freight mode of choice for shipments traveling less than 500 miles, and rail has been preferred for longer-distance shipments. In 1997, the year of the latest U.S. Commodity Flow Survey, the average distance for rail shipments originating in Iowa was 836 miles, while shipments by for-hire 
trucking averaged 363 miles (12). Interestingly, the average distance for truck trailers on rail flat cars was 1,319 miles. (By comparison, in 1997 river barge shipments from Iowa averaged 1,203 miles, which is the average distance from Iowa's transshipment points on the Mississippi River to ports on the Gulf of Mexico.) Of course, competition between any two modes will be greatest for distances at which both modes are viable.

It may be that one reason trucking has come to dominate the transportation of freight to and from Iowa is that most shipments travel short enough distances to make this the most competitive mode. Another important factor, however, is that rail is less able to compete when shipments are comparatively small. If industries in Iowa collectively were able to amass sufficiently large shipments to require socalled "unit trains," those with 70 or more cars, quite likely freight rail would be appreciably more competitive within the state.

A concern voiced by numerous business representatives who participated in the focus group meetings is that as reliability of arrival time for shipments has become a paramount consideration, rail has fallen behind trucking. Reliable arrival times are critical to JIT manufacturing and retail practices. JIT is a vitally important means of cutting inventory costs and has become a feature of most industries in this country and others. Rail representatives who participated in the meetings were well aware of this concern and indicated that their industry is modernizing in its capacity to provide reliable service. A recent article in the Wall Street Journal corroborates this assertion (13). Its authors observe that, "To make express service work, the railroads are shunting aside slower freight trains and using new tracks that bypass some of the carriers' worst bottlenecks." For example, six major railroads are joining city, state, and federal governments to invest in a new $\$ 1.5$ billion project to move the major rail hub in Chicago - the source of serious delays-away from the city. If successful, this project could substantially improve the reliability of rail shipments to and from Iowa.

Regarding the longstanding issue of holding shipments until a train has enough filled cars, rail executives are moving toward a practice of having regularly scheduled trains, regardless of how many cars are filled (13). It remains to be seen how effectively the major railroads will be able to strictly adhere to published schedules. Their ability to do so will in large part determine their competitiveness in coming years.

Currently, three Class I railroads operate in Iowa and account for about 55 percent of total track miles: Burlington Northern Santa Fe (669 miles of track), Norfolk Southern (seven miles of track), and Union Pacific (1,603 miles of track). Four Class II railroads (1,544 miles of track in total) and ten Class III railroads (320 total miles of track) also serve the state. Some of the smaller rail companies operate only in Iowa; many Class II and III railroads provide feeder service to the large Class I 
railroads. ${ }^{1}$ Overall in 2000, Class I railroads accounted for 89 percent of the rail tonmiles and 82 percent of the revenue earned by railroads in Iowa (14).

Farm and food products constitute approximately 80 percent of all rail tonnage originating in Iowa, and coal, farm products, and chemicals together account for a like percentage of all tonnage arriving in the state by rail (coal from Wyoming is the dominant category). Thus, rail service in Iowa is used almost exclusively to transport bulky, low-value goods and commodities. It is not heavily used by the state's industrial sector. The potential appears to exist for greater involvement by rail companies in transporting other freight, given that both Union Pacific and Burlington Northern Santa Fe have considerable traffic through the state. According to Iowa DOT data, the ton-miles of through traffic by these railroads increased 90 percent from 1985 to 2000 (14).

\section{Infrastructure investment choices}

Iowa is a "bridge" state in that a massive amount of freight traffic traverses it in both east-west and north-south directions. According to the FHWA, trucks traveling across the state account for 40 percent of all heavy truck VMT in Iowa (11). As we discuss in Chapter 4, concerns about heavy truck concentrations on the state's interstate and other primary highways has become a major issue for many focus group participants. As the nation's economy grows, this through traffic, combined with that originating and terminating in Iowa, will grow considerably. There can be little doubt that important facility investment decisions lie ahead, as the state's highways become increasingly clogged with heavy trucks and the potential for a new era in rail service grows.

Clearly, Iowa must work with other states to arrive at the most promising investment strategy; it simply cannot define its investment policies in isolation. A comprehensive analysis of freight investment options should be made a priority by Iowa and other states along the Interstate 80 corridor. Two major investment strategies warrant consideration in any interstate investment plan:

- Combining public and private capital to finance upgraded long-haul tracks. Several states including California, Missouri, and Vermont have begun investing in rail facilities to reduce the problems associated with heavy truck traffic. For such investments to make economic sense, it is imperative that multiple states work together and that rail companies agree to certain performance levels to ensure desired outcomes. To help make long-haul rail viable, a program of assisting short-line feeder operations probably will be necessary.

- Adding truck-only lanes to certain interstate highways. In locations where truck traffic accounts for over a fifth of the traffic and ADT exceeds 30,000,

${ }^{1}$ Class I railroads have annual gross operating revenues in excess of $\$ 50$ million, Class II railroads are those with annual gross operating revenues of between $\$ 10$ and $\$ 50$ million, and Class III railroads have annual gross operating revenues of less than \$10 million in 1978 dollars. 
a case can be made for adding such lanes and restricting large trucks to them. Even a new single lane would be a major improvement if trucks were restricted to it and could use the adjacent lane only for passing. The best solution would be to separate heavy trucks from other traffic by constructing two additional lanes and restricting trucks to them.

Both alternatives would be very costly. For them to be workable, a long-term investment plan would be essential, and equitable cost sharing between the state and users of the facilities would also be necessary. Regarding the interstate lanes, it would be appropriate for users of existing lanes to help finance them because their safety and traveling comfort certainly would be enhanced.

\section{Intermodal freight-a growing national phenomenon}

Another way in which transportation can help foster economic development is through more aggressive investment in intermodal freight transportation. Of the various forms of intermodal freight transportation, truck and rail service is likely to be the most important for Iowa's economic growth. In general, there are two forms of truck-rail intermodal transportation: trailer on flat-car (TOFC) and steel containers, either on flat cars (COFC) or double stacked. ${ }^{2}$ Each has a role to play, and each can help the state pursue various public policy goals. More specifically, TOFC has the potential to substantially reduce truck traffic on long-haul corridors such as Interstate 80 . On a per-ton-mile basis, it is appreciably safer and more energy efficient and environmentally friendly than pulling the same truck trailers by individual tractor units. Containers are particularly efficient for moving freight between nations. Customs officials can certify the contents and then attach bands on the latches, so that subsequent inspections are unnecessary until the container is opened at its final destination.

Nationally, rail-truck intermodal transportation is growing quite rapidly, tripling in the number of trailers and containers shipped during the past 20 years. Iowa has not duplicated this trend, however. In fact, intermodal service in the state has declined by almost half during the past decade. In 1980, Iowa had 23 facilities for loading trailers onto flat cars, but in 2000 , there were only six such facilities. In part, this decline reflects the shrinkage of the state's manufacturing sector, but it also indicates the movement toward fewer, larger regional facilities. This consolidation is not entirely a bad thing; such facilities are generally highly accessible to trucks and continue to provide shippers with the advantages of truck-rail intermodal transportation.

\footnotetext{
2 Intermodal containers are steel enclosures used to ship freight. For international waterborne shipping, the 40-foot-long version is the most common type, but domestic containers usually are 48 or 53 feet long. Within the U.S., containers can be carried part of the way by rail and then transferred to trucks. It is in the transfer that most of the costs are incurred, and the tradeoff tends to be between less expensive but more labor-intensive cranes versus more sophisticated, expensive equipment that is faster and thus more productive.
} 
Iowa should be vigilant not to fall behind the other states in embracing truck-rail intermodal transportation. In particular, many nations around the world are aggressively moving toward container shipping, and if Iowa is to compete in the world economy, it has to be able to accommodate such shipments. Opportunities for public-private ventures to ensure that container technology is supported should be pursued.

\section{IMPROVED AIR TRANSPORTATION}

Particularly in the case of businesses located outside Iowa's metropolitan areas, quality passenger air service is important to economic development. Numerous business representatives in the focus group meetings stressed that managers and technical staff of such companies must be able to travel quickly and efficiently to meet with corporate leadership, suppliers, customers, and others with whom they work. These representatives emphasized that for Iowa's non-metropolitan communities to be competitive for most industries, good air service is necessary. It is no longer a luxury but a basic need.

In the deregulated era (since the early 1980s), regularly scheduled airlines have pulled away from non-metropolitan areas to the point where service is spotty and uncertain. Multi-facility companies and those that interact with numerous other businesses rely almost exclusively on alternative approaches to obtain the aviation service they require, often on a time-critical basis. Most commonly, these businesses gravitate toward privately owned aircraft or flying services. Both are elements of what is commonly referred to as "general aviation," which is a broad category that encompasses essentially all types of aviation operations other than military and commercial passenger and freight carriage.

Non-metropolitan areas can improve their abilities to attract and retain employment-generating businesses by providing adequate support for general aviation. This support usually consists of:

- runways that are sufficiently long, wide, and well maintained-grass near the runway is mowed, snow is promptly removed, the pavement surface is kept smooth, lighting is operative, and ground-to-aircraft communications are functioning;

- taxiways and aprons that are sufficiently large and well maintained;

- hangars that are available for rental by businesses wishing to store their aircraft at the airport;

- a terminal building on site where flight plans can be filed, en route and destination forecast weather checked, published aids to navigation can be obtained, refreshments can be purchased, and locker rooms are available in which travelers can change clothes and groom themselves; and

- lighting, weather reporting (Automated Weather Observing System [AWOS]), and basic navigational aids. 
Instrument landing systems (ILS) that support instrument flight rules (IFR) are a highly desirable feature in airports. IFR airports are able to operate safely under poor weather conditions. Because of cost considerations, the Federal Aviation Administration (FAA) cannot maintain ILS facilities at all airports. Smaller airports must thus adhere to more restrictive visual flight rules (VFR) meaning that they require substantially better visibility (horizontal and vertical) for aircraft to take off and land. This can significantly reduce the number of days per year when these airports are able to operate. Fortunately, the emergence of global positioning systems (GPS) technology allows aircraft to operate more safely in the environment of VFR airports. GPS receivers are becoming increasingly common on-board general aviation aircraft.

\section{Airports in Iowa}

We examined the operating circumstances of Iowa's 113 airports. These airports range from large facilities that serve multiple commercial jet carriers, have IFR ratings, and have extensive terminal and hanger facilities to very small fields that are capable of serving only small aircraft that require short runways. To gain a perspective of Iowa's airports, we categorized them into five groups: large metro, intermediate airports that average 100 or more general aviation operations (takeoffs and landings) daily, intermediate airports with 50 to 99 such operations per day, small airports with 10 to 49 operations per day, and those with less than 10 operations per day.

Table 3-2 presents a summary of the five categories of airports in Iowa. All five of the large metro airports are instrument rated and have comparatively long runways that are capable of serving high-performance jet aircraft. Note that even at these premium facilities, 59 percent of the operations were by general aviation aircraft during the period of 1994 through 2003. Overall, 94 percent of all aircraft operations in Iowa during that period involved general aviation aircraft. Thus, general aviation can be viewed as a major component of Iowans' mobility.

The table shows that the largest percentage of general aviation operations occurred at the intermediate-sized airports that average between 10 and 99 operations daily. These airports accounted for 60 percent of all such operations. Overall, airports with instrument capabilities had a lower accident rate, and smaller, less-used airports tended to have comparatively high accident rates (i.e., fewer operations per accident).

Figure 3-6 shows the relationship between the number of daily operations at Iowa's airports and the lengths of these airport's runways. In the figure, the five metro airports are indicated by larger square symbols. The most important message in Figure 3-6 is that in general, there is a close relationship between runway length and number of daily operations. Exceptions to this pattern are circled; these airports have fewer daily operations than is typical for airports with their lengths of runways. The figure can be used to gain a rather basic insight into the number of daily operations that one should observe or forecast when considering a possible runway extension. A caveat to the figure is that some mid-length runways may not 
have a large number of daily operations, but the aircraft using them may require their length (e.g., corporate jet aircraft).

Table 3-2. Iowa airport characteristics and operations, 2003

\begin{tabular}{|c|c|c|c|c|}
\hline Airport type* & $\begin{array}{c}\text { Average } \\
\text { general } \\
\text { aviation } \\
\text { operationst }\end{array}$ & $\begin{array}{c}\text { Percent of } \\
\text { total state } \\
\text { general } \\
\text { aviation } \\
\text { operations }\end{array}$ & $\begin{array}{c}\text { Operations } \\
\text { per accident } \\
\text { during taxi, } \\
\text { take-off, and } \\
\text { landing }\end{array}$ & $\begin{array}{c}\text { Average } \\
\text { primary } \\
\text { runway } \\
\text { length }\end{array}$ \\
\hline $\begin{array}{l}\text { Large metro } \\
n=5(5)\end{array}$ & $\begin{array}{l}102 \\
(59)\end{array}$ & 18 & $1,440,077$ & 8,302 \\
\hline $\begin{array}{l}100+\text { daily } \\
\text { operations } \\
n=4(3)\end{array}$ & $\begin{array}{l}103 \\
(94)\end{array}$ & 15 & 167,275 & 5,625 \\
\hline $\begin{array}{l}50 \text { to } 99 \text { daily } \\
\text { operations } \\
n=12(5)\end{array}$ & $\begin{array}{c}58 \\
(87)\end{array}$ & 25 & 134,683 & 4,962 \\
\hline $\begin{array}{l}10 \text { to } 49 \text { daily } \\
\text { operations } \\
n=48(2)\end{array}$ & $\begin{array}{c}20 \\
(97)\end{array}$ & 35 & 161,326 & 4,152 \\
\hline $\begin{array}{l}\text { Less than } 10 \\
\text { daily operations } \\
n=44(0)\end{array}$ & $\begin{array}{c}4 \\
(97)\end{array}$ & 7 & 62,826 & 2,944 \\
\hline Total/Average & $\begin{array}{l}485 \\
(94)\end{array}$ & 100 & 175,934 & 3,994 \\
\hline
\end{tabular}

*Values in parentheses are numbers of airports with instrument landing systems (ILS).

t Values in parentheses are percentages of total operations that are general aviation.

SOURCES: $(15,16)$

\section{Conclusions}

The data in Table 3-2 certainly do not demonstrate that smaller airports in Iowa have poor safety records. But they do show that in general, larger airports with instrument facilities are safer. We need to stress that many factors not indicated in this one table influence accident rates, including the nature of general aviation operations, episodic conditions such as adverse weather, and surrounding topography and man-made structures.

Based on input from focus group participants and our examination of general aviation airports, we suggest that Iowa should explore cost-effective ways to enhance the efficiency and safety of smaller airports that mainly serve general aviation. Working with communities that seek to increase their attractiveness to businesses that depend on aviation, the State of Iowa should search for deficiencies in such airports and, to the extent that resources allow, remedy them. Perhaps an aviation analogue to the RISE program would have merit. Under such a program, a 
fund for airport improvements would be established, and communities could apply for resources to upgrade their airports. Justification for these requests could include documentation that one or more businesses would initiate or expand operations if improved aviation facilities were available. This provision would resemble the immediate opportunity category of RISE.

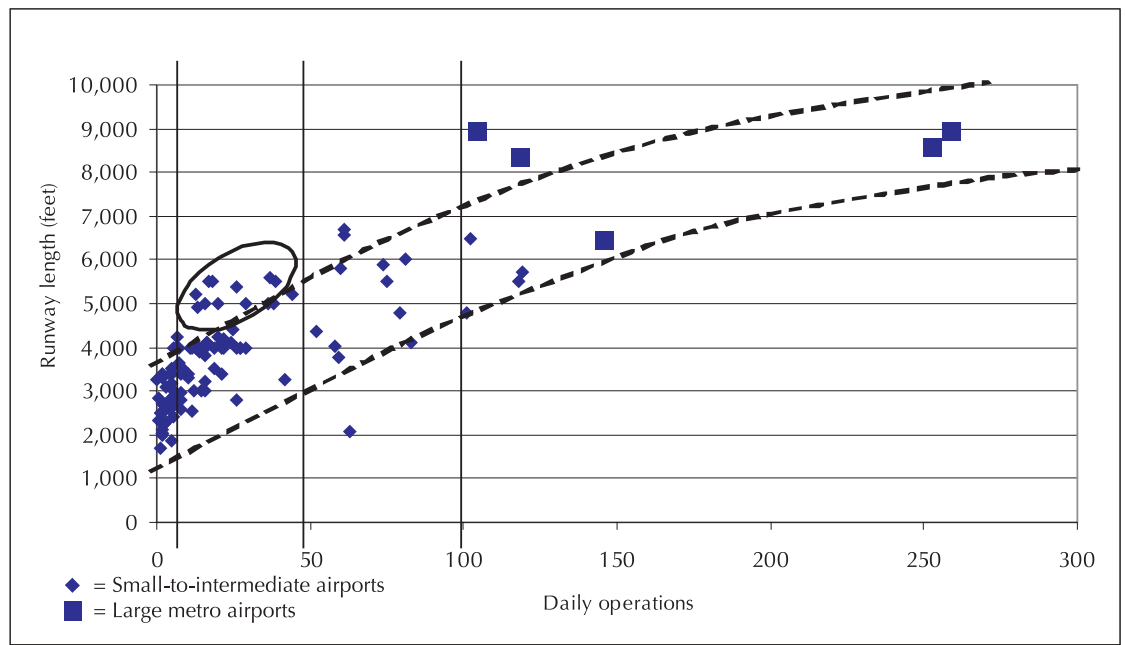

Figure 3-6. Daily operations and runway lengths of Iowa airports SOURCES: $(15,16)$

\section{SUMMARY}

Census data on commuting behavior in Iowa reveal that numerous people living in rural areas and small outlying communities travel to jobs in the state's metropolitan areas. They also commute to jobs along the I- 80 corridor. While these often-long commutes may be tedious, they do enable people to live where they choose and still earn a living; they also mean that employers in metro areas have a more extensive labor pool from which to draw workers. Studying the routes these commuters use and ensuring that they are well maintained should be a priority.

In a similar fashion, census data reveal that if Des Moines is typical, extensive commuting occurs from outer suburban areas into central cities and inner suburbs. Some outer suburban areas, such as Dallas County, are experiencing very high growth rates, and this highlights the need for long-range land use and transportation planning. Concepts such as polycentric land use patterns and jobshousing balance need to be considered, and highway and arterial upgrades should be made in ways that are consistent with the resulting comprehensive plan. Otherwise, the same sort of traffic congestion that has beset many other larger U.S. cities is likely to occur in growing Iowa metro areas. Congestion is not conducive to economic development or a good quality of life. 
Just as people must be able to move about easily to ensure a competitive economy, so also must freight be able to enter and leave Iowa locations in a reliable, costeffective manner. Currently, the state depends very heavily on trucking, which in terms of value transports over 86 percent of the freight to, from, and within Iowa. With the prospect of even more heavy trucks on roads and highways as the nation's economy grows, it is in the long-term best interest of the state to encourage freight rail service. Rail service is not a major competitor for shipments by most economic sectors in Iowa; coal dominates incoming cargo, and agricultural commodities are the main users of rail leaving the state. For rail to become more competitive, better reliability and improved intermodal capabilities will be important. If suitable agreements can be forged, it may be prudent for Iowa and other states in the region to explore cost-sharing arrangements to upgrade certain types of rail facilities.

If trucking indeed will continue to be the dominant freight mode serving Iowa, and if heavy trucking traffic bridging Iowa will continue to increase, the state should consider adding truck-only lanes to its busiest interstate highway segments. Doing so would improve traveler safety and it would help restore pleasure in journeying by auto, something that has all too often been lost, especially on interstate highways like I-80.

Finally, the nation's emerging economy is highly dependent on the ability to transport managers and other key staff quickly to multiple locations. With myriad problems facing airline travelers and less-than-impressive service in most parts of the state, general aviation has become a fundamental need. Even though the FAA cannot enable all airports to operate under instrument conditions, GPS technology has made navigation and approaches to smaller airfields safer and more reliable. There certainly is a case for the state embarking upon a program to selectively participate in upgrading airports, when doing so would have the promise of fostering economic development. 


\section{CHAPTER 4 SAFETY}

One of the most fundamental ways that transportation investments can enhance quality of life is by making it possible for people to move about the state in relative safety. While it will never be possible to remove all risk involved in moving people or goods, it is a vitally important public policy objective to identify particularly highrisk circumstances and address them as fully and creatively as possible. To fully evaluate all aspects of transportation safety in Iowa is, of course, beyond the scope of this monograph, but we can examine some of the issues that are most vividly tied to general quality of life, those about which focus group participants frequently expressed concern.

In brief, there were three general safety issues that came up in our meetings repeatedly. These were:

- Upgrading two-lane rural roads to four-lane expressways or "super-two" highways

- The needs of older drivers

- Large trucks on Iowa highways

It would be inaccurate to imply that these were the only safety issues about which focus group participants expressed concern. Other issues mentioned included conflicts between motor vehicles and pedestrians and cyclists, aggressive driving in urban areas, and travel on lower-standard rural roads. But the three general topics above definitely evoked the most discussion. We examine them in turn.

\section{CONVERSION TO FOUR-LANE EXPRESSWAYS OR SUPER-TWO HIGHWAYS}

Among the most commonly sought after highway upgrades are conversions of twolane roads to four-lane expressways or super-two highways. In Chapter 3, we discussed the economic development issues related to upgrading rural highways. We now focus on safety issues: under what conditions will upgrading rural roads improve safety and when will it not. Focus group participants tended to believe that such conversions primarily served to enhance economic development and that safety-related issues arose only when traffic volumes became high enough to make passing hazardous. Some participants believe that adding lanes would alleviate the problem of crashes on two-lane highways when sight distances are restricted by topography, curves, and weather.

A critical investment policy issue is how scarce resources can best be deployed to make the greatest overall improvement in safety on Iowa's primary roads. More 
specifically, when is it cost-effective to upgrade two-lane rural roads to super-two highways, and when is the cost-effective solution upgrading to four-lane highways?

\section{Super-two highways defined}

Super-two highways are two-lane facilities to which a series of geometric improvements have been made. These improvements, which enable the traffic to flow more efficiently, increase safety substantially. Improvements associated with super-two highways include:

- Comparatively wide (12 feet) traffic lanes to allow greater separation between opposing traffic flows

- Ten-foot shoulders that are at least partially paved

- Passing lanes approximately every five miles

- Climbing lanes on long or steep grade locations to allow orderly passing of slow-moving vehicles

- Turn lanes and acceleration lanes where needed

- Access control to reduce the number of intersections along the route to the extent practicable

Super-two highways are based on guidelines for rural arterial highways promulgated by the American Association of State Highway and Transportation Officials (AASHTO). The capital cost of upgrading a two-lane road to a super-two highway has been estimated to be approximately half the cost of a four-lane highway, and the average maintenance costs have been estimated to be half as great (1). Thus, Iowa could upgrade about twice as many miles of roadway to super-two highways as to four-lane highways with a given budget.

\section{Safety impacts of highway improvements}

An analysis by Council and Stewart (2) involved studying data from California, Minnesota, North Carolina, and Washington regarding changes in crash rates following upgrades of two-lane highways to four-lane expressways. Their results were not particularly conclusive; with average daily traffic (ADT) between 8,000 and 15,000 (high volumes for a two-lane highway), Council and Stewart observed a wide range of reductions - between 10 and 70 percent-when a two-lane highway was upgraded to four lanes. A more relevant study by Rogness et al. (3) indicated a 20 percent reduction in crashes with this type of upgrade on roads with ADT between 3,000 and 5,000. Rogness et al. also concluded that crash reduction effects increase with higher ADT.

Using Iowa data, Forkenbrock et al. (4) found that controlling for pavement condition, shoulder width, curvature, and gradient, a rural four-lane expressway with 5,000 ADT would have 31.2 percent fewer crashes per million VMT than a twolane highway with the same traffic volume. Their data consisted of 21,224 crashes on 17,767 rural primary non-interstate highway segments (comprising 7,444 miles). These crashes occurred during 1989, 1991, and 1992. This result indicates 
that if no other changes were made to a roadway (i.e., curvature, grade, and shoulder width did not change), upgrading a 50-mile stretch of two-lane rural highway with 5,000 ADT to four lanes would reduce the number of crashes by about one every three years. Using current crash cost data suggested by the U.S. DOT (5), the societal crash cost savings would be roughly $\$ 66,000$ per year for this 50 -mile stretch of highway.

The primary safety gains of two- to four-lane conversions (or adding passing lanes) stem from drivers' ability to overtake slower-moving vehicles more safely. Forkenbrock and Hanley (6) found that the length of the vehicle being overtaken is a critical factor in the safety of two-lane rural highways. They found that the likelihood of an attempted pass being unsuccessful (an aborted attempt or a crash) is about three times greater when overtaking a combination truck than when trying the same maneuver with an auto or light truck.

A lingering safety problem for rural non-interstate highways-both two- and fourlane facilities-involves at-grade intersections. To make right or left turns at such intersections, a driver must slow well below the traffic flow speed, and the potential for rear-end collisions naturally increases with the traffic volume. When turning left off the highway, a driver has to watch for traffic approaching from the rear and also must watch for approaching traffic. The potential for a crash is comparatively large at or near these intersections, and it comes as no surprise that a sizable number of fatal and personal injury crashes occurs at them.

In Iowa during 2000 , there were 7,011 crashes at a total of 5,079 rural intersections. Included were crashes occurring within 200 feet of an intersection. The general breakdown of these crashes is as follows:

- Fatalities occurred in 116 crashes (representing a total of 147 fatalities)

- Personal injuries occurred in 2,962 crashes (representing 870 major injuries and 2,514 minor injuries)

- Property-damage-only (PDO) crashes numbered 3,933

In short, about one-quarter of all fatalities in Iowa during 2000 happened at the intersections of rural roads or highways. Because there are myriad factors that influence the relative safety of particular rural intersections, it is not fruitful to compare in a summary fashion crash rates at intersections on two- versus four-lane rural highways.

To gain a perspective on the safety of four-lane expressways, the Iowa DOT has analyzed crashes that occurred at 644 non-signalized rural expressway intersections during the period of 1996 to 2000 . Frequency of crashes proved to be a function of traffic levels entering the intersection from the road crossing the expressway. Low-volume intersections, those with less than 250 vehicles entering from the crossing road daily, had 0.06 crashes per million entering vehicles, while intersections with 1,000 or more vehicles entering the intersection from the 
crossing road daily had 0.38 crashes per million entering vehicles, a rate over six times higher.

In 2000, 27.8 percent of the crashes at rural expressway intersections occurred when the vehicle entering the intersection from the crossing road collided with a vehicle on the expressway. Another 15.4 percent of the crashes were rear-end collisions that took place as a vehicle on the expressway either slowed to turn or had to brake to avoid a crossing vehicle. The third most common type of crash at these intersections involved a vehicle turning left off the expressway being struck broadside by a vehicle traveling in the opposing direction. Broadside crashes accounted for 9.5 percent of the crashes at rural intersections.

In summary, Iowa's crash data suggest that converting rural two-lane highways to four-lane or super-two facilities is likely to reduce the total number of serious crashes by about one-third. With higher ADT, the safety improvement is likely to be much greater than on lower-volume highways. Even with a conversion from two lanes to four, however, a significant safety issue remains at rural highway intersections. Various forms of geometric improvements at these intersections can help bring down crash rates by reducing the potential for vehicle conflicts. Such improvements might include left and right deceleration and turn lanes and, where traffic volumes warrant, signalizing the intersection. The limited evidence available, however, is unclear regarding the safety merits of signalizing rural highway intersections. Because of the speeds involved and differential braking behavior among drivers, rear-end collisions are a threat at signalized rural expressway intersections.

When to upgrade rural two-lane highways to four-lane expressways or to super-two highways was discussed in several focus group meetings. There was general (but not absolute) accord that the nature of the facility upgrade should be based on forecast traffic volumes. With less than about 6,000 ADT, a super-two upgrade is likely to be cost-effective. By reserving the necessary right of way to expand it to a four-lane expressway, the option is preserved to add lanes as conditions warrant.

\section{OLDER DRIVERS}

In the nine focus group meetings, we made a serious and concerted effort to include representatives of AARP, AAA, and other service organizations that are knowledgeable about older drivers' problems and needs. It was often noted that Iowa has a growing number of older drivers who continue to drive because (1) they have relied on auto transportation for many years and (2) there often are few or no alternative transportation services available to them. We have examined the nature of safety issues regarding older drivers in Iowa and explored possible options to make the driving environment safer for them and to offer alternatives to driving whenever possible.

It is a well-known fact that a relatively large fraction of Iowa's population is older. In 2000 , about 15 percent of the state's population was 65 or more years old (analysts at Iowa State University project that this number will grow by 240,000 people to 22 
percent of the state's population by 2025), and those 75 years and older accounted for about seven percent (7). Most of these older persons have driven for the better part of their adult lives, and mobility is precious to them. Large percentages of older people have driver's licenses. In fact, about 85 percent of those 70-74 have licenses, and even 40 percent of those 85 years or more are licensed to drive. Put another way, over 146,000 Iowans aged 75 years or more have current driver's licenses.

Milone (8) provides a useful summary of the cognitive changes that affect older drivers:

While long-term memory and learning skills seem not to deteriorate, a decline in short-term memory causes problems, especially in organizing information coming from a variety of sources. Decision-making in traffic is less acute. There is some decline in the ability to estimate the passage of time and to judge the speed of other motor vehicles. The traffic environment may produce too many cues at one time, thus causing confusion or erratic driving behavior.

These changes in older persons' cognitive processes are important. On the one hand, experimental evidence suggests that brake reaction time increases only slightly with age, but on the other, when tasks are more complex and the cognitive burden is thus greater, reaction times increase substantially (9).

\section{Crash experience of older drivers}

Older drivers tend to be less aggressive than younger cohorts, and they drive fewer miles, particularly during periods of darkness $(10){ }^{3}$ Yet because in many instances their motor skills and eyesight are not as good as they once were, they have a comparatively high crash rate per 100 million miles driven (see Figure 4-1; also see 11). The figure shows that the youngest drivers, those age 16 who recently began driving, have a high fatality rate, but the highest rate of involvement in fatal crashes is those aged 85 or more years. This group averages about eight fatal crashes per 100 million VMT compared to less than one for drivers aged 30 to 69 years. Put another way, 12 percent of the people who were fatally injured on Iowa roads in the year 200070 years and older.

We analyzed 2000 national and Iowa crash data for older drivers and found several notable patterns.

- Fully 86 percent of the older persons who died in Iowa motor vehicle crashes in 2000 had no previous recorded accidents.

- Fatal crashes involving persons 70 or more years of age tend to occur during the middle of the day (86 percent), suggesting that older drivers try to avoid nighttime driving. Younger age cohorts have a substantially higher fatality rate during periods of darkness.

3 A cohort is a gender-specific age group, usually five years wide (e.g., females 55 to 59 years old). 
- Of the 62 fatal crashes involving persons 70 years or more, 34 (55 percent) occurred at intersections.

- When older drivers are involved in vehicle crashes, they are more likely to die than is true of younger age groups. One of every 90 crashes involving older persons resulted in a fatality, roughly twice the rate of people under 45 years old.

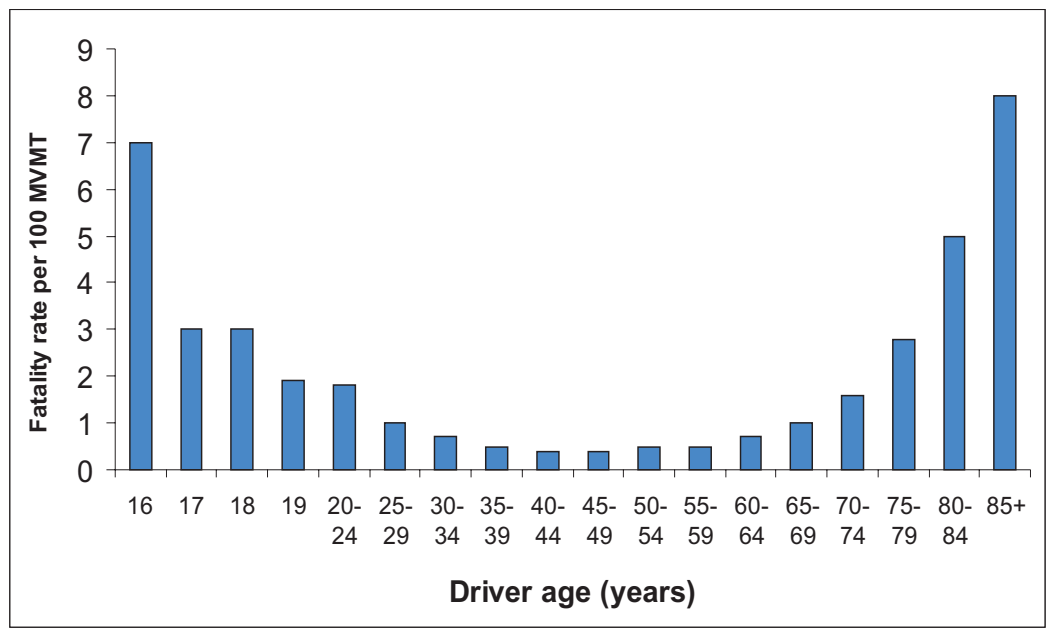

Figure 4-1. Fatal crash rates by age of driver, 1996

SOURCE: NHTSA, as cited in (7)

- The most common form of crash involving an older driver was front-to-side collisions (55 percent). In more than one-third of all fatal crashes involving an older driver, failure to yield the right of way was a factor. This was a higher fraction than for younger age groups.

- In fatal crashes resulting from a failure to yield the right of way at a stop sign, drivers over 75 years were twice as likely to be involved as were drivers under 65 years of age.

- On four-lane rural expressways, a failure to yield the right of way was the most common type of crash when an older driver was involved. In 2000, 39 percent of these fatal crashes occurred when a vehicle attempted to cross the lanes of oncoming traffic and a collision resulted. For all age groups the percentage was 28 .

- The second most common form of fatal crash involving an older driver on four-lane rural expressways was rear-end collisions (37 percent, versus 15 percent for all age groups). Often, these collisions occurred when one or more vehicles slowed to make a turn and another driver behind them did not react quickly enough.

- Alcohol and careless driving are almost never factors in older drivers' crashes. 


\section{Policy options for older drivers}

The central safety problems facing older drivers are fundamentally different from those of most younger drivers. Older drivers tend to be cautious, law-abiding, and non-aggressive, but they have diminished visual acuity and hand-to-eye coordination (12). Their cognitive powers in some cases are reduced, so they may have more difficulty multitasking. Thus, it comes as no surprise that they tend to do less well in traffic situations that are more demanding and that require multiple decisions in a compressed time period.

Crash data tell us that crashes involving older drivers are more likely to occur at intersections than is true of other age groups. They are at especially high risk at higher-speed rural intersections where traffic volumes are comparatively great. Because many of the older Iowans who depend on auto travel live in rural areas or small, remote communities, they frequently depend on rural highways to journey to destinations that are important to them (e.g., medical care, grocery shopping, visiting friends and family, and attending religious services). It follows that they frequently pass through rural intersections where crash data suggest they are comparatively likely to be involved in serious crashes.

A key policy option is to do all that is economically feasible to improve the safety of rural highway intersections. An Iowa older driving forum (7) suggested several ways to improve rural intersection safety for older drivers:

- Differentiate better between two- and four-way stops.

- Use dilemma zone protection at high-speed intersections when warranted. ${ }^{4}$

- Install left turn signals.

- Install destination lighting at rural intersections.

- Create more and longer left-turn and right-turn lanes.

- Install better lane/route designation cues (word or diagram on a sign).

- Brighten pavement markings with wet-reflective tape, raised pavement markers, or special paints.

- Maintain edge- and centerline-markings with more durable materials or more frequent application.

- Widen four-inch pavement markings to six inches or more (over 29 states have already done this).

\footnotetext{
${ }^{4}$ Dilemma zones are road segments approaching intersections. In cases where the driver may be undecided as to whether to brake hard for a changing light or to proceed through the intersection, pavement loop detectors (sensors) can be used to delay the green light for conflicting traffic when a vehicle is traveling at a high enough speed to be unlikely to stop before entering the intersection.
} 
While intersections are a primary concern, there are other steps that can be taken to enhance the safety of the driving environment for elders. Staplin et al. (13) developed a series of practical guidelines to help make roadways safer for older drivers. These guidelines recommend such features as delineation of curbs and medians, protected left turns at signalized intersections, longer timing for pedestrian control signals, and roadway signs that are easier to read. Mace (14) also suggested that road information signs should be larger and brighter. In addition, he recommends making signage more repetitive, so that if an older driver misses a sign, the essential information is provided again before a decision has to be made. Another possible approach is driver-retraining courses. To gain the confidence of elders, these courses should not be a basis for screening drivers' ability to remain on the roads, but they could be a requirement for renewing a driver's license.

Nationally, several auto insurance companies offer discounts to older drivers who complete such courses.

Thinking more broadly, alternatives to the auto should be considered to assure the mobility of Iowa's aging population. Among the alternatives worth examining are:

- Within urban areas, taxis can be a cost-effective means for assuring the mobility of older persons. A lower ride cost with a 24-hour advance reservation would help manage demand levels. Public-private partnerships between private taxi companies and public transit agencies can be a good way to provide service to older persons.

- Also within urban areas, pedestrian-oriented design features should be accorded higher priority. With housing targeted to older persons becoming more common in suburban areas, the need is growing for sidewalks, facilities for crossing major roadways, and signals that are more pedestrianfriendly (e.g., those that indicate the time remaining on the walk cycle). On a larger scale, land use planning should involve placing commercial activities in greater proximity to multiple-family housing, thus improving access for older residents living in such housing.

- Public transit service is an important means of transportation for older persons under certain circumstances. In many rural areas, however, demand densities are too low to make most forms of scheduled service feasible. Even in urban areas, demand levels are often quite low, and the service that can be provided tends to be far inferior to that available by auto-if one is still able to drive. Thus, it is not likely that in most Iowa communities transit is likely to be of high enough quality to lure driving elders from their autos if they still feel able to operate a vehicle. Perhaps new partnerships between public agencies and human service organizations could improve transit services oriented to older persons.

In summary, Iowa's population of older drivers will grow in coming years. Many of these drivers have operated motor vehicles for a very long time and have become accustomed to the level of mobility driving affords. As a group, older drivers are cautious and sensible, but their abilities to drive safely under complex circumstances have often diminished significantly. Accordingly, older drivers have 
crash rates that are relatively high. An additional problem is that older drivers are more likely to be killed when they are involved in crashes.

Banning an older person from driving is an extremely serious matter. Sweeping policies such as age limitations are unwise because the ability of older persons to drive varies dramatically. A better strategy is to make improvements to the road system to make it easier for older persons to travel by auto. An accompanying strategy is to offer retraining opportunities for older drivers with the clear understanding that such retraining is not a form of fitness-to-drive evaluation. Beyond that, better alternatives to driving must be taken more seriously in Iowa. Among the alternatives worth considering are public-private partnerships to provide taxi service, more walkable communities, and cooperatively provided transit services.

\section{LARGE TRUCKS ON IOWA HIGHWAYS}

As we discussed in Chapter 3, a very large portion of the goods consumed in Iowa arrive by truck, and a comparable portion of the state's products depart by truck. With trucking so important to the state's economy, it follows that considerable trucking VMT occur within the state. On major routes, however, a large amount of trucking VMT in Iowa is bridge traffic, meaning that this traffic has neither an origin nor a destination in the state-it is merely passing through. The heavy presence of combination truck (semi-trailer) traffic on Iowa highways was frequently mentioned as a safety concern by focus group meeting participants. Specific concerns they voiced included:

- At times, large trucks on interstate highways intimidate people traveling in autos. Occasionally, these trucks pull up close to one's rear bumper, and it is not unusual to be boxed in with trucks in front, behind, and alongside of one's vehicle.

- The braking distances of large trucks are long enough that if an incident occurs on the highway, such as a driving error by a motorist, there is an insufficient margin of safety. One cannot count on the truck being able to stop in time. This problem is worst when the weather is inclement.

- The length of combination trucks makes passing on two-lane highways considerably more difficult. Especially in hilly terrain or on road segments with multiple curves, passing can be dangerous. Bad weather also exacerbates this problem.

- On roads where large trucks operate frequently, road wear and damage tend to be greater. Concern exists that rutting and potholes make these roads less safe because one's vehicle does not track as well, and bumps and potholes can make the vehicle jump about.

Participants in the focus group meetings gave the clear impression that they have mixed feelings about combination vehicles in Iowa. They understand the value of trucking to the state's economy but wish that steps could be taken to make it less tense to operate a vehicle in proximity to them. 


\section{Analysis of large truck crashes in Iowa}

According to the National Highway Traffic Safety Administration (NHTSA), in 2002 Iowa ranked third among the states in the percentage of all road fatalities that involved large trucks (15). Between 1994 and 2002, a total of 783 people were killed in crashes involving large trucks in Iowa; this accounts for 18.8 percent of the fatalities during this nine-year period. To gain a clearer understanding of the nature of safety issues related to large trucks operating on Iowa's highways and roads, we examined Iowa data from the Trucks Involved in Fatal Accidents (TIFA) data file maintained by the University of Michigan Transportation Research Institute (UMTRI) for the years 1994-1998. The TIFA data file contains a random sample of crashes involving trucks of various configurations drawn from the federal Fatality Analysis Reporting System (FARS). FARS was first created by the NHTSA in 1975; it includes annual data on motor vehicle traffic crashes that result in the death of either an occupant of a vehicle or a non-motorist within 30 days of the crash. The crashes included involve a motor vehicle traveling on a roadway customarily open to the public. FARS data are gathered from the states using a standardized recording format.

The TIFA data file augments the FARS data with police reports on all fatal crashes involving at least one truck. These police reports vary considerably from state to state, so they are supplemented by telephone interviews. Whenever possible, the owner or driver of a vehicle involved in the crash is contacted; and failing that, the investigating police officer is contacted to lend as much detail and accuracy as possible to each case. As a result, the TIFA data file contains considerable detail on crash circumstances.

In the case of Iowa, the TIFA file contains detailed data on 237 fatal crashes involving large trucks for the years 1994-1998. During this time, FARS data indicate that there were 357 fatal crashes (resulting in 430 deaths) involving large trucks (those over 25,000 pounds gross weight), so the TIFA sample contains approximately 66 percent of such crashes. Of the 237 crashes, 167 (86.9 percent) involved combination (semi-trailer) trucks. Only 13.1 percent of these crashes involved a single vehicle. Table 4-1 provides a general overview of total fatal crashes and those involving large trucks, focusing on the types of road on which crashes occurred and the time of day at which they happened.

The table indicates that comparatively few fatal crashes involving large trucks occur during the period between $6 \mathrm{p}$.m. and 6 a.m. The greatest concentration occurs between noon and 6 p.m., with nearly as many occurring between 6 a.m. and noon. Also noteworthy is that trucks account for a larger percentage of all fatal crashes during these daytime hours. In short, during the daytime hours when traffic tends to be the greatest is when large trucks are most likely to be involved in fatal crashes.

It is perhaps surprising that Table 4-1 reveals a high number of fatal crashes on minor arterial and collector roads; 63.3 percent of all fatal crashes involving large trucks occurred on these roads. Such roads are almost exclusively two-lane facilities. Interstate highways, all of which have four lanes or more, account for 15.6 percent 
of all fatal crashes involving large trucks. Thus, while focus group participants frequently mentioned that they are concerned about the oftentimes heavy truck traffic on interstate highways, it is on rural two-lane highways where the preponderance of fatal crashes involving large trucks occurred during the 19941998 time period.

Table 4-1. Time of day and road type for fatal crashes involving large trucks in Iowa, 1994-1998

\begin{tabular}{|c|c|c|c|c|c|c|}
\hline $\begin{array}{l}\text { Time of } \\
\text { day }\end{array}$ & Interstate & $\begin{array}{l}\text { Principal } \\
\text { and } \\
\text { minor } \\
\text { arterial }\end{array}$ & $\begin{array}{c}\text { Local } \\
\text { roads } \\
\text { and } \\
\text { collectors }\end{array}$ & $\begin{array}{c}\text { Total fatal } \\
\text { crashes } \\
\text { involving } \\
\text { trucks }\end{array}$ & $\begin{array}{c}\text { Percent } \\
\text { of all } \\
\text { fatal } \\
\text { crashes* }\end{array}$ & $\begin{array}{c}\text { Percent } \\
\text { of all } \\
\text { fatal } \\
\text { crashes } \\
\text { w/trucks }\end{array}$ \\
\hline $\begin{array}{l}\text { Midnight to } \\
6 \text { a.m. }\end{array}$ & 7 & 22 & 2 & 31 & 12.0 & 13.1 \\
\hline $\begin{array}{l}6 \text { a.m. to } \\
\text { noon }\end{array}$ & 9 & 51 & 18 & 78 & 24.1 & 32.9 \\
\hline $\begin{array}{l}\text { Noon to } \\
6 \text { p.m. }\end{array}$ & 12 & 52 & 22 & 86 & 17.4 & 36.3 \\
\hline $\begin{array}{l}6 \text { p.m. to } \\
\text { midnight }\end{array}$ & 9 & 25 & 8 & 42 & 11.0 & 17.7 \\
\hline Total & 37 & 150 & 50 & 237 & 17.3 & 100.0 \\
\hline $\begin{array}{l}\text { Percent of } \\
\text { all fatal } \\
\text { crashes* }\end{array}$ & 34.4 & 19.4 & 8.3 & & & \\
\hline $\begin{array}{l}\text { Percent of } \\
\text { all fatal } \\
\text { crashes } \\
\text { w/trucks }\end{array}$ & 15.6 & 63.3 & 21.1 & & & \\
\hline
\end{tabular}

* These percentages are estimates based on adjusting the TIFA data. Specifically, for the years 1994-1998, TIFA data represent a sample of 66 percent of all fatal crashes involving large trucks in Iowa. Assuming that the sample is representative of all such crashes, the noted percentages are accurate.

Nevertheless, the table shows that over one-third (34.4 percent) of the fatal crashes on Iowa interstate highways involved large trucks, even though these trucks have represented only about 20 percent of the interstate traffic in Iowa during recent years. It should be noted that in slightly more than half of the fatal crashes involving large trucks, the truck was registered in a state other than Iowa.

Table 4-2 presents the same crash data in a slightly different way. This table shows the types of crashes involving large trucks that occurred on different standards of roads. Several figures in the table are especially noteworthy. Head-on crashes on arterials, which are generally two-lane facilities in rural areas, account for 72 (30.6) 
percent of all fatal crashes involving large trucks. Angle collisions on arterialsoften occurring at intersections-were the second most common form of crash. Note, too, that rear-end collisions were the most common form of crash on interstates.

Table 4-2 Type of crash and type of roadway for fatal crashes involving large trucks in Iowa, 1994-1998

\begin{tabular}{lccccc}
\hline Type of road & $\begin{array}{c}\text { No other } \\
\text { vehicle }\end{array}$ & $\begin{array}{c}\text { Rear- } \\
\text { end } \\
\text { collision }\end{array}$ & $\begin{array}{c}\text { Head-on } \\
\text { collision }\end{array}$ & $\begin{array}{c}\text { Angle } \\
\text { collision }\end{array}$ & Total \\
\hline Interstate & 10 & 17 & 8 & 2 & 37 \\
Arterial & 17 & 12 & 72 & 49 & 150 \\
Collector & 5 & 2 & 11 & 25 & 43 \\
Local road & 3 & 0 & 1 & 2 & 6 \\
Total & 35 & 31 & 92 & 78 & 236 \\
\hline
\end{tabular}

\section{Policy options for large truck safety}

Data on crash rates-number of crashes per 100 million miles traveled-for specific types of vehicles, including trucks, generally are not available. Yet the data presented above suggest that serious safety issues regarding heavy trucks exist in Iowa. Table 4-2 definitely indicates that arterial highways are the road type on which the greatest number of fatal crashes occurs. Among the possible actions the Iowa DOT and counties could take to reduce these fatal crashes are:

- Increase the number of passing lanes on two-lane highways using a supertwo road design, especially along segments where visibility is restricted by hills and curves. Doing so may reduce the number of head-on fatal collisions, which were the most common type of crash during the 19941998 period.

- Improve intersections of certain rural highways to reduce both rear-end and angle collisions. Large trucks are not able to brake as effectively as lighter vehicles, and this limitation can contribute to both types of crashes at rural intersections. Acceleration and turning lanes would help make intersections safer.

- Step up safety inspections of heavy trucks. Our data do not contain information about the maintenance of large trucks involved in fatal crashes in Iowa, but a more aggressive safety inspection program may help reduce these crashes. Such a program can help ensure that vehicles' braking systems are functioning properly.

\section{SUMMARY}

Safety of travelers on Iowa's road system was a topic that received considerable attention in the nine focus group meetings. Of course, safety has many dimensions, 
and it has not been the objective of this chapter to address all of them. Rather, our purpose has been to examine three safety issues that are particularly important to the state and which, if adequately addressed, could substantially enhance the quality of life in Iowa. While it may not be appropriate to refer to any of the three issues as a crisis, too many lives are lost to motor vehicle crashes in the state not to search for ways to reduce these losses.

The three general safety issues interact with each other. Older drivers, two-lane highways without upgraded intersections, and large trucks, taken together, can produce potentially dangerous situations. It also is significant that the numbers of older drivers and large trucks both will continue to grow in Iowa. This suggests that the safety issues related to them will only become more pressing as time passes. 


\section{CHAPTER 5 CHOICE OF TRANSPORTATION MODES}

From the perspectives of both the individual traveler and society, having a choice of personal transportation modes is important to a good quality of life. Modal choice is especially significant for people who have few options as to how they make necessary trips. For example, a low-income household may have only one auto but two or more members who are employed. Without workable public transit or carpooling options, someone may have to forego an employment opportunity or expend a relatively large portion of his or her earned income on the journey to work.

On a different plane, many Iowans prefer to use non-motorized transportation for certain types of trips or simply for recreation. Enhancing recreational options is key to improving the quality of life in Iowa, and it should be taken seriously as a transportation policy matter for at least two reasons. First, good recreational opportunities, such as bicycling and hiking, will increase Iowa's attractiveness in terms of tourism; people generally prefer to vacation and hold professional meetings where there are ample opportunities to relax and enjoy themselves.

The second reason that transportation facilities as recreational mechanisms are an important policy issue is that Iowa definitely needs to make itself more attractive to younger, relatively well-educated and skilled people. As we discussed in earlier chapters, the state's population composition has become skewed toward older cohorts, and Iowa has been experiencing an exodus of younger people. By enhancing opportunities for outdoor recreation, the state would be taking a step toward making itself more attractive to young professionals.

Thus, whether the objective is to improve the situation of Iowans with limited mobility or to offer increased recreational opportunities, the State of Iowa should look beyond the auto in providing options for personal travel. We recognize that choice can be costly and that circumstances may not be conducive to all possible modes of transportation or all forms of service. In this chapter, we discuss ways in which a series of alternative means of transportation could be made available in the state. Our discussion is divided into two parts: services to improve mobility, and services to increase the choice set of transportation options to help make the state more attractive.

\section{SERVICES TO IMPROVE MOBILITY}

There is no question that we have become an auto-oriented society. In 2000, Iowa had 36,000 more registered passenger vehicles than population. Especially in rural areas and communities without congestion and parking problems, the auto offers a wonderful level of mobility. But for those with limited resources or with disabilities, 
including a growing number of older persons, other modes of transportation are essential. Even for those with an available vehicle, a choice of transportation modes is often a key ingredient in improving quality of life. Our discussion of several alternative modes to improve mobility and choice begins with an examination of several forms of public transportation. We define public transportation quite broadly to include any form of publicly or institutionally provided conveyance that regularly transports people.

\section{Carpools}

In many ways, the simplest form of public transportation is the carpool, where several people routinely ride together to and from work. The advantages of carpooling to both employees and employers are well known and include substantial cost savings to participants, less boredom on longer commutes, fewer parking needs by employers, and the ability to rest or work during commuting trips by all but the driver. Societal benefits are important as well and include reduced energy consumption, less congestion, and less air pollution.

Figure 5-1 indicates the level of carpooling and transit use in Iowa's metro areas. Council Bluffs and Sioux City on the western edge of the state are the leaders in carpooling. This may be due to the substantial level of workers in these areas who commute to job sites in other locations; most notably, 44 percent of the workers residing in Pottawattamie County, the location of Council Bluffs, commute to another county (many to Omaha, Nebraska). Note that public transit use by commuters in Iowa is very low, about one to two percent, except in Iowa City and Ames, where many students ride buses to the universities in their communities.

The key to making carpools achieve their potential is to inform prospective participants of the opportunities available to them-persons with comparable schedules who work in similar places, often for the same employer. There certainly is a role to be played by local and state government in encouraging this means of commuting. For example, the Des Moines Metropolitan Transit Authority (MTA) has a Central Iowa Rideshare program that facilitates carpooling by providing a matching program. It helps interested persons locate others with whom they could feasibly carpool.

There is a strong case to be made for government and businesses in Iowa working collaboratively to promote and support carpooling. As noted, both would benefit by greater participation by commuters, and the costs of carpooling programs are fairly low. The human resources departments of many businesses are well positioned to facilitate ride matching, and local and state governments could offer the sort of web site application process that the Des Moines MTA uses. Particularly for the many commuters from the outer suburbs of the state's metro areas and from rural areas and non-metro communities, the potential for greater carpooling is quite good. 


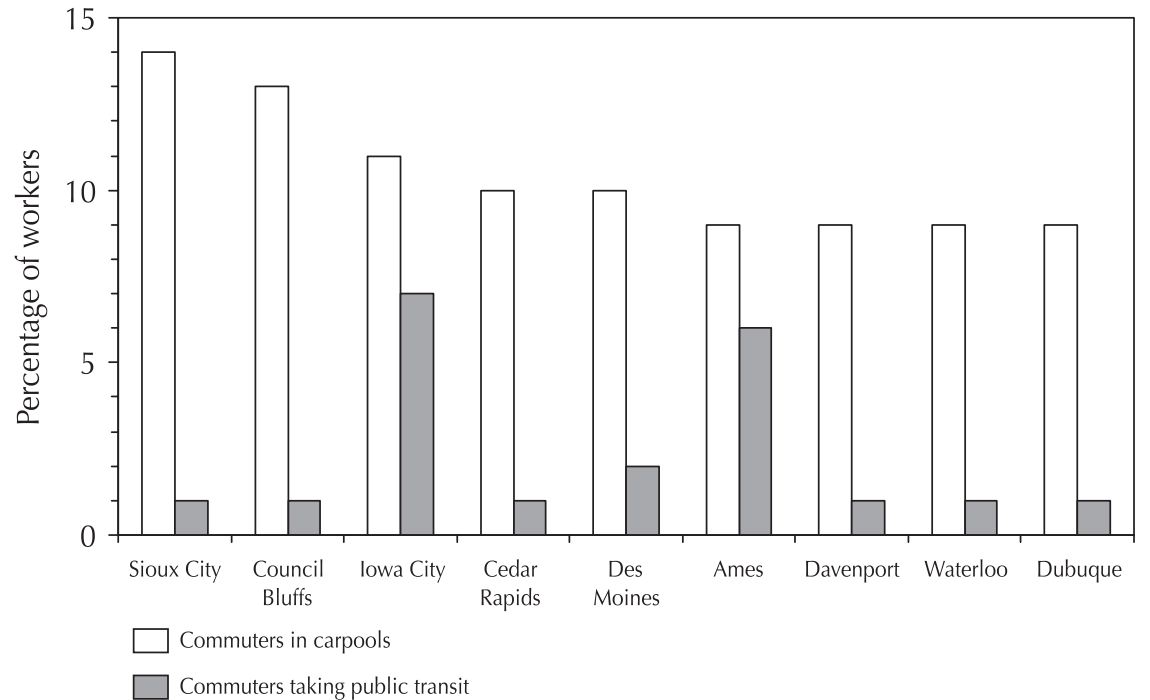

Figure 5-1. Use of carpools and public transit in Iowa metropolitan areas, 2000

SOURCE: (1)

\section{Vanpools}

Earlier we discussed the need for residents of rural areas of Iowa to travel to jobs in the state's employment centers. In the focus group meetings, business representatives often mentioned that they draw employees from considerable distances. Similarly, those involved in providing human services noted the need for rural residents to commute to jobs in other areas. Frequently, more than one household member must make such work trips, and quite often the destinations and work hours of household members are not conducive to carpooling. When economic circumstances allow, the obvious solution is to purchase more than one vehicle. An alternative to owning multiple autos-and one that favors those who for one reason or another cannot drive-is vanpools. Vanpools are typically organized by major employers; the University of Iowa, for example, has a large and successful vanpooling program. Currently, the University operates 63 vans, and over 750 employees participate. Monthly cost to an employee is a function of the distance traveled, with charges ranging from $\$ 28$ to $\$ 82$ (the latter for trips from Davenport, some 55 miles away). The payoff to the employer, of course, is access to an appreciably larger labor pool, as well as a lesser need for parking. From the employee's perspective, the program greatly reduces the out-of-pocket costs of commuting.

A limitation of vanpooling is that with rare exceptions, the only providers of this service are larger employers. Thus, rural residents who work in smaller businesses are unlikely to have access to this alternative. A notable exception is the Des Moines MTA. Its Central Iowa Rideshare, mentioned earlier, also has a successful vanpool program. It has a fleet of over 60 full-size passenger vans and minivans that are used 
by groups of five to 15 commuters for trips to and from work. The program serves communities as far as 65 miles from Des Moines. A sensible feature of the program is that Central Iowa Rideshare will arrange for alternative transportation home in the event of a family emergency. Each vanpool can accommodate one volunteer driver and up to 14 passengers. In exchange for driving the van, one does not pay a monthly fare and has personal use of the van. The driver is responsible for maintaining the van and seeing that the vanpool operates smoothly.

It seems advisable for more public agencies like MTA to have access to vanpool services. Perhaps partnerships could be organized between counties where travelers are employed and those where they live. In a very real sense, both counties stand to gain. As we observed in Chapter 3, there is considerable cross-county commuting in many parts of Iowa.

\section{Demand-responsive transit}

All 99 Iowa counties provide some form of demand-responsive public transit service that handles specific requests for transportation and does not operate on regular routes or schedules. Given the low population densities that exist in the state, this is a particularly appropriate form of transit for Iowa. It is especially well suited to smaller communities where a traditional fixed-route bus system would not be viable because of the very low demand densities.

The main users of demand-responsive services within Iowa communities are targeted populations. By far the dominant user groups are older persons and the disabled. In most of the focus group meetings, we benefited from the participation of managers of these systems, and we found that services provided and the arrangements for carrying out these services vary greatly among communities. Among the types of services offered are:

- General transportation to older and eligible disabled persons

- More specific services for elders and disabled persons, such as trips to and from medical facilities and grocery stores

- Shared services with human service agencies, such as Congregate Meals and area agencies on aging (AAAs)

- Head Start programs for pre-school children

These services are an extremely valuable way of integrating into the community older Iowans, those with disabilities, and children from economically challenged families. As such, these services should be made a budgetary priority.

We do not recommend that the State of Iowa provide extensive funding for inefficient services, but doing all we can to help transportation-disadvantaged residents of smaller communities achieve acceptable levels of mobility is a worthwhile public policy goal. To this end, periodic reviews of funding levels and allocation criteria for demand-responsive services should be carried out. 


\section{Public transit and private taxi partnerships}

Throughout this monograph and the earlier Policy Strategies volume, we have stressed the importance of assisting those who want to work but have poor access to transportation. All too often, Iowans in these circumstances cannot enter the labor market even though, given a chance, they could be valued employees. Lack of mobility can be due to many factors, including very limited public transportation, which in turn can be affected by one's residential location or work hours. For example, a person who wants to take a job on a night shift and who cannot rely on driving to work for whatever reason would find that transit buses almost never operate at night.

Public-private partnerships can bring about taxi service that is highly appropriate for communities without regularly scheduled public transit. It can also be helpful during low-demand periods for communities with transit service. Generally, it is cost-effective to enter into a contractual arrangement with a private taxi company that will provide service during specified time periods. To help prevent frivolous use of this service, a 24-hour prior reservation policy can be implemented such that people requesting service must call a city office, and the dispatcher can then prepare a "run sheet" listing the next day's clients to be picked up by time and place. A subscription option can be added so that people who work night shifts, for example, can be picked up for their work trips at the same time each day.

When demand densities are very low, this type of program can offer door-to-door service to those with a real need at a nominal cost to the community. A key to making this form of service work well is charging the user a small sum (e.g., \$.50 per trip). This will ensure that the service is not prohibitively expensive, and yet because it is not free, will discourage frivolous use to some degree.

State transportation funds should be made available to assist communities in providing this form of taxi service. Doing so can help reduce welfare dependency and materially improve the quality of life of people who are economically disadvantaged.

\section{Rural public transit}

It is difficult to provide public transit service in rural areas because the demand densities are so low. Most often, rural transit services are oriented toward older persons and those with disabilities. Occasionally, these services are also provided to pre-school children who are participating in Head Start or other special programs.

In certain parts of the state where the social and economic need is great, it is worth considering enhancements to existing rural transit services. Among the additional services that could be provided are regularly scheduled trips from smaller communities to employment centers and to health care facilities. Regarding the latter, one approach that has been successfully implemented is offering service in different quadrants surrounding a care facility on different days. People to the northwest of a community with a health care facility may be offered service on Mondays, for example. 
To provide a preliminary assessment of the relative need for rural public transit service among Iowa counties, we have developed a basic index of need. Table 5-1 shows the indicators included in the index, which has three components:

- A social need component that considers relative concentration of older and disabled people

- An economic need component that takes into account the possibility of increased employment of disabled persons and those without a vehicle

- An ability-to-pay component that reflects the relative size of a county's property tax base

Table 5-1. Variables in the rural transit need index

\begin{tabular}{|c|c|c|c|}
\hline Component & Variable name & Description & Source \\
\hline \multirow[t]{2}{*}{$\begin{array}{l}\text { Social need } \\
\text { component }\end{array}$} & Older & $\begin{array}{l}\text { Percentage of population } \\
65 \text { or more years old }\end{array}$ & (2) Table DP1 \\
\hline & Disabled & $\begin{array}{l}\text { Percentage of population } \\
\text { five or more years old } \\
\text { with a disability }\end{array}$ & (2) Table DP2 \\
\hline \multirow[t]{2}{*}{$\begin{array}{l}\text { Economic need } \\
\text { component }\end{array}$} & Employment & $\begin{array}{l}\text { Difference in the } \\
\text { employment rate of the } \\
\text { disabled population and } \\
\text { non-disabled population } \\
\text { 21-64 years old }\end{array}$ & (2) Table DP2 \\
\hline & Vehicles & $\begin{array}{l}\text { Percentage of owner- } \\
\text { occupied housing units } \\
\text { with no vehicle available }\end{array}$ & (2) Table QT-H11 \\
\hline $\begin{array}{l}\text { Ability to pay } \\
\text { component }\end{array}$ & Property tax & Property tax potential & (3) \\
\hline
\end{tabular}

Taken together, these three components provide an indication of the relative need to assist Iowa's rural counties by providing rural transit services. The resulting index of need is scaled such that 10.0 is the highest possible score, implying maximum need, and 1.0 is the lowest score. In our analysis, we included only rural counties, which we defined as not having a community of 10,000 or more residents (74 of the 99 counties). In Figure 5-2, the highest index of need for rural transit is generally in the southern counties, though some of these counties have relatively low need scores. Moderate need is indicated in parts of northeast and northwest Iowa. 


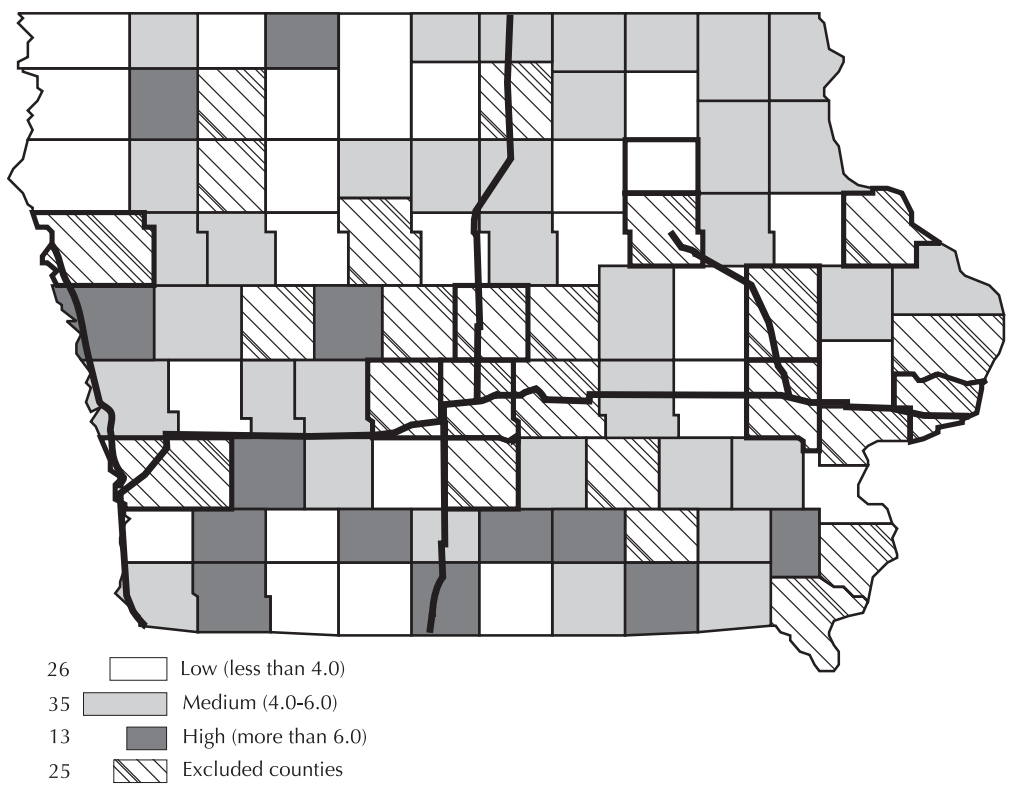

Figure 5-2. Relative need for public transit service among rural lowa counties

We recognize that this is a rather basic indicator of relative need, but it does help identify the counties in which limited funds to assist rural transit services may have the best potential to help needy populations. The index does not take into account the comparative performance of any existing transit services; the performance of such services should also be considered to ensure that the greatest possible improvement in mobility is afforded to Iowa's rural counties.

\section{IMPROVING TRANSPORTATION CHOICES}

Many members of society are attracted to a healthier life style that involves moderate physical exercise, outdoor recreation, and using non-motorized transportation when feasible. The implications for transportation policy are twofold. First, if Iowa wishes to attract and retain professional workers and their families, it must offer the types of amenities valued by such individuals. Bicycle and pedestrian trails and other facilities are a sensible investment for this reason alone. A second implication is that Iowa stands to gain in tourism if it offers attractive recreational opportunities, including non-motorized transportation travel opportunities.

\section{Trails as amenities}

Cities and regions of the U.S. vary greatly in the extent to which they facilitate travel within them using non-motorized transportation. Some communities have an integral system of paths and trails, and commuting by bicycle is a viable option. Others, particularly those that have grown rapidly over the past 20 years, are so auto-oriented that there are few sidewalks, and travel by bicycle is perilous, to say 
the least. Iowa communities that aspire to become more attractive to younger workers and their families can gain a competitive advantage by working to accommodate non-motorized transportation. Additionally, so-called "baby boomers" are increasingly looking to bicycles as a low-impact form of exercise (4), so older population cohorts will often see non-motorized transportation facilities as a valued amenity.

The Iowa DOT has relatively permissive guidelines for communities wishing to use federal pass-through funds for trails and pathways in road corridor environments. It simply requires that the regional planning affiliation (RPA) in smaller communities or the metropolitan planning organization (MPO) in metro areas demonstrate a reasonable level of expected use, connectivity with other bicycle facilities, and conformity with several other practical considerations. Currently, over 1,600 miles of recreational trails exist in the state, many of which are the product of 15 years of funding by the Iowa DOT and the federal government. Since the 1991 passage of the Intermodal Surface Transportation Efficiency Act (ISTEA), federal transportation funds have helped build 36 trail projects through the "transportation enhancement" feature that legislation created. All told, almost $\$ 126$ million has been spent on trails in Iowa since the early 1990s (5).

One important source of trails has been the conversion of abandoned railroad rights-of-way. Since the late 1970s, over 570 miles of former rail lines have been converted to trails; this is about ten percent of the miles of rail lines that have been abandoned during this time. For a truly comprehensive trails system to be developed in Iowa, participation by local governments and businesses will be necessary in the coming years. With proper support, a series of natural trail corridors could become a significant element in the state's efforts to advance the quality of life of its residents.

\section{Tourism opportunities}

Each year, thousands of visitors come to Iowa to participate in the Des Moines Register's Annual Great Bicycle Ride Across Iowa (RAGBRAI). This event is recognized nationally as a highly desirable vacation option. Why not build on this well-known event to make bicycle-based recreation a larger tourism feature of the state? There are many possible ways to do this, but one that was frequently discussed in the focus group meetings was exploiting the pleasant views near the two major rivers that flow along the east and west boundaries of Iowa. Several people expressed a desire to offer tourists the opportunity to stay in a series of bed and breakfast (B\&B) facilities along the Mississippi or Missouri Rivers. A shuttle service could move their belongings from the place where they stayed the previous night to the one that will be their destination that day. Part of the trip could be taken by boat along the river if the traveler chose, and provisions could be made for rainy weather.

Several studies have concluded that local investment in trails has had highly positive economic effects. For example, the National Park Service estimates that the $\$ 700,000$ spent on the Heritage Trail in Dubuque has resulted in an annual influx of 
$\$ 1.2$ million. It is hard to accurately estimate such impacts, but it is clear that trailbased outdoor recreation should have a larger role in Iowa's efforts to enhance its quality of life. Activity-based recreation would help recast Iowa's image as an attractive place to vacation. For the potential of this initiative to be reached, a partnership involving state government, county and municipal government, and private business is essential. Trails need to be constructed or upgraded, informational signage and viewing points must be built, a shuttle service must be developed and managed, and a national marketing effort needs to be undertaken.

\section{SUMMARY}

In this chapter, we have examined a disparate series of transportation services and facilities that have the potential to improve the quality of life for specific groups of Iowans. We have stressed that two different general policy objectives can be pursued with such services. They can help those with economic or physical challenges make trips that are important to them, whether they be to work, to seek medical care, to shop, pursue an education, or see family and friends. Because Iowa is a comparatively rural state with low population densities in many areas, the forms of public transportation found in larger cities often are not appropriate. Fortunately, innovative types of public transportation can be tailored to meet the needs of people in various circumstances. The types of services we discussed in this chapter are intended to assist people in low-demand density areas achieve reasonable levels of mobility.

We also have explored transportation services and facilities that can help Iowa become more attractive to visitors and residents as a place to recreate. The state has made an impressive start in developing a comprehensive system of trails for bicycling and hiking, and it should keep adding to and improving this system. Many parts of Iowa are a too-well-kept secret-they have untapped potential for outdoororiented recreation. Various state agencies should team with local governments and appropriate private sector groups to more fully exploit this means for increasing opportunities to enjoy the state. 


\section{CHAPTER 6 FINANCING TRANSPORTATION IN THE FUTURE}

In this monograph, we have discussed a variety of transportation policy directions that could materially advance the quality of life in Iowa. To adequately fund initiatives that may arise from these policy directions, stable, predictable revenue streams are a fundamental necessity. In various chapters, we have discussed funding needs for improvements to facilities and services such as airports, rural transit, and freight rail. Because funding for these policy initiatives would largely come from general fund appropriations, we do not focus on revenue sources for them in this chapter. We limit our scope to identifying user-derived revenue for the Road Use Tax Fund, which is the dominant source of transportation financing in Iowa.

In the simplest terms, roads and certain other transportation services are financed by some combination of user-charge revenue and local financing derived from such measures as income, sales, or property taxes. Rural primary highways are financed almost exclusively by allocations of the state's Road Use Tax Fund (RUTF) and federal allocations and programs, while county roads and urban streets depend on a blend of RUTF resources and local taxes, principally property taxes. Transit derives resources from the RUTF and federal programs, as well as from local funds. The relative roles played by the several sources of revenue for transportation operations, maintenance, and improvements are in flux. Looking into the future, a careful evaluation of how transportation in Iowa will be financed is needed.

\section{CHANGING FISCAL CIRCUMSTANCES}

Our primary focus in this discussion is on road financing because roads constitute by far the largest portion of transportation expenditures. Figure 6-1 presents the major sources of revenue for the RUTF in fiscal year (FY) 2002. The state's largest single revenue source is the motor fuel (gasoline and diesel) tax, which in FY 2002 contributed $\$ 399.0$ million. Over the past decade, however, the motor fuel tax has been declining in terms of its revenue share of the RUTF. Table 6-1 shows that in 1990, motor fuel taxes accounted for 48 percent of RUTF receipts, but by 2002, that share had shrunk to 38.5 percent. Growth in receipts from other funding sources, principally registration fees and use (sales) taxes, have enabled the RUTF to grow in constant dollars. This growth has been essentially equal to increases in VMT, as the receipts per VMT have remained virtually constant at about 3.4 cents since 1985.

The changing situation just described creates two serious concerns. First, greater reliance on registration fees and use taxes means that gradually Iowa has been moving away from cost-based user charges. The motor fuel tax, while highly imperfect, is a user-charge mechanism that is reasonably capable of charging in proportion to the actual use one makes of the state's road system. Registration fees 
and use taxes have no relationship to actual road use-a vehicle owner who drives few miles annually effectively pays a much higher per-mile user charge than the owner of an identical vehicle who travels many miles each year. For this reason, transportation economists frequently point to the inequity of such financing mechanisms.

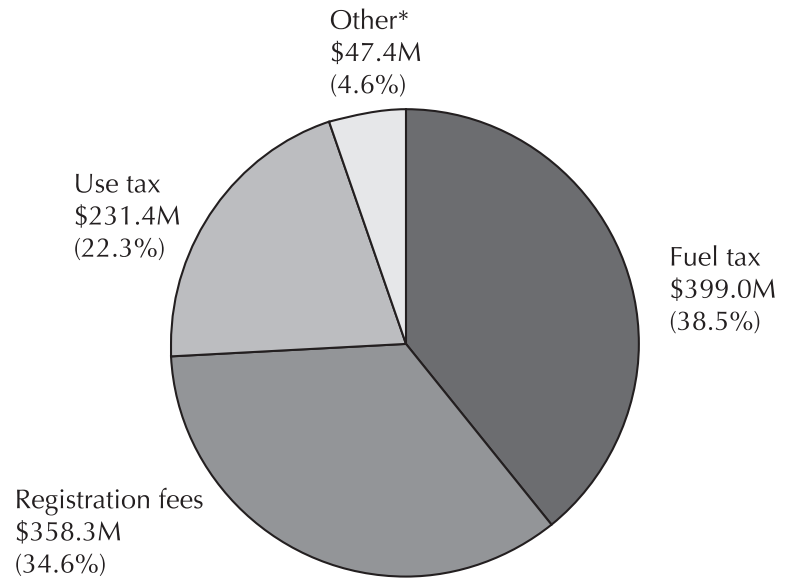

Figure 6-1. Revenue sources to the Iowa RUTF, FY 2002

*Includes driver license fees, interest, underground storage tank fees, and various other payments.

To be clear, we are not suggesting that there is no place for registration fees or use taxes in financing Iowa's transportation system. An advantage of these mechanisms is that they tend to be progressive in that those who can afford a more expensive vehicle generally pay both higher use taxes when purchasing their vehicles and higher annual registration fees. But in the interest of fairness, the primary means for financing transportation should be as closely related to actual use as possible.

Table 6-1. Iowa VMT and RUTF receipts, FY 1985-2002 (2002 dollars)*

\begin{tabular}{cccccc}
\hline Year & $\begin{array}{c}\text { State VMT } \\
\mathbf{( 1 , 0 0 0 s )}\end{array}$ & $\begin{array}{c}\text { Fuel tax } \\
\text { receipts } \\
\mathbf{( \$ 1 , 0 0 0 s )}\end{array}$ & $\begin{array}{c}\text { Total RUTF } \\
\text { receipts } \\
\mathbf{( \$ 1 , 0 0 0 s )}\end{array}$ & $\begin{array}{c}\text { Fuel taxes } \\
\text { as a percent } \\
\text { of total RUTF }\end{array}$ & $\begin{array}{c}\text { RUTF } \\
\text { receipts } \\
\text { per VMT } \\
\text { (cents) }\end{array}$ \\
\hline 1985 & $20,104,000$ & 290,185 & 689,569 & 42.1 & 3.4 \\
1990 & $23,165,000$ & 414,183 & 863,467 & 48.0 & 3.7 \\
1995 & $26,658,000$ & 401,115 & 893,293 & 44.9 & 3.4 \\
2000 & $29,821,000$ & 418,781 & $1,043,384$ & 40.1 & 3.5 \\
2002 & $31,361,000$ & 399,041 & $1,036,108$ & 38.5 & 3.4 \\
\hline
\end{tabular}

* All dollar figures converted to 2002 dollars using the Gross Domestic Product Deflator. 
The principal use-related mechanism, the motor fuel tax, has served states such as Iowa quite well for over half a century, but its future productivity is in doubt because:

- Fuel efficiency of the fleet of autos and trucks is expected to gradually improve in coming years.

- Even with current fuel efficiency levels, vehicles can traverse the state without stopping for fuel, meaning that light vehicles may not pay any motor fuel taxes for their travel in Iowa. If fuel prices in Iowa are even slightly higher than in a neighboring state, many travelers will refuel there.

- New propulsion systems, including electric hybrids and fuel cells, are emerging and have the potential to eclipse current internal combustion technology in not too many years.

- Studies such as the 1997 Federal Highway Cost Allocation Study (1) have shown that heavy vehicles underpay for their road use, and the problem will increase as these vehicles become increasingly fuel-efficient and plentiful.

\section{The growth in non-user-related road finance}

We have noted that in Iowa less than 40 percent of the RUTF is derived from the motor fuel tax; in other words, over 60 percent of it comes from taxes and fees that are not directly related to actual use of the road system. Likewise, Iowa communities and their counterparts in other states have increasingly come to rely on property taxes to finance their streets and roads. Of course, the property tax has no direct relationship to road use by the person or entity paying this tax. In Table 6-2 we display for a sample of communities - the nine places where the focus group meetings were held-(1) the total per capita property tax collected in 2003, (2) each community's expenditures on transportation (principally streets and roads and in some cases public transit) compared to the total property tax collected that year, and (3) the percent of all state and local transportation funds for the community derived from non-use-related sources.

The comparison in the second column of Table 6-2 is provided only to show the relative sizes of the two amounts; it is not to suggest that the transportation expenditures are a subset of the total property tax revenue. Local transportation expenditures also are financed by the community's RUTF allocation and any local revenue derived from transit fares, parking revenue, and other fees; note also that communities derive their general fund revenue from sources other than the property tax (e.g., hotel and motel taxes, parks fees, and various permits).

Table 6-2 shows that in general, local expenditures on transportation are similar in magnitude to approximately 20 to 30 percent of the nine communities' property tax receipts. Most importantly, the table highlights how Iowa's communities rely on revenue from sources that are not directly related to actual road use. The final column on the right of the table adds in 61.5 percent of each community's RUTF allocation-this corresponds to the portion of the RUTF that is derived from sources 
not directly related to actual road use (see Figure 6-1) - and the result is divided by the total transportation budget, including the full RUTF allocation. It is noteworthy that about 80 percent of the transportation funding in these communities comes from sources that are not directly related to road use.

Table 6-2. Local financing of transportation in nine Iowa communities, FY 2003

\begin{tabular}{lccc}
\hline Community & $\begin{array}{c}\text { Local } \\
\text { property } \\
\text { tax per } \\
\text { capita (\$) }\end{array}$ & $\begin{array}{c}\text { Transportation } \\
\text { expenditures } \\
\text { compared to } \\
\text { property tax* }\end{array}$ & $\begin{array}{c}\text { Percent of } \\
\text { transportation } \\
\text { expenditures } \\
\text { unrelated to use }\end{array}$ \\
\hline Cedar Rapids & 471.01 & .250 & 84.4 \\
Charles City & 258.47 & .223 & 77.6 \\
Council Bluffs & 429.92 & .163 & 79.5 \\
Creston & 299.72 & .317 & 82.4 \\
Davenport & 423.50 & .489 & 89.3 \\
Des Moines & 415.81 & .278 & 84.2 \\
Mount Pleasant & 289.79 & .183 & 76.8 \\
Sioux City & 341.19 & .206 & 79.5 \\
Spencer & 315.28 & .296 & 82.2 \\
\hline
\end{tabular}

* Includes RUTF allocations to the community.

SOURCES: Iowa Department of Management and Office of the Treasurer.

\section{Reforming registration fees}

It is important to point out that there is a place for non-user revenue in financing transportation services. Good access-especially to high-standard roads-can have a positive effect on property values, and via the property tax, the owner is taxed on the "unearned increment," which is the increased value arising from the access provided by the road. Note that the owner's actual use of the road is immaterial here. Another benefit of the access is "option value," the value of having good access if and when the landowner chooses to use it.

Registration fees in Iowa are comparatively high because they contain a personal property tax component. While a higher registration fee schedule worsens the inequity among vehicle owners who drive different annual mileages, these fees are generally regarded as progressive. One problem with Iowa's registration fee policy, however, is the inequity in the way it treats autos and pickup trucks. Registration fees for autos are based on the weight of the vehicle and its value when new. This fee is then reduced as the auto becomes older. The registration fee for pickup trucks weighing three tons or less is much lower, and it remains flat for ten years. 
The net effect of these different registration fee policies for autos versus pickup trucks is depicted in Figure 6-2. Our example compares a new auto and a new pickup, both weighing 3,400 pounds and having a manufacturer's suggested retail price (MSRP) of $\$ 26,000$. Through the first eight years, the auto will pay $\$ 1,265$ more in registration fees than the pickup. As the two vehicles pass the eight-year mark, the registration fee for the auto will decrease to a level slightly below that of the pickup truck. In 15 years, the auto will have paid registration fees totaling $\$ 1,125$ more than the pickup truck.

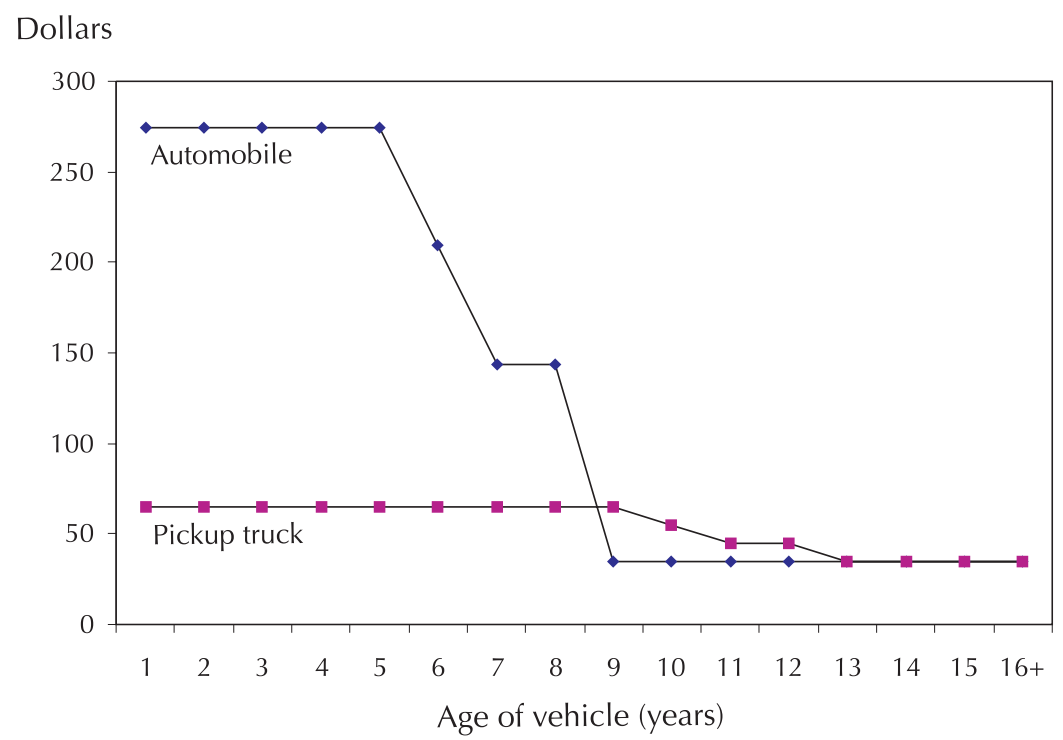

Figure 6-2. Comparison of annual registration fees for a $\$ \mathbf{2 6 , 0 0 0 \text { , }}$ 3,400 pound auto versus a pickup truck of equal price and weight

It may be that when the Iowa General Assembly enacted the registration fee schedule that substantially favors pickup trucks over autos, pickup trucks were regarded as "tools of various trades." In recent years, however, they have become a highly popular passenger vehicle. In fact, pickup trucks now are the top selling passenger vehicles in Iowa and the nation. By revising the registration fee schedule to make pickup charges comparable to those of autos, Iowa could both improve equity and generate a considerable amount of additional revenue.

The foregoing discussion noted, the primary benefits of roads accrue to the actual users of them, and road finance should reflect this use. The fairest way to charge users is to base the fees on the costs generated. That is, a heavy vehicle that causes more extensive wear and tear on a road should be charged more than a light-weight auto whose damage to the road is dramatically less (see 1). Similarly, a vehicle that travels many miles on the state's road system inflicts a greater amount of wear and therefore generates more costs than a comparable vehicle that uses the road system very little. It follows that relying increasingly on non-use-based methods of financing Iowa's roads is not good public policy. It is inequitable and can constitute a drag on the state's economic prospects by requiring higher non-use-related taxes on 
businesses and households. Iowa should work to replace its current financing mechanisms with those that are related to road use.

\section{A MILEAGE-BASED ROAD USER CHARGE APPROACH}

There is a definite trend toward decreased productivity in motor-fuel taxes and greater reliance on revenue sources not directly related to actual road use. As new propulsion systems become commonplace-and they will within a decade or so-a growing fraction of vehicles will not pay motor fuel taxes at all. When this occurs, two policy issues will become increasingly important: (1) inequities will ensue, as some vehicles will not pay the same amount for road use as comparable vehicles that are powered by traditional gasoline-burning engines and (2) revenues to the RUTF will steadily diminish. To address these issues, Iowa is one of 15 states that funded a research effort to design a new approach to assessing road user charges based on the actual number of miles traveled in each state (2). ${ }^{5}$

\section{Basic design of the new approach}

Central to the new approach is a simple on-board computer. The computer stores a record of actual road use charges. Periodically, this record is uploaded and transmitted to a data processing center, referred to as the collection center. The center bills a vehicle owner and reimburses the states, counties, and cities operating the roads on which the vehicle has traveled. The on-board system is simple, secure, and capable of protecting the user's privacy. Importantly, the on-board system enables a variety of user charge conventions. In its simplest form, this approach can be used to assess a vehicle-miles-traveled (VMT) tax. The computer calculates road mileage actually traveled and compares this mileage with that obtained through a secure odometer feed. It then applies appropriate user charge rates to the mileage traveled within each jurisdiction (typically each state). Only the user charges due to each jurisdiction are stored in the on-board computer (i.e., where travel has occurred is not stored). Periodically, the vehicle owner uploads these stored data to the collection center. The collection center operates much like a credit card billing center.

Inputs to the computer can be quite simple, involving only a global positioning system (GPS) receiver, a geographic information systems (GIS) data file, a data file containing per-mile road user charges for each jurisdiction, and the vehicle's odometer (for back-up data on distance traveled). The GIS file contains data polygons that define boundaries of the respective states. A receiver on-board the auto uses GPS signals to determine the vehicle's position. The computer reconciles this position with the stored data polygons to determine the state in which travel has occurred. The miles traveled within that polygon are multiplied by the applicable per-mile user charge rate schedule to compute user charges, which in turn are stored. When a vehicle crosses into another state, it enters a different data

5 The 15 participating states were California, Connecticut, Iowa, Kansas, Michigan, Minnesota, Missouri, North Carolina, Ohio, Oregon, South Carolina, Texas, Utah, Washington, and Wisconsin. 
polygon, and travel within that polygon is used to compute user charges. Of course, sub-state polygons, such as those defining a metropolitan area, also are feasible.

\section{Uploading road user charges}

Periodically, the vehicle operator uploads the charges due to a collection center using a smart card as a "messenger." A smart card is a small credit card-sized plastic device that contains an internal embedded computer chip in the form of a microprocessor and/or a memory module. This technology was developed in France more than 20 years ago. Smart cards are very durable and should serve a typical user for the life of the vehicle. If the smart card is lost or destroyed, it can easily be replaced at a small cost to the user (a typical smart card costs less than \$5). Communication via a smart card is done using a reader that closely resembles the credit card readers found in nearly all businesses.

Normally, the smart card occupies a slot in the vehicle's dash panel. The on-board computer continuously updates the smart card regarding total user charges owed to each state or other jurisdiction that is defined by a polygon. Data transferred to the smart card, then, are in units of dollars, the on-board computer having (1) measured the distance traveled within each polygon, (2) applied the appropriate per-mile user charge as established by the applicable jurisdiction, and (3) calculated the user charges owed to each jurisdiction. Thus, the vehicle operator can remove the smart card at any time and insert it into a reader to transmit the charges due to the collection center.

\section{Protection of user privacy}

During the data uploading process, the smart card authenticates the user and then anonymously uploads the road use information. When the collection center identifies the user, it checks for fraudulent behavior or malfunctions. If there is a problem, the smart card is notified to prompt the user to go to a service center, and the system flags that particular vehicle. During this communication, the smart card transfers a single number-the total user charges owed. Upon receipt of the vehicle's data, the collection center updates the vehicle's rate schedule (per-mile charges for each jurisdiction) through the smart card, if the stored schedule is not current. Importantly, the center also provides a one-time encryption key to the smart card to facilitate the anonymous uploading of user charges from travel in each jurisdiction. Once the collection center receives the anonymous information on how much is owed to which jurisdictions, the center correctly apportions the charges paid to the appropriate jurisdictions.

We stress that the apportionment data would be completely anonymous. It is not necessary to know which vehicle generated a particular sum of user charges for each jurisdiction; what is necessary is the amount to be apportioned. In every case, the total amount for all jurisdictions taken together equals the single value uploaded in the initial contact made by the vehicle via the smart card. Thus, when all of the necessary data are transmitted, the only figure that can be tied to a particular vehicle 
is a single dollar amount for total user charges and interest, if applicable, due. This approach maximizes user privacy.

\section{Policy flexibility}

The new approach would enable a host of policy objectives to be pursued. Foremost of these would be a stable source of revenue to support the state's transportation system, regardless of the direction vehicle propulsion technology takes. Other policy options would include:

- Local governments could levy per-mile road user charges to replace (partially or fully) the property taxes devoted to transportation.

- Visitors to communities or those passing through-who now generally do not pay property taxes for roads-could be charged the same per-mile rate as local residents.

- Eventually, higher per-mile charges could be assessed for residential streets to discourage travel on routes that cut through neighborhoods, endangering residents.

- Lower per-mile rates could be assessed to environmentally friendly vehicles.

- Per-mile rates for heavy vehicles could be varied by type of road to encourage these vehicles to travel as much as possible on higher-standard roads that can withstand greater vehicle weights.

In short, a rather simple per-mile road user charge could generate a stable revenue stream while facilitating a considerable improvement in fairness regarding payment for road use at the local and state levels. For this approach to be feasible, national application is desirable and perhaps even necessary. A variety of implementation issues need to be explored, and to this end, a national evaluation effort has been proposed. This evaluation will be concluded before alternative propulsion systems become a significant portion of the national fleet of autos. If the concept proves successful, a collaborative effort between the auto industry, the federal government, and the states will be needed to implement it. The new approach to assessing road user charges appears sound in concept and may be a means through which the road systems of Iowa and the nation will be financed in coming years.

\section{SUMMARY}

Like most other states, Iowa is becoming increasingly reliant on non-user-based financing of its road system and other services that are supported by the RUTF. While there certainly is a sound basis for some of the necessary revenue for the RUTF to come from mechanisms such as vehicle registration fees and use (sales) taxes, fairness and economic efficiency call for the preponderance of funds for the state's road system to be derived from use-based charges. In essence, such charges ensure that those who make greater use of the road system and those who impose greater costs pay more to support it. 
The primary use-based funding mechanism, the motor fuel tax, accounts for a steadily shrinking portion of the RUTF, and its future prospects are not bright. With new vehicle propulsion systems emerging and likely to play growing roles in future years, a new approach to assessing road user charges is needed. In this chapter we have summarized a new approach that avoids the pitfalls of the motor fuel tax and is inherently flexible, so that a variety of policy initiatives could be supported by it. A national evaluation will determine its viability as a means for placing increased emphasis in transportation finance on actual use of the state's roads. 


\section{CHAPTER 7 RECOMMENDATIONS}

During this three-year research and consultation effort, researchers at the University of Iowa Public Policy Center collaborated with the Office of Systems Planning at the Iowa DOT to examine policy issues facing Iowa. Our interest has been in major issues related to the quality of life in which transportation could play a positive role. After circulating our initial monograph, Policy Strategies for Iowa in Making Major Road Investments, the Iowa Transportation Commission requested that we discuss our suggested policy directions with a broad cross-section of stakeholders across the state. During the summer and fall of 2003, we convened nine focus group meetings and benefited greatly from the insights of the 174 participants. This monograph blends the results of the meetings with more extensive research on the several policy issues that are especially important to the state.

In this chapter, we provide a series of recommendations that build on the analyses contained in the preceding chapters. The recommendations are strategic in nature; our hope is that they will help provide a broad policy context within which the Iowa Transportation Commission can evaluate individual projects and programs in the coming years.

\section{FACILITY INVESTMENT}

We have argued that there are three primary reasons for investing in transportation facilities: to promote economic development, to improve safety, and to meet capacity requirements. The three reasons, of course, interact; they are not independent of one another. For example, congested roadways beget crashes, and unsafe facilities raise costs and hinder economic competitiveness. Our recommendations regarding facility investment revolve around these three considerations.

\section{A road investment strategy}

Roads are by far the most substantial public facility investment in Iowa and all other states. It is widely recognized that our state has an extensive, perhaps overbuilt, road system of 113,435 miles. The roads and highways that constitute this system vary greatly in terms of the vehicle miles of travel (VMT) they carry. The state's interstate highways and portions of its primary road system constitute the backbone of the road system. We briefly examine potential changes to each of the three categories of Iowa's road system.

County roads. In a perfect world, roads that carry very little traffic would be closed and the land devoted to more productive uses. Unfortunately, roads often act as an entitlement, and closing them is exceedingly difficult. In the end, counties 
responsible for these roads often are forced by fiscal limitations to provide them with limited maintenance. It is safe to say that no discussion of road investment (and disinvestment) in Iowa would be complete without suggesting once again that the state should search for ways to reduce the size of its 89,137-mile county road system. As agricultural operations have grown in scale, rural populations have decreased, and commuting routes to employment centers have become better defined, many segments of the county road system have become of questionable value. Simply put, the resources devoted to very low-volume county roads could be much better used, perhaps to upgrade the maintenance on commuting routes and other key elements of the county road system.

Incentives should be given to counties to transfer ownership of the lowest volume and least critical segments to adjacent landowners. To avert economic hardship, bridges on these segments and the roads themselves should be brought up to an acceptable standard prior to the transfer.

Primary roads. The primary road system, which includes interstate highways, constitutes about nine percent of the state's road system, but it carries over 60 percent of the traffic. It is the backbone of Iowa's road system. For over a decade, the Iowa DOT has been working to improve its Commercial and Industrial Network (CIN), a subset of the primary road system. This network consists of 2,275 miles, about one-quarter of the primary road system, and was so designated as a way of strategically investing in roads that can best enhance the state's economic competitiveness. Focus group meeting participants strongly supported the allocation of resources to the CIN and generally expressed their preference that the standard of road on particular segments be determined mainly on the basis of current and forecast traffic volumes.

In Chapter 3, we discussed the advisability of upgrading selected two-lane roads to super-two highways as a cost-effective way to improve safety and generally facilitate more effective traffic flows. The Iowa DOT's plans for upgrading segments of the CIN originally involved bringing many of them up to super-two standards, along with restoration of the pavement surface, upgrading bridges, and, when feasible, grade-separating rail crossings. We recommend that super-two upgrades be applied to the CIN when feasible. Our discussion of safety-promoting upgrades in Chapter 4 stressed the need for rural intersection improvements, and super-two upgrades would definitely help this objective be attained.

One of the advantages of super-two highways is that as traffic volumes increase, they can be further upgraded to four-lane highways. Part of the plan for developing the CIN is to construct four-lane highways in strategic locations where forecast traffic volumes warrant. Several participants in focus group meetings stressed that in certain areas of the state, four-lane highways could serve a catalytic function in strengthening the economy. Another consideration is the particular need for eastwest routes that can accommodate heavy trucks transporting freight to communities well removed from interstate highways. 
Based on the focus group meeting participants' insights and an analysis of freight flows in Iowa, we agree that selective upgrading to four-lane highways should proceed. Other parts of the CIN should be upgraded to super-two standards as quickly as resources allow.

Urban streets and roads. In Chapter 3, we discussed the critical issue of using urban roads as a formative tool in shaping the state's growing areas in ways that can be sustained. Numerous participants in the focus group meetings mentioned the need to develop Iowa's cities in ways that avoid the growth-related problems experienced in many cities across the U.S. We examined commuting patterns from outer suburban areas surrounding Des Moines and observed that many residents of these outlying areas commute rather long distances into Des Moines and other inner municipalities. In time, there is a very real possibility that the same sort of congestion, air quality degradation, and high infrastructure costs that other cities are experiencing will plague Iowa's most productive cities.

In this monograph and others $(1,2)$, we have urged Iowa's metropolitan areas to coordinate land use plans, transportation investments, and other infrastructure improvements to achieve an urban form that will enable residents to enjoy a high quality of life. Among the suggestions we have offered are:

- Think regionally. The aspirations of each municipality, taken alone, often do not aggregate into a developmental pattern that is beneficial to the region as a whole. By working together, governmental units can advance their region's competitiveness and general livability

- Understand the land market. We have stressed that transportation investments change the relative accessibility of locations within a metro area. Improvements in accessibility encourage the types of land use best able to pay for highly accessible locations. Thus, transportation investments influence the land market in predictable ways, and these investments can be used to help the metro area develop in a sustainable manner.

- Group jobs and housing. Through progressive land use and transportation planning, it is possible to cluster where people live and where they work, thus reducing the need for long commutes.

The important point is that cities cannot curb or prevent congestion solely by investing in greater highway capacity. Land use is in every way as vital a policy tool for creating long-term growth that is conducive to a high quality of life as are transportation investments. Transportation investments need to be a part of a larger development strategy that is regional in nature.

\section{A growing role for aviation}

At essentially every focus group meeting, the growing role of aviation in fostering economic development was cited. Special emphasis was placed on general aviation, which includes most forms of aviation other than commercial and military.

Investment of public funds in airports serving general aviation at times can be controversial because of concerns that such investments may be regressive. On the 
other hand, a growing number of businesses have discovered that having access to general aviation aircraft and facilities at which to operate them is a key to being competitive. More specifically, certain types of businesses, such as those engaged in manufacturing, need to have the capability for their senior officials to meet on short notice with suppliers, customers, and others associated with their operations.

Failure to carry out such meetings can place the business at a serious competitive disadvantage.

It would be prohibitively costly to bring all of Iowa's general aviation facilities up to a desired standard, such as 5,500 foot by 100-foot runways and instrument (IFR) navigation capabilities. The key is to judge which investments have a real potential to increase the economic productivity of a community and the state to the extent that the investments' benefits exceed their costs. Fortunately, the Iowa DOT has considerable experience with an analogous effort in the form of the road investment program, RISE (Revitalize Iowa's Sound Economy, a road investment program geared to foster economic development). With a sophisticated evaluation mechanism, a comparable program for general aviation airports could be a useful way to strengthen Iowa's competitive position with regard to certain industries.

To fund such an investment program, we recommend that the Iowa DOT pursue General Fund resources from the General Assembly and that revenue from the eightcent per gallon aviation fuel tax (and the three-cent per gallon jet fuel tax), aircraft registration fees, and the use tax from aircraft sales be fully allocated back to the aviation program.

\section{FREIGHT TRANSPORTATION}

It has been said by many that Iowa is highly dependent on transportation-little of what the state produces is consumed here, and little of what Iowans consume is produced here. Traditionally, transportation planning and policy analysis have given short shrift to freight considerations, often to the detriment of economic development and general quality of life. Fortunately, that has been changing, and many state and local governments now recognize that working with shippers and carriers to make freight movements as safe, efficient, and cost-effective as possible is a vitally important element of policy development (see, for example, 3 ).

One of the most commonly discussed topics in the nine focus group meetings was the issue of how best to ensure efficient, safe freight transportation in Iowa. As we discussed in Chapters 3 and 4, the state depends heavily on trucking to move freight into, within, and from it. In a real sense, this is a microcosm of the nation, within which trucking increasingly is the dominate mode. We have suggested that Iowa needs to take a longer-term view and explore ways the state can control the growth of large trucks on its roads and highways while growing its economy.

\section{Freight rail with an eye to the future}

In its recommendations regarding the new transportation reauthorization bill in Congress, the American Association of State Highway and Transportation Officials 
(AASHTO) observed that major trends in freight transportation can be summarized by century (4). These trends, expressed as eras, have been the:

- "Sail Era." In the 18 ${ }^{\text {th }}$ Century, colonial economies were built around water transportation.

- "Rail Era." The 19 $19^{\text {th }}$ Century saw the rapid development of rail service first along the east coast and then across the developing regions of the U.S.

- "Truck Era." During the $20^{\text {th }}$ Century, highway construction led to an interstate grid that facilitated the growth of long-haul trucking into the dominant mode.

- "Integration and Information Era." In the $21^{\text {st }}$ Century, emergence of a global economy and major advances in information technology will precipitate a new paradigm.

AASHTO has suggested that the new paradigm for freight movement in the $21^{\text {st }}$ Century will include telecommunications and low-cost long-haul transportation by water, rail and air. Containerization - with "efficiently linked trucks, double-stack trains, and container ships-will grow in importance as an efficient, secure way to ship freight globally" (4). In the near future, intermodal freight is likely to become an increasingly cost-effective alternative to trucking for longer distances (over 400 to 500 miles). As discussed in Chapter 3, intermodal rail consists of (1) container on flatcar (COFC), (2) trailer on flatcar (TOFC), and (3) double-stack container configurations.

It is important to note that intermodal freight typically carries higher-value, lowerweight freight than unit trains or carload services. As such, it may become a highly viable mode for transporting a wide variety of freight along major corridors that today are dominated by large trucks. Should this actually occur, the safety and travel comfort objectives for auto travelers discussed in this document may well be realized. It follows that Iowa should work with other states and the rail industry to do everything possible to encourage the growth of intermodal freight. The ability to more efficiently link places like Iowa-which are well removed from oceans-to international markets is worth pursuing for the state's long-term economic welfare.

Making intermodal rail a primary mode for long-haul shipment of higher-value freight will require considerable change in several areas:

- Facility investment. Major improvements are needed, including replacement of tracks and, where necessary, addition of new lines; improvements in height clearances to accommodate double-stack trains; bridge upgrades; upgrades of at-grade road crossings; and the addition of container-loading facilities, including double-stack loading.

- Improved performance by rail companies. Better reliability and more responsive business practices will be essential if the rail industry is to take on a larger role in transporting the nation's freight. Needed improvements will require an influx of additional capital. 
- More aggressive collaboration by multiple states. Rail facility planning cannot be done on a piecemeal basis. Regional bottlenecks (i.e., "choke points") and track inadequacies should be addressed along major corridors, which traverse multiple states. Iowa should redouble its efforts to explore long-term intermodal freight solutions.

AASHTO contends that the freight rail system in the U.S. faces a choice between a "market-driven evolution," whereby some growth in rail capacity would occur, but the modal switch from highways would be nominal at best; and a "public-policydriven evolution" that would lead to substantial improvements in rail service and to a greater modal shift. The latter direction, AASHTO contends, would relieve longterm highway congestion and support local and state social, economic, and environmental goals. In short, AASHTO concludes, a well-crafted public-private partnership could help advance the quality of life in states like Iowa.

A public policy-driven scenario depends on the states and the federal government working together to strengthen the rail industry and the services it provides. Ultimately, there are three general policy directions that governments could take. They could provide: (1) grants to help rail companies contribute to policy goals; (2) loans, loan guarantees, and lines of credit to foster reinvestment; and (3) taxoriented assistance such as accelerated depreciation and tax-exempt bond financing. With this approach, the rail companies would need to agree to meet certain performance standards.

There is no doubt that for freight rail to become a more viable means of transporting goods within Iowa and the U.S., new approaches must be taken by both the rail companies and the governments through which their tracks run. Iowa should assess its alternative futures, comparing the costs and benefits of partnering with freight rail companies to upgrade freight rail service versus adding lanes to interstate and other highways to support the large increases in truck traffic that will follow sustained growth in the nation's economy.

\section{SAFETY}

One of the most powerful ways in which transportation investments can increase the quality of life for Iowans is to make their travel safer. As we stated in Chapter 4, the three safety-related needs that received the most attention in the nine focus group meetings were: upgrading rural roads to make them safer, addressing problems related to older drivers, and coming to grips with large trucks on the state's highways. We noted that these three needs interact, in that roads with less safe design features can make conditions more difficult for older drivers, and the presence of heavy truck traffic can increase the likelihood of a serious crash.

\section{Upgrading rural roads and highways}

Earlier, we discussed the value of upgrading rural roads in the interest of economic development. At least as compelling an argument can be made for making selective investments in these roads to improve their safety. The two greatest safety-related 
problems confronting users of rural roads are (1) passing other vehicles when hills and curves obstruct visibility or opposing traffic limits the time available to make a successful pass and (2) turning movements at intersections. The Iowa DOT keeps detailed data on crash experience as a function of road characteristics, traffic volume, and traffic mix (i.e., presence of heavy trucks), and these data can help establish the specific conditions that should constitute priorities for upgrading in the interest of safety.

A generally cost-effective way to address both of these safety problems is to upgrade priority segments to super-two standards. The passing lanes of super-two highways remove the difficulties of overtaking vehicles when conflicts with opposing traffic are likely, and intersection safety is substantially improved by left and right turning lanes, acceleration lanes, and a degree of access control.

When current or forecast traffic warrants, four-lane upgrades virtually eliminate the safety problems associated with passing, and having two lanes in each direction greatly reduces the likelihood of rear-end collisions that are among the most serious safety threats associated with turning movements on rural roads and highways. Grade-separated intersections, of course, are the safest, but they also are costly investments and thus have to be reserved for especially busy intersections.

In Chapter 4 we addressed the types of upgrades to rural roads and highways that would be especially beneficial to Iowa's growing number of older drivers. Studies have indicated that the greatest single problem experienced by older drivers is lefthand turns. We listed a series of nine specific types of improvements (see pages 3940 ) that were suggested by an Iowa older driving forum, improvements that can materially improve intersection safety for elder drivers. Many of these improvements are not all that costly, and they can contribute greatly to the quality of life of a sizable and growing segment of the state's population.

\section{Other safety enhancements for older persons}

In addition to upgrading rural intersections, there are other cost-effective approaches to improving the safety of Iowa's elders. Where needed, larger, brighter, and more repetitive road signs can help give older drivers better advance warning of upcoming conditions that will require decisions. Quite apart from road upgrades, we strongly recommend that other approaches be taken to foster greater safe mobility for the state's seniors. These include subsidized taxis with 24-hour reservations, much greater emphasis on pedestrian-friendly designs in the environment of streets and roads, and upgrades to public transit service where feasible.

\section{Large-truck safety}

We observe in Chapters 3 and 4 the fact that Iowa's economy depends heavily on large trucks, and we further note that because of the state's location, it experiences a very large amount of so-called "bridge" or through traffic that has neither an origin nor a destination within the state. Crash data reveal that while large trucks may not cause a disproportionate share of serious crashes and fatalities, they are involved in 
more fatal crashes than their miles traveled would indicate. We examined the bestavailable data and found that while large trucks account for about 20 percent of interstate highway VMT, they are involved in 34 percent of all fatal crashes.

Noteworthy, too, is that almost two-thirds of the fatal crashes involving large trucks occur on rural two-lane roads and highways. This fact further argues for the passing lane investments we discussed above.

\section{Safety is a key to quality of life}

Iowa's safety record is certainly as strong as those of comparable states, but there always must be a search for ways to protect the traveling public even more. Being able to feel safe when walking, riding in a motor vehicle, or using some form of nonmotorized transportation is fundamental to maintaining a high quality of life. In the preceding discussion and in Chapter 4, we have not attempted to address every possible type of need in the state with regard to improved safety. Rather, we have focused on issues that are particularly pressing and those with the greatest potential to materially improve the safety of travelers in Iowa.

Participants of the nine focus group meetings consistently placed safety at or near the top of the policy objectives they would like to see transportation investments pursue. Because of its central importance to quality of life, we recommend that safety be accorded the highest consideration when possible transportation investments are identified and when funding priorities are determined.

\section{EXPANDING ALTERNATIVE MODES}

In Chapter 5, we explored ways in which alternatives to the auto could be used to expand the choice of transportation modes for Iowans. We noted that there are two main reasons for expanding this choice:

- Low-income persons and those physically unable to drive often have severely restricted mobility, and enabling them to move about can both enhance their quality of life and help increase the pool of available workers.

- Many younger, well-educated people value outdoor, exercise-oriented recreation opportunities, such as those afforded by walking and bicycling trails. Such facilities can help entice them to visit the state as tourists or to move here as professionals.

\section{Serving those with few options}

To be competitive for economic growth, Iowa needs to minimize the number of people who would like to work but who are constrained by a lack of transportation, and it needs to be perceived as a pleasant, healthy place to live and work. Basing the state's future almost exclusively on auto transportation is neither prudent nor very creative. There are a variety of cost-effective approaches to increasing the transportation options available in Iowa. Among them are:

- Carpools. The Iowa DOT should work with leading transportation providers such as the Des Moines Metropolitan Transit Authority (MTA) to identify approaches to creating easily accessible databases for carpool 
matching. With greater numbers of people having access to the Internet, the potential for matching is greater than it ever has been. Businesses, especially larger employers, should be consulted and encouraged to play active roles in promoting carpooling. Its potential is quite good for reducing long-term congestion in growing areas like Des Moines.

- Vanpools. One of the most effective means of transporting people from small communities and rural areas to jobs in medium-sized and larger cities in Iowa is vanpools. We noted several highly successful vanpool programs and believe that there is considerable untapped potential for them to help connect workers to jobs. The Iowa DOT should form a statewide task force to investigate how business and government could partner to greatly expand the number of vanpools that are active in the state.

- Demand-responsive transit and taxi services. These two options are particularly appropriate in areas where travel demand densities are very low, as they are for special populations in many parts of Iowa. Human service agencies and municipal and county governments need to be flexible when thinking about how to cost-effectively provide transportation services to those with mobility needs in places and at times when there are relatively few travelers. We need to keep in mind that at times, uncommon services well may be the best solution for serving many Iowans.

We evaluated the relative need for rural transit service among the state's counties and developed a simple index of this need. In general, very rural areas of the state tend to have the most acute need, especially those in the southern tier of counties and some in the northern part of the state. These counties have sizable elderly and disabled populations for whom isolation is a serious impediment to quality of life.

\section{Options as effective amenities}

It is widely understood that Iowa needs to redouble its efforts to attract and retain young, well-educated professionals to strengthen the state's ability to compete in the modern technology-driven world marketplace. Good roads simply are not enough to set Iowa apart from competing states and cities; creative transportation options are needed. Among these options are hiking and bicycling trails, especially near places that have natural amenities and are easily accessible from population centers. Over the past several decades, the state has made reasonably good progress in constructing what is now 1,600 miles of recreational trails, but more remains to be done.

\section{FINANCING NEEDED TRANSPORTATION IMPROVEMENTS AND SERVICES}

Nationally and in Iowa, transportation financing is not in a good state of affairs. Historically, the key principle underlying transportation finance has been to "pay as you go." That implies that those who use more transportation services and those who cost more to serve will pay more. Over the years, however, the trend has shifted to an increased reliance on funding sources that have no direct relationship to either amount of use or cost of that use. We found that the motor fuel tax, the historic mainstay of road finance in the U.S., has been steadily falling as a fraction of 
the Iowa Road Use Tax Fund (RUTF); it represented only 38.5 percent of that fund in FY 2002. Further, we observed that the future of the motor fuel tax is very much in doubt, as fuel efficiencies for most vehicles, including heavy trucks, steadily improve. Adding to the doubtful prospects of this key revenue source are impressive advances in alternative propulsion systems, such as electric hybrids and fuel cells. It is safe to say that as the years pass, the motor fuel tax will play a smaller and smaller role in financing the state's road and highway system.

\section{Excessive reliance on non-use-related financing}

Our examination of the nine communities we visited to conduct focus group meetings revealed that between 77 and 89 percent of the state and local funds used to finance streets and roads is derived from sources not directly related to use. That is far too high a reliance on such sources, and it represents a substantial departure from the pay-as-you-go financing that has been an appropriate tradition in this country for the better part of a century.

To make matters worse, non-use-related financing mechanisms in Iowa have peculiarities that are inefficient and unfair. We examined the disparate registration fees of equally priced and equally heavy autos and pickup trucks and found that over an eight-year time span, the auto would pay fully $\$ 1,265$ more than the pickup truck in annual registration fees. Now that pickup trucks are used predominantly as passenger vehicles, it is time to revisit this distortive convention.

\section{A new financing approach directly based on road use}

For the past five years, a research team at the University of Iowa has been developing a new approach to assessing road user charges that is based on the number of miles a vehicle travels within each jurisdiction. The new approach is designed to accommodate a variety of policy options that a state or sub-state area may find appropriate, but most importantly, it promises to enable travel within a jurisdiction by any sort of vehicle to be assessed a fair and consistent user charge.

Whether this approach or another ultimately proves to be most acceptable to motorists and decision makers, the need is great to reverse the trend away from use-based road financing and back to assessing charges according to the amount of road use and the costs generated by this use. By moving in this direction several laudable public policy outcomes are possible, including substantial reductions in the local property taxes now used to finance roads and other transportation services and the ability to charge all who travel in a jurisdiction, regardless of whether they reside there or not.

A national evaluation of the new approach to assessing road user charges is being contemplated by the U.S. Congress. The evaluation will answer numerous questions about public acceptability, technical feasibility (reliability, ease of use, and cost), and productivity in its ability to provide a stable source of revenue. If the evaluation is positive, state and local governments will have available an important policy tool with which to ensure that their transportation systems are adequately financed. 


\section{CONCLUSION: MULTIMODAL TRANSPORTATION IS THE FUTURE}

Both our analysis and the response to it by participants in the nine focus group meetings point to intermodal passenger and freight transportation as the way of the future. Throughout history, Iowa and the nation have tended to rely on one dominant mode to carry commodities and freight and to transport people. Currently, these dominant modes are highway-based, and for good reasons. Autos afford an unprecedented level of mobility, and trucking provides reliable, door-todoor freight movement.

It has become increasingly clear, however, that greater modal diversity is needed. Single-occupant autos are contributing to congestion, which results in diminished air quality and excessively long commuting times. Those who do not have access to transportation by auto are increasingly left out of the activities that most people take for granted. People who prefer non-motorized transportation often find that the facilities for these modes of travel are inadequate.

By the same token, heavy truck traffic on major highways is evoking safety concerns by other road users. As the economy grows, most analysts expect to see truck traffic continue to escalate, in part because rail is transporting a shrinking portion of the freight entering and leaving Iowa. Changes in business practices portend an increased need for business leaders to travel quickly and with short notice to multiple locations.

The unmistakable message conveyed by the data we analyzed and the focus group participants is that Iowa needs to think intermodally. It especially needs to redefine the roles played by non-highway transportation modes including freight rail, general aviation, and non-motorized means of conveyance. Many of the policy directions that are called for will require the cooperation of multiple states that share the circumstances facing Iowa. Together, this state and others must partner with private sector shippers and carriers, communities within these states, and various service providers to develop new approaches to ensure that transportation is in step with the current era and that it has the potential to meet the needs of a changing world. 


\section{REFERENCES}

\section{Chapter 3: Economic Development}

1. Forkenbrock, David J., and Norman S.J. Foster. 1996. "Highways and Business Location Decisions." Economic Development Quarterly, Vol. 10, No.3 (August), pp. 239-248.

2. Forkenbrock, David J. 2002. Policy Strategies for Iowa in Making Major Road Investments. Iowa City, IA: University of Iowa, Public Policy Center.

3. MacDonald, Heather I., and Alan H. Peters. 1993. Employment and Commuting by Rural Women on the Metropolitan Periphery. Iowa City, IA: University of Iowa, Public Policy Center.

4. U.S. Census Bureau. 2002. 2000 Census: Summary File 3. Washington, DC: U.S. Department of Commerce. Available at http//factfinder.census.gov

5. U.S. Census Bureau. 2003. "Residence County to Workplace County Flows for Iowa." Washington, DC: U.S. Department of Commerce. Available at http://www.census.gov/population/cen2000/commuting

6. Bureau of Transportation Statistics (BTS). 1995. 1990 Census Transportation Planning Package: Urban Element Part 1: Place of Residence. BTS-CD-15-14. Washington, DC: U.S. Department of Transportation.

7. Bureau of Transportation Statistics (BTS). 2004. 2000 Census Transportation Planning Package: Urban Element Part 1: Place of Residence. File T_CTPP2000_PART_1A.zip. Washington, DC: U.S. Department of Transportation. Available at http://www.transtats.bts.gov/

8. Iowa Department of Transportation (Iowa DOT). 2003. 2000 Iowa Crash Facts: A Summary of Motor Vehicle Crash Statistics on Iowa Roadways. Ames, IA: Iowa DOT. Available at http://www.dot.state.ia.us/mvd/ods/facts00.htm

9. U.S. Census Bureau. 2002. 2000 Census: Summary File 3. Washington, DC: U.S. Department of Commerce. Available at http//factfinder.census.gov

10. Downs, Anthony. 2004. "The Need for Regional Anti-Congestion Policies." Transportation Reform Series. Washington, DC: The Brookings Institution.

11. Federal Highway Administration (FHWA). 2003. Freight Management and Operations-Iowa Profile. Washington, DC: Federal Highway Administration, Office of Operations. Available at http://www.ops.fhwa.dot.gov/freight/ freight_analysis/state_info/state_profiles.htm

12. U.S. Census Bureau. 1999. 1997 Commodity Flow Survey, 1997 Economic Census. Washington, DC: U.S. Department of Commerce. Available at http://www.census.gov/prod/ec97/97tcf-ia.pdf 
13. Machalaba, Daniel, and Christopher J. Chipello. 2003. "Battling Trucks, Trains Gain Steam by Watching Clock." The Wall Street Journal, July 25.

14. Iowa Department of Transportation. 2001. "Iowa's Rail System Background." Ames, IA: Iowa Department of Transportation, Office of Systems Planning.

15. Federal Aviation Administration (FAA). 2002. National Aviation Safety Data Analysis Center. Washington, DC: U.S. Department of Transportation. Available at http://www.nasdac.faa.gov/

16. AirNav.Com. 2003. Web site with information on the nation's airports. Available at http://airnav.com

\section{Chapter 4: Safety}

1. Wilbur Smith Associates. 1992. U.S. Highway 63 Corridor Development Study. Columbia, SC: Wilbur Smith Associates.

2. Council, F.M., and J.R. Stewart. 1999. "Safety Effects of the Conversion of Rural Two-Lane to Four-Lane Roadways Based on Cross Sectional Models." Transportation Research Record 1665. Washington, DC: National Research Council, Transportation Research Board, pp. 35-44.

3. Rogness, R.O., D.B. Fambro, and D.S. Turner. 1982. "Before-After Accident Analysis for Two Shoulder Upgrading Alternatives." Transportation Research Record 855. Washington, DC: National Research Council, Transportation Research Board, pp. 41-46.

4. Forkenbrock, David J., Norman S.J. Foster, and Thomas F. Pogue. 1994. Safety and Highway Investment. Iowa City, IA: University of Iowa, Public Policy Center.

5. U.S. Department of Transportation (U.S. DOT). 2002. "Revised Departmental Guidance: Treatment of Value of Life and Injuries in Preparing Economic Evaluations." Washington, D.C.: U.S. DOT, Office of the Secretary.

6. Forkenbrock, David J., and Paul F. Hanley. 2002. Safety Policy Considerations in Truck and Rail Freight Transportation. Iowa City, IA: University of Iowa, Public Policy Center.

7. Iowa Highway Safety Management System (ISMS). 2002. Iowa Safe Mobility Decisions for Older Drivers Forum Report. Ames, IA: Iowa Highway Safety Management System.

8. Milone, A.M. 1985. "Training and Retraining the Older Driver." In J.L. Malfetti, ed. Needs and Problems of Older Drivers: Survey Results and Recommendations. Falls Church, VA: AAA Foundation for Traffic Safety.

9. Solomon, D. 1985. “The Older Driver and Highway Design.” In J.L. Malfetti, ed. Needs and Problems of Older Drivers: Survey Results and Recommendations. Falls Church, VA: AAA Foundation for Traffic Safety.

10. Lyman, Jacquelyn M., Gerald McGwin, Jr., and Richard V. Sims. 2001. "Factors Related to Driving Difficulty and Habits in Older Drivers." Accident Analysis and Prevention, Vol. 33, pp. 413-421. 
11. McGwin, Gerald, Jr., Victoria Chapman, and Cynthia Owsley. 2000. "Visual Risk Factors for Driving Difficulty Among Older Drivers." Accident Analysis and Prevention, Vol. 32, pp. 735-744.

12. Daigneault, Genevieve, Pierre Joly, and Jean-Yves Frigon. 2002. "Previous Convictions or Accidents and the Risk of Subsequent Accidents of Older Drivers. Accident Analysis and Prevention, Vol. 34, pp. 257-261.

13. Staplin, L., K. Lococo, K. Byington, and D. Harkey. 2001. Guidelines and Recommendations to Accommodate Older Drivers and Pedestrians. FHWA-RD-01051. Washington, DC: U.S. Department of Transportation, Federal Highway Administration.

14. Mace, Douglas J. 1988. "Sign Legibility and Conspicuity." Transportation in an Aging Society. Special Report 218. Washington, DC: National Research Council, Transportation Research Board, pp. 270-293.

15. National Highway Traffic Safety Administration (NHTSA). 2004. Traffic Safety Facts 2002. Washington, DC: U.S. Department of Transportation.

\section{Chapter 5: Choice of Transportation Modes}

1. U.S. Census Bureau. 2002. 2000 Census: Summary File 3. Washington, DC: U.S. Department of Commerce. Available at http//factfinder.census.gov

2. U.S. Census Bureau. 2002. 2000 Census: Summary File 4. Washington, DC: U.S. Department of Commerce. Available at http//factfinder.census.gov

3. Forkenbrock, David J., and Lisa A. Schweitzer. 1996. Distributing State Road Use Tax Funds to Counties. Iowa City, IA: University of Iowa, Public Policy Center.

4. Iowa City Press-Citizen. 2004. "Cycling Gains Popularity." Iowa City: Iowa City Press-Citizen (April 14).

5. Iowa Department of Transportation (Iowa DOT). 2003. "Issue Paper on Iowa Recreational Trails." Draft, dated November 18. Ames, IA: Iowa DOT.

\section{Chapter 6: Financing Transportation in the Future}

1. FHWA. 1997. 1997 Federal Highway Cost Allocation Study. U.S. Department of Transportation. Washington, DC: Government Printing Office.

2. Forkenbrock, David J., and Jon G. Kuhl. 2002. A New Approach to Assessing Road User Charges. Iowa City, IA: University of Iowa, Public Policy Center.

\section{Chapter 7: Recommendations}

1. Forkenbrock, David J. 2002. Policy Strategies for Iowa in Making Major Road Investments. Iowa City, IA: University of Iowa, Public Policy Center.

2. Forkenbrock, David J., Sondip K. Mathur, and Lisa A. Schweitzer. 2001. Transportation Investment Policy and Urban Land Use Patterns. Iowa City, IA: University of Iowa, Public Policy Center. 
3. Strauss-Wieder, Anne. 2003. Integrating Freight Facilities and Operations with Community Goals. NCHRP Synthesis 320. Washington, DC: National Research Council, Transportation Research Board.

4. American Association of State Highway and Transportation Officials (AASHTO). n.d. Transportation: Invest in America, Freight-Rail Bottom Line Report. Washington, DC: AASHTO. 


\section{APPENDIX A SUMMARIES OF FOCUS GROUP MEETINGS}

This appendix provides very brief summaries of the main points raised in the nine focus group meetings. The summaries are presented in the order that the meetings occurred, and the key points are listed under the major topical categories around which the meetings were structured. While all participants were provided the same materials and the same topics were discussed, the meetings varied somewhat in terms of the issues on which the participants tended to focus. In part, this variation was due to differences in preferences and concerns in different parts of the state. We do not elaborate or comment in this appendix on the points mentioned, but we definitely took them into account in the analyses presented in the preceding chapters.

\section{SIOUX CITY}

Participants in this meeting generally stressed the importance of transportation investments in different modes to help make the Sioux City area more competitive for economic activity and more attractive to potential residents. A regional approach to such investments generally was favored.

\section{Economic development}

- The focus in economic development should be on encouraging local business start-ups and expansions, and the Iowa DOT should consider investment policies that reward Iowa businesses for making desirable location decisions.

- U.S. Highway 20 should be expanded in order to provide relief to I-80. Making the highway four lanes to Sioux City would benefit not only the city but also the state.

- Longer-distance commuting is an important issue because numerous people travel from smaller communities to employment centers. Facilitating these commutes is a good way to increase the availability of labor. Vanpools warrant consideration.

- Improved air travel services in Sioux City and throughout the state are needed to attract and retain businesses. We need to improve linkages with the nation's largest markets (especially Chicago). Lack of better air service has been a deterrent to growth in the Sioux City area.

- Too much of the revenue generated by the aviation fuel tax is diverted to the General Fund, and not enough is used to improve aviation facilities in Iowa. 
- It is necessary to improve and increase the capacity of rail systems in Iowa in order to reduce emphasis on trucking. An example might be assisting small, short-line rail companies.

- Transportation issues should be addressed at the regional level, not only on a community-by-community basis.

- The extent to which counties can afford to maintain roads is very limited, and it may be unfair to ask farmers to maintain the roads that serve them when other residents in the state do not.

- Iowa should encourage the production of value-added commodities, and it should develop transportation systems to cater to such needs, especially rail service.

- Strategies for intermodal transportation should be seriously considered. Shippers and freight carriers should be involved in the process of developing these strategies.

\section{Sustainable urban form}

- The outlying areas around Sioux City are developing in a low-density pattern. We need to look for ways to encourage more compact development, and transportation investments are a policy tool to consider.

\section{Safety}

- The Iowa DOT should emphasize increased safety at construction sites. Also, construction companies could be given incentives to have longer working hours and thereby reduce the inconvenience to travelers.

- Selective modifications to Iowa's road system are needed to accommodate older drivers.

- Some states are reducing the number of rail crossings, and perhaps Iowa should work to do that as well.

- Transit services are needed that can help older persons move about more safely, and awareness should be increased about the existence of services that are appropriate for older persons.

\section{Choice of modes}

- The Missouri River should be used more for transporting agricultural products. However, higher user fees should not be introduced as they would act as a deterrent.

- We should encourage bicycling and hiking during all seasons of the year. One way to do this is to construct bicycle lanes as a step toward reducing traffic. A system of trails along the Mississippi River could help promote tourism.

- Mechanisms should be installed on transit buses to allow the carrying of bicycles. 


\section{CRESTON}

A central theme of focus group members was that it is essential to look at transportation systems comprehensively-intermodal systems, transportation needs for such value-added products as ethanol, and bicycle trails to improve quality of life. Participants also stressed that it is important to address the needs of areas of the state that might not be as developed as the larger cities but that can generate substantial economic activity, given the right conditions.

\section{Economic development}

- State government should encourage economic development in rural areas by decentralizing government agencies and locating offices in smaller communities. When feasible, government activities should even be moved to rural areas.

- The potential for value-added industries, such as ethanol production, is excellent, but we need to have better rail service to transport the product to the West Coast and other markets.

- Investment in the new West Des Moines mall is bad for the state as neighboring counties will lose retail business, and the city of Des Moines will further deteriorate. The Iowa DOT should develop more restrictive policies related to financing infrastructure that would support questionable land use decisions.

- Regarding freight rail, global positioning system (GPS) equipment should be installed on individual cars to help facilitate just-in-time deliveries as a means of reducing dependence on trucks. In addition, unit trains should be encouraged, especially for grain commodity hauls.

- A more extensive partnering of government and the rail industry is needed to ensure that adequate facilities are in place to foster economic growth.

- Inland waterways need greater investments for locks and dams, especially on the Mississippi River, to encourage economic development and reduce the use of large trucks.

- Transferring roads to lower levels of jurisdiction might lead to closing some roads, thus affecting development potential in rural areas. Also, it will unduly burden rural areas, which have higher repair needs. Similarly, areas in southern counties will have to maintain a large number of bridges due to numerous streams in those areas. However, there was consensus that the Iowa DOT and counties should not have to maintain underutilized roads.

- Highway expansion is a tool to retain business in rural areas, and retention was considered to be more important than attracting new businesses. Several participants supported the option of constructing super-two highways as a lower-cost alternative to four-lane highways. 
- Inadequate infrastructure for trucking companies could cause to them leave Iowa and move distribution centers to neighboring states, which in turn could lead to job losses.

- The Des Moines Metropolitan Transit Authority's rideshare program is valuable to Creston because it transports workers to jobs, allowing them to live in rural communities.

\section{Safety}

- Instead of building new infrastructure in the interest of safety, the Iowa DOT should focus on maintaining the existing infrastructure; doing so would help enable scarce resources to be used wisely.

\section{Choice of modes}

- Bicycle trails should not be a priority because scarce resources could be better used for purposes other than trails. There could be an excise tax levied on bicycles to help fund trails in lieu of support from the Road Use Tax Fund.

- A need exists for transit systems to better serve the older population, especially in rural areas.

- Given that Iowa advocates the policy of connecting people to jobs, vanpools should be encouraged.

- A north-south passenger-rail line, if developed, would give people more options, especially older persons and low-income populations.

\section{COUNCIL BLUFFS}

Several participants observed that auto dependence needs to be reduced in order to improve the use and popularity of transit systems. The true costs of trucking and auto usage should be reflected in user charges in order to open opportunities for other modes, especially freight rail. Participants in this meeting tended to emphasize the need for improved rail service.

\section{Economic development}

- The importance of taking a regional approach to investing in transportation facilities (e.g., airport and highway upgrades) was stressed time and again. However, issues about rural areas being unwilling to give up their current facilities in the interest of regional development is a barrier.

- Long-distance commutes into the Council Bluffs and Omaha metropolitan area are steadily increasing. Not only is this an issue for rural commuting routes, it also has implications for city streets and arterials that are experiencing increased traffic volumes. 
- Truck traffic on interstate highways has become heavy. Iowa needs to consider options to address the problems that will grow as heavy truck traffic continues to increase.

- It is essential to encourage better air services because of the economic development stimulus that these services can provide. On the other hand, some people would prefer to devote available resources to better streets and roads.

- Regionally owned rail facilities could be developed. An example of this is rail banking in South Dakota.

- Investments in passenger rail should be regarded as a possibility in the longer-term future. Several participants observed that a modern form of passenger rail could be an effective way to connect cities in the Midwest.

- Upgrading rail tracks is important so that businesses can locate near these facilities and make use of them. Public-private partnerships are needed to defray the substantial capital costs involved.

- Iowa needs to decide whether plants should be encouraged in large towns or small areas. Discussion alluded to the advantages of a more dispersed pattern of development rather than to clustering in big cities, given the need for employment opportunities in rural areas and small communities.

- It would be better if Iowa would ship out finished products rather than raw commodities. Value-added activities, such as the production of soy diesel fuel, have the potential to increase the state's income.

\section{Sustainable urban form}

- Efficient investment policies for roads are vital to developing sustainable urban areas and productive rural areas. This was mainly with reference to handing down lower-volume roads from the primary road system to counties. Because counties do not have many resources available to them, it would hamper their maintenance efforts. The state should take into account population and growth areas when handing down roads.

- Downsizing the county road system was not considered to be a viable option, as farmers need to get to the market and need an extensive road network. On the other hand, the cost of snow removal and maintenance on low-volume roads is a severe fiscal burden for counties.

- Iowa's cities need to plan ahead to prevent sprawl; the relationship between transportation and land use was discussed as being an important determinant in development patterns. We need to use road investments as a means to channel development in ways that can be sustained.

\section{Safety}

- The many at-grade railroad crossings pose safety problems. To the extent possible, these crossings should be reduced in number and when feasible they should be grade separated. 


\section{Choice of modes}

- Multiple modes of transportation should be planned; the flexibility and number of choices available should be increased. As Iowa works to attract the technical and managerial personnel it needs, recreational choices such as bicycle trails have a real value.

- Well-developed bicycle trails and parks are not sufficiently recognized to be a policy tool. Therefore, the Iowa DOT should work to improve local governments' understanding of and attitudes toward bicycling.

- As well as offering healthy recreation, bicycling events such as RAGBRAI can be used as tools of economic development.

\section{SPENCER}

In general, a regional approach to investing in transportation elements was seen as the best way to get resources to smaller areas that do not have the population to support such investments on their own. Some participants feel that regional air services would increase the available destinations, especially within the state. On the other hand, several participants suggested that current transportation facilities should be maintained before making investments in services that do not benefit most people in this region of the state.

\section{Economic development}

- The role of the Iowa DOT in funding the infrastructure to the new mall in West Des Moines was questioned due to the negative impact the mall will have on the rest of the region.

- Outward, low-density residential growth around Iowa communities would be moderated if those who generate the infrastructure costs were required to bear these costs.

- For value-added industries such as ethanol production to be profitable, the efficiency of rail service must increase.

- The lack of access to I-90 is a concern because road maintenance and access are seen as key to making just-in-time (JIT) activities work. Transportation investments can lead to development and facilitate clustering of JIT suppliers and workers.

- Greater cooperation between the rail companies could open up more lines and thus assist in the shipping of farm commodities to market. It is the responsibility of the rail companies to maintain and upgrade rail facilities and equipment; tax dollars should not be used.

- The lack of access to interstate highways is a concern, along with the long driving times created by Iowa's highway grid system. A super-two highway would adequately serve Spencer's need for a beltway. 
- Trucking in Iowa would benefit from increased weight limits. However, larger, heavier trucks destroy local roads, so they should be charged for the increased damage.

\section{Choice of modes}

- Bicycle trails and sidewalks can act as an incentive for people to stay in the community by adding to their quality of life.

- A subsidized taxi service with advance reservations would be a good option for transportation-dependent people in Spencer. Another need is a form of demand-responsive service to regional medical facilities.

- There is a need for increased transit service in and around small towns. Older persons, in particular, often have great difficulty moving about. Combining the resources of several towns-along with those of the Iowa DOT, counties, and school districts-may be beneficial to all. An example is shared garage services between school and public buses.

- A better distribution of revenue from taxes would greatly aid general aviation. The aviation fuel tax currently generates $\$ 8$ million each year, yet general aviation gets back less than $\$ 2$ million.

- Carpooling is a good option for smaller communities, but the wide variation in job locations and work schedules makes it difficult to organize carpools.

\section{DAVENPORT}

Several focus group meeting participants suggested that by working together, communities will be able to more effectively attract the capital investments and the workforce needed by the state. By investing in Iowa's urbanized areas, we can protect Iowa's historical districts and advance the quality of life in those cities. The need to increase revenue for transportation projects was seen as a major issue. Increasing the motor fuel tax is a way to achieve this.

\section{Economic development}

- Cooperation benefits all. If the cities within regions of Iowa were to work together more effectively, the state as a whole would be more able to attract the needed capital and workforce.

- When building the capacity for JIT business activity, extra lanes to a factory would be used more. This expansion is more important than increased maintenance, such as accelerated snow removal.

- For value-added economic activity to be successful, adequate river and rail services are needed to provide inexpensive transportation. Costs can also be kept down by processing agricultural commodities in Iowa, thereby decreasing the volume of raw commodities that are shipped from the state.

- A severe limitation for some firms in Iowa is that insufficient products are generated to require a unit train. Cooperation between businesses, the Iowa 
DOT, and rail companies is needed to search for ways to accommodate the needs of Iowa shippers.

- Outside help is needed by rail companies for their infrastructure to be updated.

- Increasing accessibility to intermodal facilities will greatly enhance intermodal shipping, which currently is underutilized. Vehicular and rail congestion near terminals is a special problem.

- Bridges are vital to the economy. They keep the city moving and connected. Delays to trains crossing the Mississippi River are a problem to these trains and to vehicles that the trains in turn delay.

- Aviation is key to economic stability and growth. Businesses rely on it to move employees and customers. A regional approach to upgrading and managing airports would increase efficiency and improve service.

- Super-two highways are a logical way to improve access within a region of the state. Several participants stressed the advisability of increasing the number of miles of super-two highways.

- The Iowa Commercial and Industrial Network (CIN) of highways is serving the state well; it is increasing Iowa's competitiveness.

- Secondary and rural roads need to be maintained, but budget constraints limit what can be done.

\section{Sustainable urban form}

- Transportation must be viewed as a policy tool in promoting in-fill development and slowing outward development to avert low-density landuse patterns in outlying areas. This is a concern in the Quad Cities area.

\section{Safety}

- Decreasing congestion would greatly increase safety. Eliminating the need for trucks to go through downtown by creating a new link between U.S. Highway 20 and the Illinois Bridge is one way to achieve this.

- Congestion on certain rural interstate highways is a growing safety concern. Whether adding truck lanes is a good solution is unclear.

- At-grade intersections on four-lane highways are a serious problem in some locations. When traffic warrants, building grade-separated interchanges would improve safety.

\section{Choice of modes}

- Bicycle trails add to the quality of life within an area, but they also have the potential to act as an economic catalyst. 
- Iowa needs to rethink the way transportation is financed so that the state can adequately fund transportation modes alternative to the auto. For one thing, registration fees for pickup trucks need to be increased.

- Transit is needed in rural areas, especially by seniors. Inconsistent service makes it an unlikely alternative for many people, decreasing the user base. The minimal demand makes financing difficult, as does the low density of the service area. Rideshare lots can be a more viable alternative to traditional public transit.

\section{CHARLES CITY}

An emphasis in this focus group meeting was that by limiting our thinking and not expanding our goals, we may miss many opportunities. We need to think creatively, especially when it comes to funding. Many resources go unused, such as attractive tourist destinations, due to poor connectivity and a lack of advertising. Creative thinking will lead to a better allocation of funding, services, and other resources.

\section{Economic development}

- Improved cooperation and communication will allow the tax base to grow in all areas instead of focusing economic gain within concentrated zones of Iowa. An incentive-based approach to cooperation may be the best way to overcome some people's hesitation to endorse regionalism. Regionalism is the key to economic growth in this area of the state.

- Inferior infrastructure and poor access are impeding commercial activity in the area.

- When it comes to growth, many companies are finding the limited number of qualified workers to be a limiting factor. Long-distance commuting should be facilitated.

- Regarding aviation service, due to high match rates, cities often are unable to get federal funding. Cooperation between cities would give them more persuasive power when seeking funding to improve their aviation service, and that in turn would increase their economic base. A more efficient reallocation of aviation tax funds also would help. Many businesses need the ability to "air-taxi" their clients.

- Cooperation between governmental units and railroad companies would allow rail use to expand. Iowa also needs to provide the infrastructure needed to best utilize resources, such as double-stacking facilities.

- As a road investment strategy, super-two highways make a lot of sense.

\section{Safety}

- Super-two highways provide passing lanes, which help make them safer than traditional two lane roads, especially in hilly areas. Iowa needs to more aggressively upgrade to this standard of road. 
- Grade-separated rail crossings are hindered by federal policy that only requires railroad companies to defray a certain percentage of the cost. Communities often cannot afford needed safety improvements to crossings.

- Iowa needs to do more to address the needs of older drivers. Solutions must come from discussions involving the older persons, physicians, and legislators. None of these groups can produce good approaches alone.

\section{Choice of modes}

- Bicycle trails are a great tourist attractor, but they are not being used to their fullest potential.

- The Waterloo-Cedar Falls area is steadily developing an excellent system of trails; to increase the momentum toward more trails, most new highway projects should include a trail component.

- Inadequate general aviation service harms Charles City. It has a 4,000-foot runway but needs 5,000 feet. The state's General Fund should be used to assist the Iowa DOT in financing improvements to local airports to promote economic development.

- The current way of allocating public transit funds, which is by counting riders or miles operated, does not adequately measure use or need and may result in an unfair allocation of funds.

\section{MOUNT PLEASANT}

There was a general consensus among participants that a comprehensive view of transportation-both spatially and modally—is the best way to achieve the area's goals regarding economic growth and quality of life. Awareness of options available for transportation was perceived to be low among most residents. In some cases, this lack of awareness has resulted in low demand for alternatives to the auto.

\section{Economic development}

- Regionalizing airports would allow more needs to be met for quick access to multiple destinations. Ability to move quickly is very important in business location decisions. Several businesses have left the area in part because of inadequate aviation facilities.

- Constructing new four-lane highways would not drastically help existing businesses, although it may help attract a few new ones. Super-two highways with wide shoulders to accommodate farm equipment received greater support.

- Long-distance commuting to Burlington and Mount Pleasant is a growing phenomenon. Sizable fractions of these communities' workers are regional commuters.

- With growing truck traffic, Iowa may have to add truck lanes to portions of the interstate highway system serving the state. 
- Policy issues were considered as the biggest block in allowing freight rail to compete with trucks. Development of rail facilities around value-added facilities was proposed.

- Intermodal transportation should be encouraged-especially, connectivity with freight rail should be improved. However, this approach to transporting freight will work only when there are significant volumes, otherwise increasing the number of stops would decrease efficiency and speed.

- Value-added economic activity needs to fostered. High-fructose corn syrup is more profitable than ethanol and represents a substantial opportunity.

- Depending on a community's industry mix, short-line railroads can be vital to its economy. Iowa needs to identify which rail services are vital and do all it can to preserve them. Among the options mentioned was public ownership with tracks leased to different users.

- Increasing funding for maintenance of existing infrastructure was one of the most important issues discussed. A strong majority of participants supported an increase in the motor fuel tax. It may be, however, that a higher diesel fuel tax would hurt the trucking industry economically.

\section{Safety}

- Increasing rail safety is important. It could be accomplished by more active enforcement of grade crossing and trespassing regulations or by equipping locomotives with new technology to alert approaching vehicles.

- Adding length to runways at selected airports would increase safety and therefore increase demand.

- Many senior citizens often are not aware of the options available to them, in part because many have relied on the auto for so many years.

- Construction of market-rate housing for assisted living that provides transportation services to its senior residents is a needed and valuable option.

- In some Iowa communities, bicyclists and pedestrians face serious safety risks. A combination of land use controls and facility investments are needed to remedy this situation.

- Crashes involving animals are a growing problem in Iowa. Greater effort is needed to protect travelers on certain highways where the problem is worst.

\section{Choice of modes}

- Multiple modes of transportation should be planned-flexibility and number of choices available should be increased. 
- Southeast Iowa is lacking in bicycle and hiking trails due more to a shortage of funds than a lack of interest. Changes in the mindset of people would be required to shift resources to trails.

- Changes need to be made that decrease dependence on autos and allow people to bicycle or walk to work or to shop.

- Providing door-to-door services in rural areas is more economically viable than running empty buses. Service with a six-hour-in-advance request format should be provided to seniors.

- It now is possible to take an intercity bus to Mount Pleasant and board a passenger train. This sort of intermodal personal transportation has untapped potential.

\section{CEDAR RAPIDS}

Some participants feel that better cooperation between passenger transportation modes (e.g., bus transit, taxis, and demand-responsive transit service) would improve many people's mobility. Participants repeatedly argued for developing a metropolitan-area comprehensive plan to improve the efficiency of resource use. Growth needs to be guided through incentives, not restrictions.

\section{Economic development}

- A motor-fuel tax increase is supported by some, but trucking industry representatives are against it. These representatives feel that policies made by the Iowa DOT should enable their industry to remain profitable.

- A lack of funding is the single biggest deterrent to better air travel facilities. Regionalizing airports is the only way to keep general aviation facilities operational.

- Infrastructure improvements were agreed to be the first step toward improving rail usage. Possibly agreements could be worked out for sharing some of the costs between rail companies and state and local governments. A problem short-line railroads face is their inability to qualify for lowinterest federal loans.

- For major improvements to be made in freight rail, Iowa must work with other states to help finance infrastructure improvements. One state cannot solve the facility problem alone.

- Subsidies provided to trucking and rail should be equalized to enable rail to become a viable competitor.

- There are roles to be played by both trucking and rail in just-in-time economic activity. These roles need to be understood, and appropriate policies need to be developed to ensure adequate infrastructure.

- More and better rest stops along interstate highways can actually lower shipping costs because drivers can take brief rests and be more productive and safer. 
- Regarding value-added industrial development, ethanol is a questionable long-term investment; meat processing probably is a better option for the area.

- Linn County is encouraging regionalism, and there is support for more efforts. However, some local governments fear losing funding, causing further deterioration of their infrastructure.

- Strong support was expressed for ending sub-allocations of regional funding for transportation investments to individual communities.

- For economic growth in Iowa's metropolitan areas to continue, it is inevitable that workers will need to be drawn from adjacent counties. Some employers reported drawing workers from up to 75 miles away. Wellplanned commuting routes will continue to grow in importance.

\section{Sustainable urban form}

- Increased neighborhood connectivity was advocated, especially connectivity between arterials and local streets.

- Developers often pay for various amenities for subdivisions, and the city should provide public transit and other services to these areas.

\section{Safety}

- More services need to be provided for seniors to enable them to move about safely without attempting to drive.

- Speed limits in areas with poor safety records need to be reduced.

- Grade crossings at major roadways are major safety problems.

- Iowa has some rural intersections that create safety problems for truckers and other motorists. Selective improvements to them should be considered.

- Rest stops for trucks should be increased to improve safety. Also, unsafe roads should be addressed, possibly by more aggressively adopting supertwo upgrades. Increasing safety would decrease insurance costs and increase profitability.

\section{Choice of modes}

- Bicycle trails can be viewed as both a tool for recreation and for economic development because they can increase the potential for tourism.

- There is need for a changes in attitudes toward bicycling from being seen strictly as a means of exercise to seeing it as an inexpensive mode of transportation.

\section{DES MOINES}

It is necessary to keep in mind a long-term perspective in order to meet the metropolitan area's development goals. Participants emphasized coordination 
between state and local transportation policies to facilitate economic development. Active community and regional participation was repeatedly stressed as a key to effective planning.

\section{Economic development}

- Low-fare air carriers and corporate aviation are among the most viable options to keep pace with changing travel needs. The current tax structure should be used to maintain airport facilities, and more resources should be circulated back into these facilities.

- Public transit often is the only way poor people can commute and thereby improve their incomes. Eventually, passenger rail may become a viable alternative to highway construction as the Des Moines area grows.

- Many people are commuting distances of more than 50 miles for manufacturing jobs because plants in several smaller communities have been shutting down, while there has been strong growth in the Des Moines area.

- More trucking operations are leaving Iowa than are coming in. Increasing insurance costs, as well as high fuel and capital costs, are barriers to entry. On the other hand, Iowa is relatively easy for truckers to navigate because there is very little congestion. This helps make the state competitive for JIT activities.

- Access to freight rail is important for businesses, and when they lack this option, they shift to trucks for transporting their products.

- Developing central pick-up and distribution sites would improve efficiency and speed of rail service, and it would provide options such as doublestacked containers.

- Increasing the capacity of dams and locks is a particularly good use of public funds because it would facilitate shipment of Iowa-grown commodities.

- Ethanol as a value-added product is seen as a significant economic development tool by some, while others are skeptical of its viability and use. Also, Iowa produces other value-added products besides ethanol, such as processed beef and pork. Transportation improvements to assist meat processing industries should be addressed.

\section{Sustainable urban form}

- Sensible urban development is more than just a transportation issue. For growth to be effective, it must be supported and pursued by the community. Transit options and other alternatives to single-occupancy autos must be increased. Regional plans must provide for a broader array of options.

- Iowa's relatively low congestion is one of the biggest attractions to prospective companies and their employees. Preference often is given by state and local agencies to new construction of business facilities over 
maintenance of existing ones; greater emphasis should be accorded to sustenance.

- Policies should be future-oriented and should encourage densities that support systems beneficial to small towns located near metro areas. An example of such a system is the development of light rail.

\section{Safety}

- Lack of transportation options available to seniors is causing some to use other options like motorized scooters on paved trails. We need to develop better facilities and services for seniors.

- Iowa should require that proof of insurance be provided when registering a vehicle or renewing it annually.

\section{Choice of modes}

- Fare levels in urban transit are not as important as service levels in attracting riders. Cities need to redouble their efforts to offer quality transit service.

- Vanpools have been a huge success, especially in rural areas, as they provide commuters viable transportation service and provide employers access to a larger labor pool.

- Lack of integration of trails with transit systems limits their use. But trails can help facilitate economic growth. There is evidence that Dubuque experienced an impressive return on an investment in trails.

- Iowa should increase the motor fuel use tax and allocate the additional revenue to transportation modes that are alternatives to the auto. 